Portland State University

PDXScholar

\title{
The Economically Disadvantaged Speak: Exploring the Intersection of Poverty, Race, Child Neglect and Racial Disproportionality in the Child Welfare System
}

Angela Gail Cause

Portland State University

Follow this and additional works at: https://pdxscholar.library.pdx.edu/open_access_etds

Part of the Social Work Commons

Let us know how access to this document benefits you.

\section{Recommended Citation}

Cause, Angela Gail, "The Economically Disadvantaged Speak: Exploring the Intersection of Poverty, Race, Child Neglect and Racial Disproportionality in the Child Welfare System" (2020). Dissertations and Theses. Paper 5478.

https://doi.org/10.15760/etd.7352

This Dissertation is brought to you for free and open access. It has been accepted for inclusion in Dissertations and Theses by an authorized administrator of PDXScholar. Please contact us if we can make this document more accessible: pdxscholar@pdx.edu. 
The Economically Disadvantaged Speak: Exploring the Intersection of Poverty, Race, Child Neglect and Racial Disproportionality in the Child Welfare System

\author{
by \\ Angela Gail Cause \\ A dissertation submitted in partial fulfillment of the \\ requirements for the degree of
}

Doctor of Philosophy

in

Social Work and Social Research

Dissertation Committee:

Keva M. Miller, Chair

Katharine Cahn

Mary Oschwald

Ruth G. McRoy

Lisa K. Bates

Portland State University

2020 
C2020 Angela Gail Cause 


\begin{abstract}
The relationship between poverty and child maltreatment has long been addressed in the literature. Disproportionally, children, especially those of color, are more likely to live in poverty than adults. It has been established that the risk of child maltreatment increases the longer impoverishment is experienced. Thus, the likelihood that racial disproportionality may have negative impact upon the child welfare system is potentially increased. Much attention has been given to the overrepresentation of certain children of color within the child welfare system when cared to their representation within the general population. This study explores the intersection of poverty and race upon child maltreatment through the lens of economically disadvantaged families of various racial backgrounds. Implementing a phenomenological approach, focus groups were conducted with economically disadvantaged families sharing their first-hand experiences of parenting with limited means and their views on the intersection of poverty, race, and child maltreatment. The findings point to three primary areas: (1) The strain of managing life with inadequate financial means results in significant strain on poor families; (2) In spite of the ongoing challenges, poor parents exert great efforts to care for their children; and (3) Adding to their challenges, poor families face additional stressors when having to engage with either the public welfare or child welfare systems. Results further indicate six underlying issues adding to the stressors of living in poverty: (1) Challenges of single parenting; (2) Impact of race and racism on poor families of color; (3) Impact of limited funding and other resources within the community; (4) Living with mental health and disabilities; (5) A constant fear of child welfare intervention; and (6) Biased and inconsistent practices within the public welfare and child welfare systems. Finally
\end{abstract}


findings suggest a negative impact to racial disproportionality when child welfare fails to properly understand how to best serve poor families of color. 


\section{Dedication}

"We stand upon the shoulders of our ancestors, doing the very task that they assigned to us, the task of rising higher than them." Author Unknown

This dissertation is dedicated to my ancestors who paved the way for me to have the opportunity of academic pursuit. Specifically, this work is dedicated to my grandmother Annie B. Luckett Berry who instilled in me the desire to achieve an education, to learn something new every day, and the perseverance to never abandon my dreams. In kind, I also dedicate this work to my children and grandchildren. May each of you, with appreciation and respect, follow in the steps of your ancestors, desire to learn something new every day, acquire knowledge, believe in your ability and courageously pursue your dreams. 


\section{Acknowledgements}

Seeds planted for this accomplishment began early during my childhood years and have been continuously nurtured by different individuals over the decades that have followed. Thus, time must be taken to thank those who have supported and encouraged my desire for academic pursuit, for I am extremely grateful.

I appreciate my parents and grandmother, Solomon \& Margaree Daily, Mr. Henry L. Green, and Ms. Annie B. Luckett Berry, who never failed to tell me how very proud they were of me. Likewise, to each of my siblings: Diann, Thomas, Henry, Francine, Dorothy, Christina, Marcia, Annie, Pamela, Carlous, Brenda, and Gerald. Thank you for your ongoing support, words of encouragement and admiration. I love, appreciate, and admire each of you, too. I offer sincere gratitude for my many extended family members who have cheered me on over the years. I am grateful to have had the support of the village supporting myself and my family during those foundational years.

Throughout the years there were others who believed in my ability to achieve, and have extended support and guidance. I wish to thank Ms. Mattie Wilson, Ms. Velma Henderson, Mr. Wilbur Davis, George \& Mary R. Ruffin, Ms. Francis E. McClendon, Mr. Bobby Berry, Mr. R. L. Kelly, Mr. Sylvanus O. Lloyd, Mr. Preston Morris, Ms. Annie O. Davis, Bishop \& Mrs. B. J. Luckett, Robert \& Ruth Hamilton, and Ms. La Vern B. Brown. In addition, my hometown church, Second Temple Church of Christ Holiness USA, provided role models of college bound youth as examples to follow. I acknowledge, too, my teachers from Mary C. Jones Elementary, Johnson Elementary, Lanier Jr./Sr. High School and later Manual Arts High School who further stoked the ambers for academic success. I also must recognize my sisters from other 
mothers, Ms. Valarie Yates-Robertson who always offered words of wisdom and inspiration; and Ms. Deidre Calcoate who always reminded, "Girl, you got this!"

There are those from the academic and professional community who offered their support. Specifically, Dr. Cora Adams, Mr. Mark Schwartz, Ms. Jakki Hillis Kolzow, Ms. Linda Weinman, Ms. Miriam Green, Ms. Kelly Barber, Ms. Lois Day, Ms. Rene DuBois, Mr. Jerry Burns, and Mr. Tou Chow. Your support has not gone un-noticed. I wish to acknowledge, too, the Doris Duke Foundation and faculty and staff of Chapin Hall University of Chicago for their support and continued guidance. I'm also especially blessed also to have a circle of African American women of academia, the “Accountability Circle.” Drs. Smith, Quinn, Hardy, and McClane-Davis, I am grateful for each of you for your ongoing encouragement and support! Much appreciation, too, goes to the various faculty and staff of the Portland State University School of Social Work and Social Research with special thanks to the PhD. Program Director, Dr. Junghee Lee and PhD. Program Assistant, Ms. Thet Mar Win. I am especially grateful to my advisor and Committee Chair, Dr. Keva M. Miller for her leadership, support and guidance. I appreciate, too, each member of my Committee Drs. Katharine Cahn, Lisa K. Bates, Ruth G. McRoy and Mary Oschwald. I've gained the friendship of peers, Dr. Christopher Burkett and Ms. Beckie Child whose mutual cheers and support have been awesome, to say the least. I would be remiss if I failed to acknowledge the participants of this study who spoke freely their truths. This work would not have materialized absent their willingness to share their stories. Thank you!

Lastly, but certainly not least, I am blessed to have a beautiful and loving family. To my children, son-in-law and husband THANK YOU! Marcus, Meredith (Michael) 
and Myra, words cannot express my joy, love, and appreciation for each of you! Your love, support, encouragement and admiration strengthen me in indescribable ways. Michael your nurturance, strength, patience, encouragement, daily support and commitment to making me happy has been my beacon during those many times of tiredness. I am forever grateful to you all!

Most importantly, I give thanks to my creator for the blessings of a beautiful life filled with unspeakable joy, compassion, strength and love that sustains my every breath. In this and every moment, gratefulness is my song for my cup is over flowing! 
Table of Contents

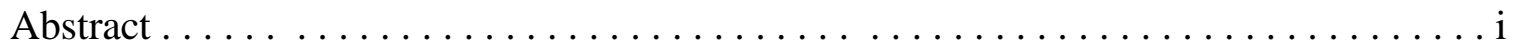

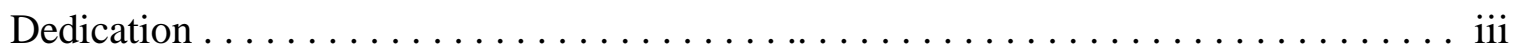

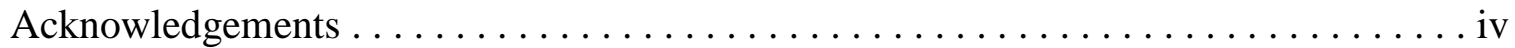

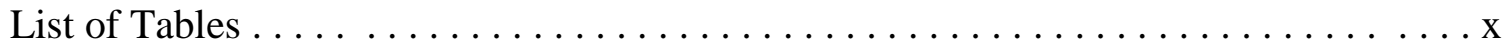

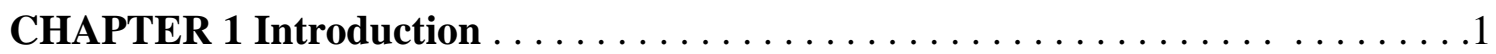

Background and Scope of the Problem. . . . . . . . . . . . . . . 2

Intersections between Poverty, Race, and Child Welfare . . . . . . . . . .5

Poverty and Child Welfare. . . . . . . . . . . . . . . . . . . . 7

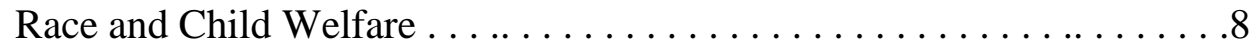

Families' Voices in the Discussion of Poverty,

Race and Child Welfare ........................... 10

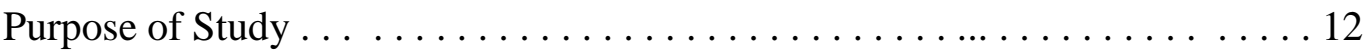

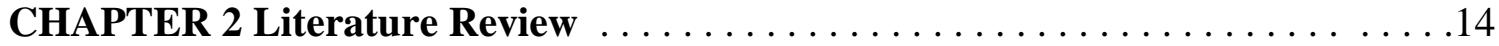

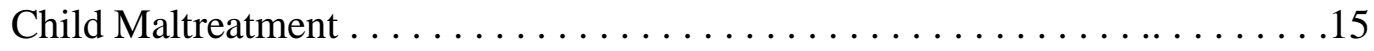

Historical and Contextual Understanding of the Family and Children in

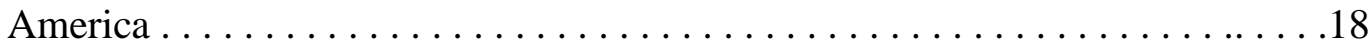

Definition of Racial, Ethnic and Tribal Terminology . . . . . . . . . . . . . . . 19

Indigenous Populations Pre and Post European Contact: The Families

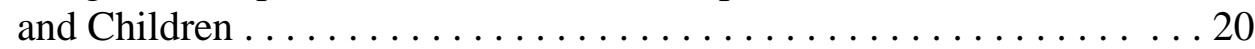

African Populations Pre-Slavery - The Reconstruction Period: The

Family and Children . . . . . . . . . . . . . . . . . . . 22

European Settlers Colonial Era - The $18^{\text {th }}$ Century: The Family and

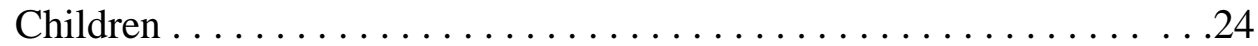

Origins of the National Child Welfare Dialogue . . . . . . . . . . . . . 26

The $19^{\text {th }}$ Century: Precursor for the National Debate . . . . . . . . 26

The $20^{\text {th }}$ Century: Evolution of the National Child Welfare Dialogue $\ldots 30$

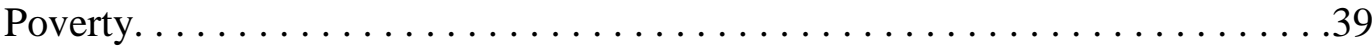

Historical Overview: Welfare as a Systemic Approach . . . . . . . . . 41

Poverty and Child Welfare . . . . . . . . . . . . . . . . . . . . 49

The Impact of Poverty and Race . . . . . . . . . . . . . . . . . . . . . . . . . . . . . .

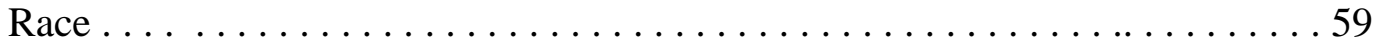

Racial Disproportionality and Child Welfare . . . . . . . . . . . 67

Theories Explaining Racial Disproportionality . . . . . . . . . . . . . . . 70

Disproportionate Need . . . . . . . . . . . . . . . . . 71

Human Decision-Making . . . . . . . . . . . . . . . . 76

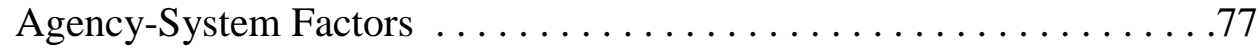

Placement Dynamics . . . . . . . . . . . . . . . . . . . . . .78

The Potential Impact of Policy on Racial Disproportionality . . . . . . . . . 80

Multiple Determinants . . . . . . . . . . . . . . . . . 80

The Existence of Racial Disproportionality within Oregon's Child Welfare

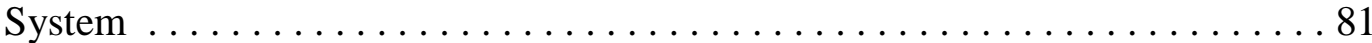


The Necessity of Including the Voices of Families in the National Discourse. . .82

Theoretical Framework . . . . . . . . . . . . . . . . . . . . . . . 84

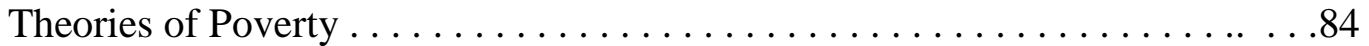

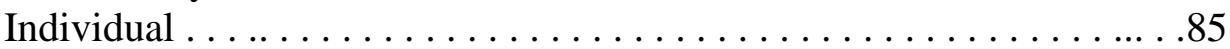

Cultural ............................. . 87

Political-Economic Structure . . . . . . . . . . . . . . . . . . . . 88

Geographic ............................... 89

Cumulative \& Cyclical . . . . . . . . . . . . . . . . . . . . . . . 90

Relevance of the Theories of Poverty on the Study . . . . . . . . . . . . . 90

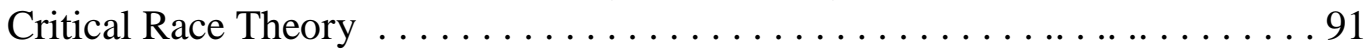

Endemic Reality of Racism . . . . . . . . . . . . . . . . . 92

Race is a Social Construct ... . . . . . . . . . . . . . . . . . . 92

Differential Racialization . . . . . . . . . . . . . . . . . . . . 93

Interest Convergence . . . . . . . . . . . . . . . . 93

Advancing the Voices of Individuals and Populations of Color . . . . . 94

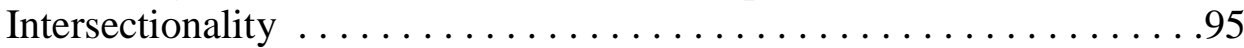

Relevance of CRT to the Study . . . . . . . . . . . . . . . . . 95

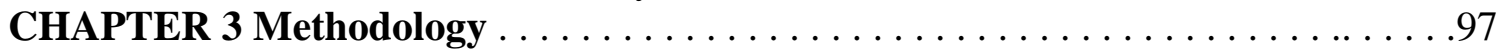

Study Design . . . . . . . . . . . . . . . . . . . . . . . . . 98

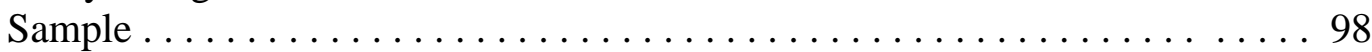

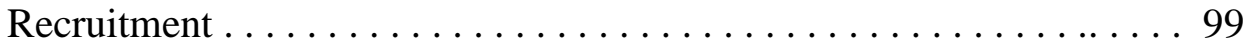

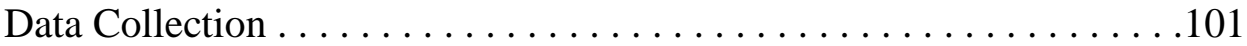

Focus Group Guide . . . . . . . . . . . . . . . . . . 102

Data Analysis . . . . . . . . . . . . . . . . . . . . . . . 104

Reflexivity ............................... 107

Trustworthiness .............................. . 108

CHAPTER 4 Results . . . . . . . . . . . . . . . . . . . . . . . . . . . . 109

Descriptive of Participants . . . . . . . . . . . . . . . . . . . . . . . 109

Theme One: Financial Strain Creates Significant Strain . . . . . . . . . . . . 115

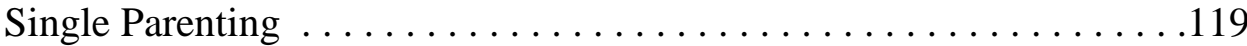

Race \& Racism . . . . . . . . . . . . . . . . . . . . . . . . .121

Limited Community Resources $\ldots \ldots \ldots \ldots \ldots \ldots \ldots \ldots \ldots \ldots$

Mental Health . . . . . . . . . . . . . . . . . . . . . . . . . . .129

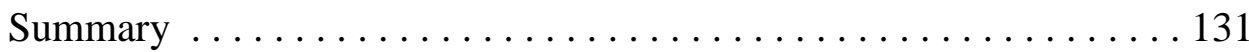

Theme Two: Concerns for Children . . . . . . . . . . . . . . 133

Fear of Child Welfare ...................... 139

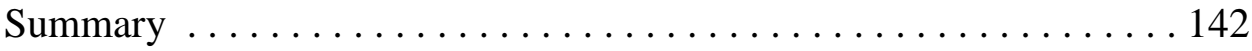

Theme Three: Dealing with the System: Public Welfare Program \& Child

Welfare Program . . . . . . . . . . . . . . . . . . . . . . . 144

Biases and Inconsistencies . . . . . . . . . . . . . . . . 146

Racial Disproportionality. . . . . . . . . . . . . . . . 150

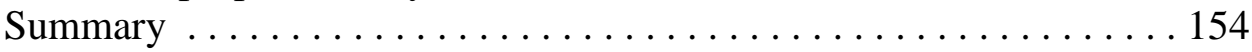

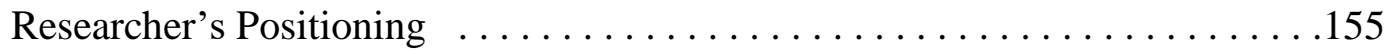

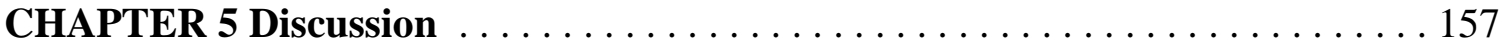

Theme One: Financial Strain Creates Significant Strain . . . . . . . . . . . 158 
Theme Two: Concerns for Children ....................... 161

Theme Three: Dealing with the System: Public Welfare Program \& Child

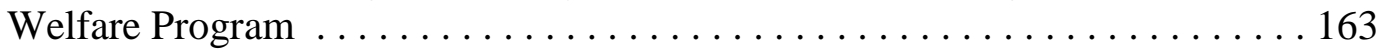

Sub-Theme One: Single Parents . . . . . . . . . . . . . . . . . . . . . . 164

Sub-Theme Two: Race \& Racism . . . . . . . . . . . . . . . . . . . . 165

Sub-Theme Three: Community Resources and Limited Funding . . . . . . . . . 167

Sub-Theme Four: Mental Health and Disabilities . . . . . . . . . . . . . . 168

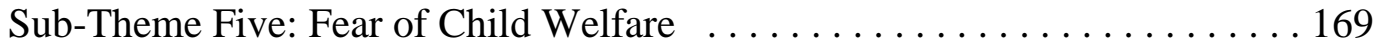

Sub-Theme Six: Biases and Incentives $\ldots \ldots \ldots \ldots \ldots \ldots \ldots \ldots \ldots \ldots \ldots$

Sub-Theme Seven: Racial Disproportionality . . . . . . . . . . . . . 171

Study Limitations . . . . . . . . . . . . . . . . . . . . . . . . . . . . . 173

Implications for Future Policy . . . . . . . . . . . . . . . . . . . . . . . . . 173

Implications for Future Practice . . . . . . . . . . . . . . . . . . . 177

Implications for Future Research . . . . . . . . . . . . . . . . . . . 179

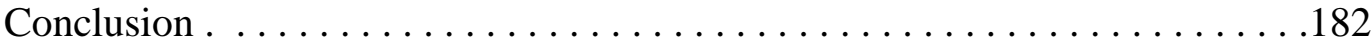

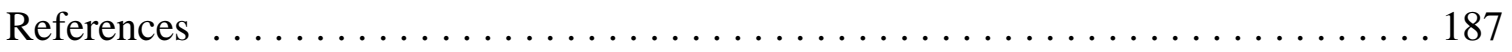

Appendix A: Informed Consent ............................... 221

Appendix B: Letter of Invitation ... . . . . . . . . . . . . . . . . . . . . ...224

Appendix C: Focus Group Guide ........................... 225

Appendix D: Demographic Questionnaire .......................... 226 


\section{List of Tables}

Table 1: Participant Demographic Profile.................................... 110

Table 2: Study Themes and Sub-Themes..................................... 112

Table 3: Data Clustering Results........................................... 113 


\section{CHAPTER 1}

\section{Introduction}

"If the structure does not permit dialogue the structure must be changed." Paulo Freire At the turn of the $20^{\text {th }}$ century, there was mounting debate regarding the wellbeing and protection of the nation's many vulnerable children. The hardships facing hundreds of poor destitute children ignited the beginnings of a century long debate regarding the needs of dependent children (Bremmer, 1970; Downs et al., 2004; Folks, 1900). Today poverty remains a major concern that affects child well-being as it has been identified as a significant risk factor of child maltreatment and a topic of much debate (Bartholet, 2009; Butterfield et al., 2017; Kim \& Drake, 2017; Pelton, 1981; Pelton, 2015; Roberts, 2002). Race and how children and families' racial identities play a role in child welfare policies also have a longstanding prominence within the national child welfare dialogue, as represented by the ever-present reality of racial disproportionality (Cause et al., 2014; Derezotes et al., 2005; Horowitz \& Wolock, 1981; Magruder \& Shaw, 2011; McRoy, 2011; Miller et al., 2010; Miller et al., 2012; Miller et al., 2013; Pelton, 1981; Pelton, 2011). Racial disproportionality refers to the overrepresentation of a racial group within the child welfare system than their presence within the general population. Particular questions arise when poverty and race intersect (Evans-Campbell, 2008; Roberts, 2002; Wilson, 2009). Thus, the complexities embedded within the national child welfare discourse include the role and function of poverty and race, and the intersection between the two phenomena in predicting or causing child abuse or neglect. While the debate has unfolded over decades, minimal attention has been given to incorporating the voices and opinions of those with the most expertise on the issues; the 
parents themselves. This dissertation is designed to advance the debate, by bringing in the lived experiences of parents who are economically disadvantaged; and identified as being at risk for or have current involvement with the child welfare system. Specifically, participants of this study are recipients of the public welfare benefits and identified as at risk due to a history of numerous referrals to or current open case with the child welfare system. Findings may potentially advance policy, practice and future research concerning racial disproportionality as parents' perspectives brings contextual meaning and understanding concerning the intersectionality of poverty, race and child maltreatment.

\section{Background and Scope of the Problem}

Poverty proves to be a challenging subject to address as it is complicated by societal beliefs suggesting the poor are lazy and responsible for their plight; expectations of self reliance promoted within American culture; and shame associated with being poor (Bullock, 2008; Chase \& Walker, 2012; McIntyre et al., 2003; Seccombe, 1999;

Seccombe et al., 1999; Wilson, 2010). Chase and Walker (2012) cautions that due to the experiences of shame and ultimate loss of dignity, those who are poor position themselves to present as managing/coping well when often they are not and at times may withdraw from society. Entities such as the Children's Defense Fund and the Annie E. Casey Foundation have maintained continuous efforts to keep poverty and its ill effects upon children, in particular, in the forefront; and further have called for the need to resolve the impoverishment impacting the lives of many of America's children (Annie E. Casey Foundation, 2019; Children's Defense Fund, 2015; Children's Defense Fund, 2017; Children's Defense Fund, 2019). 
Wight et al. (2010) noted concerns regarding the increased number of children nationally living in poverty early in the $21^{\text {st }}$ century showing children in the United States who lived in poverty rose to $21 \%$ from 2000 to 2008; an increase of an additional 2.5 million children living in poverty. This last decade, however, began to show a decline in the number of American children experiencing poverty (Children's Defense Fund, 2019; First Focus on Children, 2019; Semega, et al., 2019). According to Semega et al. (2019), 2018 marked four consecutive years of decline in the national poverty rate at $11.8 \%$; a 0.5\% percentage point decrease from 2017. Per Semega and colleagues (2019), those living in poverty during 2018 was 1.4 million fewer than reported in 2017.

While the decreased poverty rate is notably progress, First Focus on Children (2019), indicates that approximately $16.2 \%$ of children in the United States remained in poverty during 2018, equating to 11.9 million children. In addition, the Children's Defense Fund (2019) reports that approximately one out of every five children in the United States lives in poverty amounting to 12.8 million children. Although, First Focus on Children (2019) notes a slight decrease in the number of children living in extreme poverty, there remained $6.9 \%$ equating to 5 million children experiencing dire circumstances during 2018.

Similarly, the literature supports that children, especially those of color, are disproportionately poor compared to the adult population (Child Trends Data Bank, 2016; Child Trends Data Book, 2019; First Focus on Children, 2019; Jiang et al., 2016). The Child Trends Data Bank (2016) reports that dating back to the mid-1970s children have been more likely to live in poverty than adults. First Focus on Children (2019) further indicates that children continue to be $54.4 \%$ more likely to live in poverty than adults and 
that in 2018 children were found to be 1.4 times more likely than adults to live in extreme poverty meaning they fall $50 \%$ below the poverty line. The data reflects, too, that race is indicative of who amongst the nation's children are impoverished (Annie E. Casey Foundation, 2015; Child Trends Data Bank, 2019; Children's Defense Fund, 2014; Children's Defense Fund, 2017; Children's Defense Fund, 2019; First Focus on Children, 2019).

National data indicate that families of color are disproportionately poor with approximately every third child of color being poor (Annie E Casey Foundation, 2015; Children's Defense Fund, 2014; Children's Defense Fund, 2019). First Focus on Children (2019) reports children of color as being three times more likely than White children to live in poverty. The Children's Defense Fund (2019) reports "more than two in three poor children are children of color" (p 7). According to First Focus on Children (2019) children of color, disproportionately experienced extreme poverty when compared to White children in 2018; African Americans at 13\%, Latinos at 9\%, and Whites at 4\%. In addition, Child Trends Data Bank (2019) indicates that overall White and Asian children are less likely to live in extreme or deep poverty than African American and Latino children.

Similarly, the child welfare system nationally continues to show disproportionate representation of African American and American Indian/Alaska Native children (Billingsley \& Giovannoni, 1972; Child Trends Data Bank, 2019; Duarte \& Summers, 2012; Harris, 2014; Hill, 2006; Johnson-Motoyama et al., 2018; McRoy, 2004; McRoy, 2011; Miller et al., 2012). Furthermore, the Children’s Defense Fund (2017, 2020) estimate that children of color will be more than $70 \%$ of America's children living in 
poverty, which is all the more reason to better understand the impact of the role and function of poverty and race, and the intersection between the two phenomena when addressing child maltreatment.

\section{Intersections between Poverty, Race, and Child Welfare}

The interconnectedness between poverty and race is rooted in history. An exploration of intersection of poverty and race in the discussion of the present-day child welfare issues requires some contextual understanding of history (Day, 2000; McGowan, 2005; Ventrell, 1998). Day (2000) acknowledges that while the United States has from its origins expounded ideals of equality and a democratic society where privileges of class, wealth, etc. do not place one individual above another, there is no guarantee of access to resources and opportunities. The Constitution, for example, initially extended citizenship to those with the ability to own property, predominantly white males. People of color, including indigenous peoples, women, and poor European immigrants were excluded (Day, 2000; Gustavsson \& Segal, 1994). In Omi and Winant's (1994) examination of race within the United States, they further emphasized that "... the racial legacies of the past - slavery and bigotry - continue to shape the present" (p. 53). Although legal acts of segregation and other discriminatory practices have been abolished for decades there remains no assurance that the populations of color, especially the poor, are better positioned to access the necessary resources to live a prosperous life. Thus, history too often does not reflect an accurate reporting of the historical experiences of people who are economically disadvantaged and people of color. Furthermore, the respective histories of poverty, race, and child maltreatment significantly influence current day experiences, attitudes, thoughts, and opinions. 
Understanding the association between poverty and race has proven particularly challenging and at times controversial when scholars, practitioners, and policy-makers have sought to address racial disproportionality within the child welfare system (Bartholet, 2009; Bartholet et al., 2011; Billingsley \& Giovannoni, 1972; Chibnall et al., 2003; Hill, 2006; Roberts, 2002). Some scholars argue the rationality of poverty as a primary cause for the disproportionate representation of families of color with child welfare involvement when consideration is given to the high propensity of economically disadvantages within communities of color that offer limited supports and few resources (Barth, 2005; Bartholet, 2009; Bartholet et al., 2011). Thus, the suggestion is that poor families, and particularly those of color, have a greater propensity for more contact with those entities designated to offer economic assistance and other supports. Therefore the argument asserts that economically disadvantaged families and families of color have an increased likelihood of visibility to child welfare (Barth, 2005; Bartholet, 2009; Donnelly, 2005; Hill, 2006). Other scholars counter these assertions by pointing to possible misconceptions of poverty by child welfare professionals when investigating child maltreatment for families of color which results in skewed conclusions and inappropriate service plans (Evans - Campbell, 2008; Roberts, 2002). The criticism offered is that poverty related circumstances may likely be indistinguishable from neglect and mistakenly determined to be child maltreatment. Thus, conceivably, lead to incorrect determinations and raise particular concern for families of color when considering racial disproportionality within the child welfare system. 


\section{Poverty and Child Welfare}

While much of the debate at the first national convening of the White House Conference on the Care of Dependent Children in 1909 focused on how to best establish surrogate homes (i.e., traditional foster care) for the thousands of dependent children who were either living in institutional settings (i.e., orphanages), or who had been left to survive by their own means on the streets, the attendees acknowledged that poverty was the primary issue putting children at risk. These children were poor and destitute. More than a century later, America continues to face the reality of economic challenges for many of its children, as the number of those growing up in impoverished circumstances has reached epic proportions (Annie E. Casey Foundation, 2016; Children’s Defense Fund, 2014; Children's Defense Fund, 2017; Children's Defense Fund, 2019; First Focus on Children, 2018; First Focus on Children, 2019).

Despite the nation's improved economic conditions over recent years, the 2019 Children's Defense Fund reports that over 12.8 million children are classified as poor. While this reflects a decline from the 2017 Children's Defense Fund report which indicated over 13.2 million children as living in poverty, there remains approximately one out of five who experience poverty. In addition, the Children's Defense Fund (2017) further reported that over 1.2 million children enrolled in the nation's school are homeless; approximately 14.8 million children face hunger; and 3.9 million are without adequate health insurance. Furthermore, First Focus on Children (2018) notes that close to one out of five of the nation's very young children, meaning those less than six years of age, were impoverished in 2017. The Children's Defense Fund (2019) specifies that child poverty is considered to exist when a family of four has an annual income that is 
less than $\$ 25,465$ and extreme/severe when the annual income of a family of four falls below $\$ 12,823$.

Issues related to poverty, efforts to address the needs of the poor, issues concerning child maltreatment, and efforts to ensure the safety and well-being of children have historically been interlinked. Public welfare and child welfare programs, while operating as separate systems, often overlap in that the two systems share common interests in establishing stability and economic security for children and families. According to Howze (2005) most incidences of child maltreatment throughout the United States involve economically disadvantaged families who are living at or below the established poverty levels. Sedlak and colleagues (2010) reports that children living in poverty in the U.S., including those whose families are recipients of Temporary Assistance to Needy Families (TANF), are overall 5 times more likely to be subjected to child maltreatment, 3 time as likely to experience abuse and 7 times as likely to be neglected. The Children's Defense Fund (2014) reports that nationally close to $80 \%$ of maltreatment allegations are attributed to neglect. Johnson-Motoyama et al. (2018) acknowledge "disproportional poverty" as one theoretical explanation for racial disproportionality within the nation's child welfare system (p. 29).

\section{Race and Child Welfare}

In an historical overview of child welfare McGowan (2005) asserts that the system was designed from homogenous origins based upon Eurocentric values and norms and initially poised to solely address the needs of White children. She notes that African American children were not included in service delivery until after the enactment of the 1935 Social Security Act. During the latter half of the 19th century attention was 
essentially drawn to the horrific circumstances facing poor immigrant European children (Bremmer, 1970; Butler, 2012; Folks, 1940; McRoy, 2004). Orphanages, Houses of Refuge, and later the Orphan Trains movement that were used to address the needs of dependent children initially excluded children of color (Billingsley \& Giovannoni, 1972; Family \& Children Services Division Minnesota Department of Human Services, 1995; McGowan, 2005; McRoy, 2004; Roberts, 2002; Roberts, 2005; Ventrell, 1998). It was several decades after that initial 1909 White House Conference on the Care of Dependent Children that the interests of children of color appeared on the national child welfare agenda. Furthermore, since the inclusion of children of color in the child welfare agenda, the system has struggled to adequately meet their needs.

Unfortunately, today the child welfare system disproportionately represents children from certain populations of color, particularly African American and American Indian/Alaska Native, which is a matter of much concern and debate (McRoy, 2004; McRoy, 2011; Miller et al., 2010; Miller et al., 2012; Miller et al., 2013; National Indian Child Welfare Association [NICWA], 2019; Puzzanchera \& Taylor, 2019; Sedlak et al., 2010; Summers et al., 2013; U.S. General Accounting Office, 2007). Children of color make up approximately $53 \%$ of the nation's foster care population while representing 44\% of the general child population (Annie E. Casey Foundation, 2019; Children's Bureau, 2019). According to Puzzanchera and Taylor (2019) nationally African American children were 1.67 times their representation in the foster care system than their representation within the general population during the federal fiscal year 2017. Puzzanchera and Taylor (2019) further report that American Indian/Alaska Native children during 2017 were found to be 2.66 times their representation in the foster care 
system compared to their representation within the general population. The NICWA (2019) notes that although some states have shown decreased racial disproportionality of the numbers of American Indian/Alaska Native children in their respective local foster care system, nationally their overrepresentation has continued to increase since 2009. In addition, while the finding of Latino children being disproportionately represented is not as prevalent nationally, some State and County localities report an overrepresentation of these children in their respective State foster care systems, compared to their representation in the general population (Duarte \& Summers, 2012; Padilla \& Summers, 2011; Summers, 2015; Summers et al., 2013).

Furthermore, while this data shows a decline in their overrepresentation from previous years, racial disproportionality remains a concern for African American children. Sedlak and colleagues (2010) in the most recent National Incidence Study (NIS -4) for the first time found higher incidences of abuse in African American families than for White families, though all waves of the NIS have found disproportionality by race. Courtney and colleagues (1996) suggest that the ongoing reality of racial disproportionality within the child welfare system warrants the acknowledgement and inclusion of race in any analysis of child welfare.

\section{Families' Voices in the Discussion of Poverty, Race and Child Welfare}

Absent within this discourse, and arguably a critical issue within the national discussion, are the voices of families, especially those who experience poverty and are at risk for or currently involved with the child welfare system, particularly families of color. Day (2000) notes that the perspectives of poor families and particularly families of color as historically being absent from the discourse. As a result, an inaccurate portrayal of 
their respective truths coupled with the silencing of their voices is reflected in the reporting of history which leads to social welfare policy and programs that reflect inherent systemic classism and racism.

Research supports the value of seeking the opinion and views of parents who are involved with the child welfare system as well as those who are recipients of social/public welfare benefits such as Temporary Assistance to Needy Families (TANF) who are potentially at risk for child welfare involvement (Anderson, 2001; Banerjee, 2002; Cause et al., 2014; Jindani \& Murdock, 2009; Pelton, 2011; Yatchmenoff, 2005). This historical absence of parents' voices within child welfare research is glaring. Tapping these voices is potentially vital to contributing to an understanding of the role and function of poverty, race, and the intersections between the two issues.

Elevation of the perspectives of families who are at risk for or have been involved with the child welfare system reflects the philosophical principles of social work (Krumer-Nevo, 2018; Pelton, 2011). The social work profession prides itself on maintaining values and ethics that promote dignity, self-determination, and social justice. The absence of the independent perspectives of families in the national child welfare dialogue, particularly those representing historically vulnerable and marginalized populations, is contradictory to the social work code of ethics.

Strega (2007) suggests that child welfare predominately embraces a principle that individuals who are "not White, middle class, heterosexual, and able-bodied are less likely to be able to parent" (p.68). Thus many scholars advocate for an awareness of the effect that inherent historical negative beliefs about poor people, people of color and 
economically disadvantaged people of color in particular has on social work practice (Billingsley \& Giovannoni, 1972; McRoy, 2004; Pelton, 2011; Strega, 2007).

The literature points to the value and necessity of including parents' voices in matters concerning child welfare (Cause et al., 2014; Drumbrill, 2006; Osterling, 2008; Palmer et al., 2006; Pelton, 2011; Yatchmenoff, 2005). For example, many scholars who conduct research on racial disproportionality in child welfare systems consider parents' views significant to understanding the various factors associated with racial disproportionality. They consider parent input an essential voice in the national dialogue to provide contextual understanding (Cause et al., 2014; Dettlaff \& Rycraft, 2008; Harris \& Hackett, 2008; Miller et al., 2010; Miller et al., 2012; Miller et al., 2013). Where families' independent voices are absent, silenced and/or compromised in the current child welfare dialogue, social work must be challenged to include them, actualizing its basic principles of dignity, self determination and social justice.

\section{Purpose of the Study}

The purpose of this study is to explore the role, function, and intersection of poverty and race on the risk for child maltreatment, through the lens of families who were previously serviced by the former Family Stability and Employment Unit (FSEU) under the Oregon Department of Human Services (DHS), Self Sufficiency Program (SSP). FSEU was a specialized unit located within Multnomah County under the SSP designated to provide prevention services to TANF recipients identified as being at risk for or have current involvement with the child welfare system. The aim of this study is to explore the following, specifically examining potential differential responses based on participants' racial identity: 
(1) The extent to which parents perceive how their economic situation as recipients of public welfare benefits affects their parenting capacity.

(2) The extent to which parents perceive race as a factor that contributes to child welfare involvement.

(3) The extent to which parents perceive how the intersection of poverty and race influences child welfare involvement.

(4) Which supports are valuable to alleviating challenges in their ability to adequately parent and prevent child welfare involvement.

The remaining chapters provide an exploration of each study aim through the lens of economically disadvantaged families. This exploration begins with a review of the literature taken from a historical perspective. The literature review offers an overview of the development of societal views regarding poverty, race and the evolution of the child welfare dialogue. Through focus group discussions, families address their challenges with parenting while navigating life with minimal financial means. The findings of the study emerge from parents' views as participants speak directly from their lived experiences. 


\section{CHAPTER 2}

\section{Literature Review}

This literature review approaches the conversation about child well-being from a historical perspective. Operating through a historical lens potentially brings context to the multiple complexities surrounding the intersections of poverty, race, and child maltreatment.

The literature review begins with an explanation of child maltreatment and how it is defined. Today some raise concerns that the definition, due to the lack of clarification between child neglect and poverty related issues, negatively impacts some populations such as the poor and people of color (Pelton, 1981; Roberts, 2002). Next, a brief exploration of the distinct views held historically about children by the indigenous populations, enslaved Africans and English/European settlers during the early development of the United States will be presented. Further outlined is an overview of the unfolding of national child welfare dialogue throughout the course of history. Attention to the roles, functions, and intersections of poverty, race, and child welfare over time is discussed. Subsequently, the importance of incorporating the perspectives of families in the today's national discourse is recognized.

Finally, a theoretical framework provides understanding behind the attitudes toward poverty, race, and the compromised voice of the oppressed, such as the poor and populations of color. Throughout, the literature review underscores the historical absence of the voices of families who are at risk or are child welfare involved; and the limited understanding of their lived experiences of the phenomena of poverty and race. 


\section{Child Maltreatment}

The term child maltreatment refers to: 1) types of abuse such as physical, emotional/psychological, and sexual; and 2) neglect which implies failure or inability to adequately supervise and/or provide for the basic needs of children such as shelter, food, educational and medical care (Child Welfare Information Gateway, 2013; Depanfilis, 2005; Donnelly, 2005; Haralambie, 2005; Scannaoico \& Connell-Carrick, 2005; U. S. Department of Health and Human Services, 2013). Federal policy directs local governments to enact laws for the protection of children, requiring mandatory reporting and specifications regarding what constitutes child maltreatment. Child Welfare Information Gateway (2013) notes the Child Abuse Prevention and Treatment Act (CAPTA), per 2010 amendments stipulates that at a minimum State's statutory definition must specify child abuse and neglect as:

Any recent act or failure to act on the part of a parent or caretaker which results in death, serious physical or emotional harm, sexual abuse or exploitation; or an act or failure to act which presents an imminent risks of serious harm. (p. 2)

All States have adhered to this requirement as well as incorporated their own additional implications of child maltreatment (McGowan, 2005; Rose \& Meezen, 1993; Scannapieco \& Connell-Carrick, 2005). Oregon, for example, includes "Threat of Harm" in their definition of child abuse. The Oregon definition adds, according to Child Welfare Information Gateway (2016), "threatened harm to a child that means subjecting a child to a substantial risk of harm to the child's health or welfare" (p. 61). The inclusion of Threat of Harm as a child abuse allegation may not be used by other states when defining child maltreatment. 
The federal government under the Children's Bureau monitors and assesses State child welfare programs' performance outcomes associated with the treatment and experience of children and families and systemic barriers perceived as impacting the achievement of outcomes through periodic Child and Family Service Reviews (CFSRs) (McGowan, 2005; Milner et al., 2005). According to Milner and colleagues (2005), the CFSR assessments are based on a model that is structured by family centered practice principles; enhances the capacity of parents to appropriately care for and attend to children's need; promotes individualized service plans; and encourages the utilization of community-based services. The ultimate aim of CFSR assessments is the assurance that safety, permanence, and wellbeing for children and families are adequately achieved for all who become involved with the nation's child welfare system. According to Milner and colleagues (2005) safety implies that all children are protected against child maltreatment, and as appropriate and feasible ensured a safe environment within their families of origin; permanence denotes that all children will have a permanent stable home life, the ability to maintain/preserve familial ties, and relations; and child and family well-being implies that parents achieve improved capacity to adequately care for and appropriately meet the needs of their children including educational, physical, and mental health. McGowan (2005) asserts that today CFSR assessments are a major component informing the nation's agenda for policy modifications and the enhancement of services for children and families.

There is limited understanding concerning the role, function, and intersection of poverty and race possibly impeding the ability of child welfare to attain safety, permanence, and wellbeing for all children. Korbin $(1979,1985)$ stresses the value in 
contextually understanding the implications of societal factors such as poverty and cultural factors based upon race/ethnicity. The application of a one-size-fits-all design by child welfare is not conducive when attempting to attain safety, permanence, and wellbeing (Korbin, 1979; Korbin, 1985; Evans-Campbell, 2008). Evans-Campbell (2008) notes, for example, the relevance to child welfare practice of contextually understanding the distinctive views amongst parents from different individual racial groups regarding what constitutes child maltreatment. Some awareness of the varying concepts held by different racial, ethnic, and cultural groups of the institution of family, its function within the greater community; as well as the role delineation of its members such as parents, children, and extended relatives is important to understanding child maltreatment. The extent to which government has involvement with family affairs such as parenting; child welfare's views surrounding parenting capacity; and the overall wellbeing of children and families; and the defining of child maltreatment has been a progressive development throughout the course of history that has been significantly framed by societal tendencies (Day, 2000; McGowan, 2005; Ventrell, 1998).

Child maltreatment as explained by Ventrell (1998, p. 6), “... must be defined in historical context," as the understanding and treatment of children has changed throughout time dependent upon societal views and values. Ventrell (2005) further illustrates how the nation's collective perspective towards children has shifted over time from being property as in possessions owned by their parents; to being the benefactors of welfare in effort to meet wellbeing needs; to being individuals who are citizens with rights. Under these respective views, protection of children has been shaped by beliefs that promoted supporting the rights of parents in how they treat their children, to offering 
financial support to relieve economic disadvantages impeding child well-being, to the passage of laws to ensure the rights and protection of children as citizens (McGowan, 2005; Scannapieco \& Connell-Carrick, 2005; Ventrell 2005). Additionally, Donnelly (2005) reminds that today's medical paradigm ("the battered child syndrome"), which is the basis for current child welfare practice, varies differently from the earlier model which addressed child protection as a social problem to be resolved by addressing poverty. The contention by some scholars, therefore, is that today's approach to child maltreatment is flawed as it does not permit the isolation and removal of poverty related issues when assessing for neglect (Donnelly, 2005; Pelton, 1999; Pelton, 2015; Roberts, 2002); thus, concluding that poverty unjustly factors into decision making during child maltreatment assessments. Understanding the inherent complexities surrounding the child welfare national dialogue, especially the role, function, and intersection of poverty and race in child maltreatment circumstances warrants a glance at the historical progression.

\section{Historical and Contextual Understanding of the Family and Children in America}

The collective attitudes and actions towards the institution of family and children by American society have been influenced by the various religious beliefs, regional and ethnic particularities, culture, and political persuasions of a given era. However, often due to practice models leaning predominantly upon of Eurocentric values, family and other societal systems for populations of color have lacked full representation in history. Scholars caution that the underlying influence of Eurocentric perspectives must be accounted for when presenting the histories of people of color in the United States (Duran, n.d.; Williams, 1987). Zinn (2001) portrays the less-told version of the developing United States detailing the impact to indigenous and African American 
populations and stresses the moral importance of an honest/truthful depiction of history. LeMaster (2001) further recognizes the attention more recently given by historians to including the usually untold story, such as that of indigenous populations.

In reviewing the historical progression of child maltreatment and the evolution of the national dialogue, some acknowledgement of the effect that the European invasion of the North American continent had upon the institution of family and the state of children for indigenous tribal nations, African slaves, and the newly arriving poor Europeans is most important. While not exhaustive, this overview provides some perspective of how each of these respective groups understood the concept of family and children, which may prove especially helpful when reflecting upon the current day initiative of child welfare to attain safety, permanence, and well-being for all children. Albeit brief, a historical examination presenting comparisons and contrasts of how these distinctive populations operated potentially offers insight regarding the role, function, and intersections of poverty and, race upon child maltreatment. The incorporation of poverty and race in this historical review is best done together rather than separately because of their overlapping nature in the context of history.

\section{Definitions of Racial, Ethnic and Tribal Terminology}

It is important to clarify the use of terms regarding racial, ethnic, and tribal identities/affiliation. American Indian/Alaska Natives represent the indigenous populations who are the original inhabitants of the North American continent. The terms Native(s), indigenous, tribe(s), and tribal refer to American Indian/Alaska Natives and are used interchangeably when discussing today's American Indian/Alaska Native population. African Americans first arrived to North America as enslaved peoples from 
the continent of Africa. The terms African(s) and slave(s) refer to the ancestors of African Americans and are used interchangeably when discussing today's African American population. The terms colonists, settlers, and European(s) are also used interchangeably and reference the early peoples arriving to the North American continent from England and European countries; many of these are ancestors of today's White American population. Finally, the terms pre-colonial and pre-contact refers to the time period existing before the arrival of Europeans to the North American and African continents (Ziibiwing Center of Anishinabe Culture \& Lifeways, 2011; Zinn, 2001).

\section{Indigenous Populations Pre and Post European Contact: The Families and Children}

Indigenous populations, approximately 10 million at the time of European contact in 1492, occupied the North American continent some 15,000 plus years before being invaded; and by the late 1800 's, it is estimated that the population had been reduced to 250,000 (Burns, 2009; Day, 2000; Snipp, 2005; Ziibiwing Center of Anishinabe Culture \& Lifeways, 2011). Tribal nations operated within communal systems sustained by their respective customs and traditions. These were representative of rituals, ceremonies, and teachings passed on from one generation to another regarding family: the care, wellbeing, and training of children; the designated role, status and place of men, women and the elders within the family, clan and larger tribal communities; and how to live throughout the lifespan (LeMaster, 2001; Ziibiwing Center of Anishinabe Culture \& Lifeways, 2011). Some tribes, many in the southeast region of the continent as reported by LeMaster (2001), were matrilineal whereby family lineage and the training of children was established through the mother's family. According to Peterson (2012), children were seen as "sacred" and viewed as "gifts" from the "creator" of "spirit world" (p. 1). 
Native households were multigenerational; children were born into a welcoming community where extended family and clan structures provided great support to the nuclear family and the general wellbeing of children (LeMaster, 2001; Peterson, 2012; Ziibiwing Center of Anishinabe Culture \& Lifeways, 2011). Native children were trained through storytelling, observance of others and direct hands on instructions by parents, extended relatives, clan members, and elders (LeMaster, 2001; Peterson 2012; Ziibiwing Center of Anishinabe Culture \& Lifeways, 2011).

Tribal structures supporting traditional family life primarily remained intact until the advent of the Boarding Schools where the intent was to annihilate tribal ways of being. This was done through the acculturation of the children and the infiltration of patriarchal standards thereby removing the leadership status of women that had been sustained within some tribal nations (Fisher \& Ball, 2002; LeMaster, 2001; Peterson, 2012; Smith, 2009; Ziibiwing Center of Anishinabe Culture \& Lifeways, 2011). In addition, Peterson (2012) reports the passage of the Browning Rule by the United States government declaring Native parents as children themselves, possessing inferior intellectual abilities, to further justify the removal and far away placement of children to prevent any remote influence of tribal ways of life. The massive removal of children from tribal communities attributed more to the deterioration of the Native family than any previous wars or the attempt of genocide against indigenous populations (Fisher \& Ball, 2002; LeMaster, 2001). Huyerser (2010) further suggest that the act of cultural genocide, of which the Boarding School era was a major contributor, greatly attributed to family instability for Natives. 


\section{African Populations Pre-Slavery - The Reconstruction Period: The Families and}

\section{Children}

Arowolo (2003) reports, that prior to European contact and the African Diaspora, Africa was comprised of approximately 10,000 various states, kingdoms, and/or communal/tribal groups whose living arrangements ranged from small family settings to large well-structured clans. While there were some ethnic differences, established amongst the numerous populations spanning the continent were cultural/customary ways of life governing familial relations, parenting, the general well-being of children, and the community (Arowolo, 2003; Katola, 2014; Miller, 2010; Semwaza, 2013). According to Semwaza (2013), women held a high status and most African societies, like some of the indigenous tribal nations, were matrilineal having the lineage of the children flow through their mother's family. The education/training of African children during precolonial times was done informally by parents, older siblings, elders, clan, and tribe to socialize, and sustain family, clan, and ethnic family history. This practice of education, and training also promoted the success of the community (Boaky-Boaten, 2010; Katola, 2014; Mazonde, 2001). One generation to the next honored the obligation of passing on oral traditions such as songs, storytelling, and myths to teach children values such as love, and respect; but also clan, ethnic, and family history. Children were taught how to cultivate peaceful relations within the community and beyond; obedience to parents and elders; duties towards God; reverence to ancestors and future generations; appreciation for the environment; morals/ethics; and a sense of generosity (Boaky-Boaten, 2010; Katola, 2014; Mazonde, 2001). Igboin (2011) explains that Africans held immense reverence for children. Comparable to the indigenous people of North America, Semwaza 
(2013) notes that African familial relation extended beyond the nuclear family to extended family and the community; children were the collective responsibility of the community at large. In addition, throughout Africa spirituality was intrinsically incorporated into the upbringing of children (Boaky-Boaten, 2010; Katola, 2014). BoakyBoaten (2010) states reincarnation, an aspect of many traditional spiritual beliefs, as attributing to the respect held for children. Igboin (2011) further notes a spiritual view amongst traditional African cultures connecting all back to the origins of their creator (i.e., God); therefore, binding everyone together as brothers and sisters.

Perhaps, it is this innate belief that helped to sustain connectedness to one another during slavery as disruption to family relations for enslaved Africans occurred where children, siblings, mothers, and fathers were separated from one another and sold as property. Tolman (2011) notes that when familial separation occurred, slaves mutually nurtured and cared for others' children: and parents instructed children to reference other non-related slaves as kin (i.e., aunt, uncle). Literature suggests that despite the strain caused by the separation of family members one from another, this did not lessen their shared interest, and concern for each other; family ties/connections remained a priority (Crawford, 1991; Tolman, 2011). This was clearly demonstrated, for example, as parents and spouses/mates took enormous risk of punishment to secretly visit their loved ones (Crawford, 1992; Tolman, 2011). Another indication of the importance placed upon family by slaves is described by actions following emancipation whereby considerable effort was made by many slaves to find and reunite with family members (Crawford, 1992; Tolman, 2011). Slavery, as did the Boarding School experience for Native American/Alaska Natives, served to dismantle the institution of family gravely altering 
the status and role of parents (Boaky-Boaten, 2010; Leary, 2005; Miller, 2010; Tolman, 2011).

Additionally, Crawford (1992) reports slavery fostered a sense of fatherlessness as that some children were fathered by the slave owner or a relative of the slave owner but maintained the status of property. Zinn (2001) suggest that removed from the communal life of clan, tribe, rituals/ceremonies, and traditional customs, the African slave was completely disadvantaged. Under the institution of slavery, the slave owner now had full authority, making provisions for children as well as their parents.

Even after slavery ended, efforts to establish, sustain family, and to care for children were extremely challenging. For example, economic struggles resulted in parents having to concede to employment situations that were not conducive to the financial health of the family. Most often both parents worked outside the home and some families entered into sharecropping arrangements that essentially kept them financially indebted to their former owners (Leary, 2005; Tolman, 2011). Furthermore, Tolman (2011) contends that some former slave owners' utilized laws pertaining to apprenticeships as justification for keeping freed children committed to their care. As reported by Miller (2010), many households also remained single parented following slavery.

\section{European Settlers Colonial Era through the $18^{\text {th }}$ Century: The Families and Children}

The understanding of family and the designation of children during colonial times and continuing to current day is framed from Eurocentric values and ideals which are primarily patriarchal (LeMaster, 2001; Ziibiwing Center of Anishinable Culture \& Lifestyles, 2011). Initially, the guiding principles were heavily influenced by beliefs held by the Puritans arriving from England as a distinct Christian sect adhering to prescribed 
rigid religious beliefs (Bremmer, 1970; Burns, 2009; Chudacoff, 2007; Kang, 2009;

Thurston, 1930). The family, children, and all aspects of life were understood through the Puritan lens (Chudacoff, 2007; Herring, 2001, Kang, 2009). Subsequently, the experiences of newly arriving poor European families, in so far as how they operated within their family units, communities, and the developing United States society, were heavily impacted by Puritan values (Chudacoff, 2007, Herring, 2001; Herring, 2003). Central to the Puritan model for life was a prevailing covenant with God emphasizing works/deeds, redemption/salvation, and grace with the ultimate desire/hope for an everlasting life with God (Herring, 2001; Herring, 2003; Kang, 2009). This theological practice, according to Herring (2001), ultimately guided family functioning and "permeated" parenting (p. 3). Whereas Christ was the head of the church, the father was the head and master of the home obligated to guide the family to salvation. Children were perceived as being born out of sin; therefore, seen as evil and needing to be saved (Herring, 2001; Kang, 2009). Play, for example, was to be purposeful or serving some real function such as teaching morality. Otherwise it was seen as idle and a sin (Burns, 2009; Chaudacoff, 2007). This is not to say, as Chaudacoff (2007) acknowledges, that the early colonists were lacking love and affection for their children.

Several scholars have depicted the view of children during the colonial period as pseudo adults recognizing little to no differences between the mental, emotional, and physical development of children compared to that of adults (Bremmer, 1970; Downs et al., 2004; Folks, 1900; Hacsi, 1995; Watkins, 1990). Chaudacoff (2007) advises that the perception and treatment of European children varied throughout the different colonial regions noting the presence of other religious groups such as the Quakers and Catholics 
who acknowledged children as being developmentally different from adults. However, as mentioned by Herring (2001), even those colonists who were not Puritan adopted the Puritan model for the family, embracing the covenant concept. Thus, women and children were subservient; gender roles were well defined; and the practices of home, including training and discipline of children operated, under the strict biblical principles aimed at ultimate salvation. Due to the high reverence for work, poor European children, in particular, were designated to work at very young ages and expected to contribute to the economic stability, moral good, and salvation of the family. As the country took shape, children were incorporated in the general labor force to help sustain overall economic security of the growing nation.

Essentially Christianity, including Puritan principles and other faiths, was the foundational structure of the family, views towards children and colonial society. Christianity intricately became part of an equation that reinforced ethnocentric values of European heritage and customs as superior to other peoples. This was evidenced in the later role Christianity played in the use of boarding schools to civilize and assimilate American Indian/Alaska Natives into American society (Hirshberg \& Sharp, 2005; LeMaster, 2011; Lister, 2004; Smith, 2009; Ziibiwing Center of Anishinabe Culture \& Lifeways, 2011).

\section{Origins of the National Child Welfare Dialogue: A Historical Overview}

\section{The $19^{\text {th }}$ Century: Precursor for the National Debate}

Christian principles, according to Scannapieco and Connell-Carrick (2005), supported parenting practices such as corporal punishment and a global perception of 
children as property of their parents throughout the $19^{\text {th }}$ century. Folks (1900) states, however, that by 1825 there was universal acknowledgement of:

The right and duty of the public authorities to intervene in cases of parental cruelty, or gross neglect seriously endangering the health, morals, or elementary education of children and to remove the children by force if necessary and place them under surroundings more favorable for their development. (p. 97) Folks (1900) further expressed a perspective that child maltreatment posed a threat to the State, which consequently lead to the gradual recognition and establishment of legal guidelines for the protection of children. In addition, Folks (1900) offered the example of provisions made by New York City in 1833 allowing officials such as the mayor, aldermen, or judge's authority to:

Commit to the almshouse, or other suitable place, for labor and instruction, any child found in a state of want or suffering, or abandonment, or improperly exposed or neglected by its parents or other person having the same in charge, or soliciting charity from door to door, or whose mother was a notoriously immoral woman. (p. 97)

Similarly, Thurston (1930) noted concern for abuse to children under indentured servitude whereby the Massachusetts legislature appointed a State Agent to investigate the wellbeing of indentured children and when warranted, address any maltreatment with the children, their masters and/or the courts. While there were such beginning efforts towards the oversight of child maltreatment amongst some State and local governments, matters concerning child maltreatment and overall wellbeing were primarily relinquished 
to the private sector (Bremmer, 1970; Downs, et al., 2004; Folks, 1900; National Child Abuse and Neglect Training and Publications Project, 2014).

The New York Children's Aid Society (CAS), established in 1853, and its founder Charles Loring Brace illustrates an important private sector child welfare initiative (Bremmer, 1970; Cook, 1995; Downs et al., 2004; Folks, 1900). CAS, under the leadership of Charles Loring Brace, enacted the Orphan Trains movement, which took action concerning the dire situation where approximately 30,000 neglected children were confined to living on the streets of New York City (Downs et al., 2004; Folks, 1900). The Orphan Trains movement is acknowledged as the first account of a structured systematic method of assessing individual family homes for the placement and care of children, the beginning of foster care as known today (Atwater et al., 1950; Cooks, 1995; U. S. Department of Health and Human Services, 2012). According to CAS, the Orphan Trains continued operation through 1929 placing over 120,000 children.

Another such example is the New York Society for the Prevention of Cruelty to Children (NYSPCC) established in 1875 following a highly publicized case involving the horrific maltreatment of a young girl, Mary Ellen Wilson (Eskin \& Kravitz, 1980; Myers, 2008; National Child Abuse and Neglect Training and Publications Project, 2014). Although earlier incidences of child maltreatment are cited in history, the Mary Ellen Wilson case is the one most prominently recognized within the child welfare profession (Costin, 1992; Downs et al., 2004; Eskin \& Kravitz, 1980; Meyers, 2008; National Child Abuse and Neglect Training and Publications Project, 2014; Watkins, 1990). Likewise, this particular case is ultimately noted as being the impetus for the development of legal parameters for addressing child maltreatment (Downs et al., 2004; Eskin \& Kravitz, 
1980; Myers, 2008; National Child Abuse and Neglect Training and Publications Project, 2014). Watkins (1990) challenges the accuracy of the Mary Ellen Wilson case being credited as the origin for initiating legal guidelines for child maltreatment noting earlier maltreatment accounts in history. While the Mary Ellen Wilson case was concerned with maltreatment Ventrell (1998) notes another instance in 1882 purely concerning neglect whereby the Illinois courts ordered the removal of a nine-year, Winefred Bean, from her parents' care based upon their failure to provide for her basic needs. Downs and colleagues (2004) explain that while laws had created a basis for intervening in the interest of abused and/or neglected children, no definitive methods existed amongst the various private agencies or government officials for clearly identifying incidences of child abuse and/or neglect in instances where the family was not already known via some private or public financial support effort. The American Public Humane Services Association (APHSA) notes that laws written for the protection of animals were used as the model for intervention in the Mary Ellen Wilson case, as no child welfare protection laws were on the books. Folks (1900) acknowledged that societies for the protection and prevention against the cruelty of animals existed at least eight years prior to the establishment of such groups for children. Regardless of how and/or when statutory laws for the protection of children emerged, it suffices to say that the $19^{\text {th }}$ century marked specific changes in societal views and actions concerning child maltreatment.

It should also be noted that during this same era, delinquency was also an ongoing focus of public attention as the response to children committing criminal behavior resulted in judicial actions similar or the same as adults. Consequently, Folks (1900) reports that at the beginning of the $19^{\text {th }}$ century reformatory institutions were on the rise, 
with the first being established in New York City. By the end of the century in 1899, the nation's first juvenile court was established in the State of Illinois primarily to address delinquency (Costin, 1992; Downs et al., 2004; Eskin \& Kravitz, 1980). Today dependency and delinquency matters are addressed through the juvenile court system and there exists a close connection between the juvenile court system and the child welfare system.

The growth of orphanages expanded expeditiously during the $19^{\text {th }}$ century partially as a means of addressing the welfare of poor White children whose needs could not adequately be met by their parents (Bremmer, 1970; Folks, 1900; Jones, 1993; Minnesota Department of Human Services, 1995; U. S. Department of Health, Education and Welfare Social and Rehabilitation Service, 1967). Folks (1900) reported that some States, including Oregon, began to appropriate funds to support private institutions such as orphanages. The use of orphanages/institutional care as a primary solution for the care of neglected children would later be challenged during the forthcoming 1909 Conference on the Care of Dependent Children, comprising much of the national debate (Downs et al., 2004; Folks, 1940; U. S. Department of Health, Education and Welfare Social and Rehabilitation Service, 1967).

\section{The 20 ${ }^{\text {th }}$ Century: Evolution of the National Child Welfare Dialogue}

The 20th century highlighted a series of conferences solely focused on the examination of the various components necessary to ensure child well-being and safety. The conferences were coordinated and managed under the leadership from the White House often taking on themes that in some manner reflected the national interests of that particular era. The conferences began in 1909 and continued approximately every decade 
until 1970. These conferences served to uniform national understanding regarding the care of America's children.

The Proceedings of the Conference on the Care of Dependent Children (1909) notes that an urgent appeal was written to President Theodore Roosevelt in 1908 by several concerned advocates of the day expressing "the problem of the dependent child is acute; it is large; it is national' (p. 18). The President's response was the assembly of the nation's first attempt at public discourse focusing on the multiple needs of disadvantaged children. The White House Conference on the Care of Dependent Children convened January 25, 1909 bringing together various professionals having some particular interest in child wellbeing (Billingsley \& Giovanni, 1972; Grahn-Farley, 2011; Holt, 2010; Jambor, 1958; Richardson, 2011; U. S. Department of Health, Education and Welfare Social and Rehabilitation Service, 1967). This and subsequent White House Conferences would present the national agenda concerning child welfare (Grahn- Farley, 2011; Holt, 2010; Richardson, 2011; U. S. Department of Health, Education and Welfare Social and Rehabilitation Service, 1967).

Much of the foundational premise underlying today's child welfare system originates from the early discussions of the White House Conferences. One example of this would be the tenet that removal of children from their parent's care should be temporary and not permanent. Today, reunification remains at the forefront of child welfare practice; and is typically the first case plan goal and most desirable permanency outcome. Ironically, while poverty remains recognized as a prominent concern regarding child wellbeing and a major indicator of child maltreatment, the initial emphasis that 
children not be removed from the care of their parents solely due to poverty also originates from the 1909 White House Conference on the Care of Dependent Children.

This 1909 conference holds further significance as it set the course for the government having a role within the institution of the family when parents demonstrate the inability to adequately care for their children (Grahn-Farley, 2011; Holt, 2010; Richardson, 2011; U. S. Depart of Health, Education and Welfare Social and Rehabilitation Service, 1967). According to Bradbury (1962), the 1909 conference is credited with paving the way for financial support to mothers who were widowed or having to work outside the home; Illinois and Missouri were the first to pass mother's pension type legislation 1911. It was also determined during this initial conference as noted by Senate Documents (1909) that the nation required a government department to oversee and direct matters concerning America's children. Subsequently the Children's Bureau emerged in 1912 under the federal government having primary responsibility for oversight and monitoring the overall well-being and protection of children (Bradbury, 1962; Costin, 1992; Folks, 1940; Glasser, 1950; Grahn-Farley, 2011; Holt, 2010; Roberts, 1951; Senate Documents, 1909; U. S. Department of Health Education and Welfare Social and Rehabilitation Service, 1967; U. S. Department of Health and Human Services, 2012).

The 1930 White House Conference on Child Health and Protection notably introduced greater inclusion for the needs of every child (Folks, 1940; Holt, 2010; McGowan, 2005; U. S. Department of Health, Education and Welfare and Rehabilitation Service, 1967). According to the White House Conference on Child Health and Protection (1933), Homer Folks, chairman of the Socially Handicapped-Dependency and 
Neglect committee, acknowledged that while gains/improvements for many children had occurred since that first call to action in 1909, also noted additional attention being warranted for some children who "handicapped by considerations of color, national origin, or mass migration, do not share in the provisions made by public and private agencies for dependent children" (p. 320). In addition, similar to current times, the committee further notes that the earliest national discussions regarding child welfare and child well-being struggled with fully understanding how to best meet the needs of some children based upon race indicating:

Serious thought and special effort is necessary to adapt child welfare methods and agencies to the unusual needs of the Negro, Mexican, Puerto Rican, and Indian children and other children, where there are problems of race, nationality, or mass migration. (p. 339)

The committee's report of the White House Conference on Child Health and Protection (1933) further stated that:

The dependent and neglected children of Negro, Puerto Rican, Mexican and Indian families, present special problems needing consideration and while there is theoretical agreement among leaders in health and social welfare that the children of these groups should receive the benefits of the same standards of care as those given to other children their needs are in reality little understood by the general public and in many communities are almost wholly ignored. (p. 278)

The committee's report explained, for example, that issues such as higher death rates, greater unemployment, lower wages, higher rents and higher numbers of unwed mothers for African American households as justification for specialized approaches in 
meeting the needs of these children (Committee $\mathrm{C}-1$ : White House Conference on Child Health and Protection, 1930). Unfortunately, the socioeconomic concerns expressed then for African American families and children continue to have relevance today. The culmination of the 1930 conference, as acknowledged by the U. S. Department of Health and Human Services (2012), issued the declaration of a Children's Charter pledging nineteen declarations assuring rights and security for all children regardless of race and ethnicity.

Later as witnessed during the 1940 White House Conference on Children in a Democracy, the government's role in family economic stability further expanded partially due to the increased loss of private funds formerly available to families, and the loss of family income resulting from the Great Depression. The successful passage of the Social Security Act in 1935 had initiated the development of Aid to Dependent Children creating financial assistance to impoverished families; unemployment insurance, vocational services, and old-age pensions (Bradbury, 1962; Breckinridge, 1940; Lenroot, 1940; McGowan, 2005; Meyers, 2008). Additionally, according to McGowan (2005) the enactment of the Social Security Act denotes the beginning efforts to actively assist/support children and families of color. Furthermore, important to today's public child welfare system, provisions of the Social Security Act issued authorization for the Children's Bureau to work collaboratively with local State child welfare entities to secure and maintain wellbeing and protection of dependent, neglected children and those at risk of delinquency (Bradbury, 1962; Breckinridge, 1940; Eskin \& Kravitz, 1980). This stipulation was especially significant, as it further specified the role of government in the protection of children (Eskin \& Kravitz, 1980; Meyers, 2008; Thomas, 2012). 
In subsequent years, the national agenda would have the support of research attesting to the adverse effect of poverty on a child's personality development. Furthermore, the ongoing controversy regarding the role of social welfare (i.e., AFDC, TANF), in mitigating issues such as marital conflict, single parenting, inadequate housing, and inadequate child care would enter the discussion. All of which were being recognized as stressors potentially impacting the parenting capacity of low-income families and possibly subjecting children to neglect and/or delinquency. Case load size and training of social welfare workers, as they are today, were also acknowledged as systemic barriers to properly addressing at risk concerns for certain low-income families.

Race continued to be on the national agenda and addressed at the White House Conferences. Richards (1951) reports ongoing concerns noted during the 1950 Midcentury White House Conference on Children and Youth regarding the impact of racial segregation and Jim Crow practices on the personality, mental, and emotional development of children. Richards (1951) expresses the conflicting values messaged to youth by the legal sanctioning of segregation. Specifically, it was suggested that child welfare agencies be proactive in mitigating the negative effects of racial prejudices upon children of color. Additionally, over the years, there became an acknowledgement of the significance of cultural differences and the impact of culture upon a child's personality development (Bradbury, 1962; Richards, 1951). The fact- finding report from the 1950 conference, A Health Personality for Every Child (1951) recognized the respective cultural differences of American Indian/Alaska Native, Mexican American, Chinese, and Eastern European Jewish children. 
The inclusion of parents' and children's voices in the national dialogue initiated at the 1940 White House Conference on Children in a Democracy set a precedent for their participation in future conferences (Bradbury, 1962; U. S. Department of Health, Education and Welfare and Rehabilitation Service, 1967). Over the decades, through 1971, the White House continued to convene conferences summoned by the President, growing in size to over 6000 participants in later years increasing the voices/input of youth, parents, populations of color, and even international representatives (Bradbury, 1962; Grahn-Farley, 2011; Holt, 2010; Richardson 2011; Roberts 1951; U. S. Department of Health, Education and Welfare Social and Rehabilitation Service, 1967; U. S. Department of Health and Human Services, 2012). Oscar Ewing, Chairman of the 1950 Mid-Century White House conference on Children and Youth summed up the importance of the White House conferences serving as the venue for inclusion of all in the national child welfare dialogue stating "the voice of this Conference should be a great chorus of many voices, a united call to action by all of us here and by thousands upon thousands who stand with us through every state in the nation" (Richards, 1951, p. 47). The inclusion of voice thoughtfully incorporated, according to Roberts (1951), the participation of populations of color consistent with their respective representation in the general population.

The White House conferences provided a forum and platform for a national debate informing the nation on critical matters such as the causal factors influencing the removal of children from their parent's care, (i.e., poverty), pros and cons of removal children from their parent's care; institutional care versus non-institutional care; foster care; financial support to families and family economic security; child labor regulations; 
medical/health care specific to mothers and children; education; recreation/play; mental health; childhood development; delinquency; the roles of government, private sector and community in supporting children and their families; and federal and state collaborative partnerships in governing child wellbeing (Atwater et al., 1950; Bradbury, 1962; GrahnFarley, 2011; Richardson, 2011; Roberts, 1951).

According to an overview of the White House conferences by the U. S. Department of Health, Education and Welfare Social and Rehabilitation Service (1967), the intent of the White House Conference series was to serve as a structured/formal approach to informing the general public, private, local, State, and national legislative members of child welfare matters as oppose to having an advisory capacity or particular benefit to any federal department sections. Consequently, the White House conferences framed and focused the collective national understanding surrounding child wellbeing, which would serve as the foundation for an ongoing national discussion of child welfare. A gathering of medical doctors during 1962, however, marked a pivotal juncture in the national dialogue. Whereas the greater portion of attention garnered by the Children's Bureau and the White House Conferences had gone to research and exploration of what experiences constitutes child well-being, the seminal report of Dr. Kempe, The Battered Child Syndrome, called the nation's attention to child abuse by framing it as a medical issue. Subsequently, the Children's Bureau developed initial guidelines for reporting child abuse. Consequently, the period during $1963-1967$ resulted in all states legislating statutory authorization to report and/or respond to incidences of child maltreatment (Donnelly, 2005; Rose \& Meezan, 1993). Federal legislation followed in 1974 with the enactment of the Child Abuse Prevention and 
Treatment Act (CAPTA). Prior to CAPTA, the Social Security Act (driven by the commitment to meet poverty-related needs) was the way the federal government became involved with families. In addition, before CAPTA, according to Rose and Meezan (1993), defining neglect had been met with universal ambiguity and there was no consensus to what extent a parent's failure to provide or meet their child's need represented neglect. However, the mandate of CAPTA that states enacts laws addressing child abuse and neglect categorically elevated child neglect to the same level of concern as child abuse. Furthermore, CAPTA ignited the beginning of ongoing federal policies specific to child maltreatment and the governance of the nation's child welfare system.

The establishment of CAPTA advanced the federal government in managing a series of long-term examinations concerning the occurrences, gravity and conditions surrounding child maltreatment that provides a baseline understanding to inform/direct research and the ongoing national dialogue. To date, four National Incidence Studies (NIS) have been periodically conducted: NIS-1 (1979 - 1980); NIS-2 (1986); NIS-3 (1993); and NIS-4 (2010). Reports from the first three NIS studies consistently found increases in the occurrence of child maltreatment from one study period to the next. The NIS-4 was the first to find a decline in instances of child maltreatment. Variance in the occurrence of child maltreatment is attributed to economic changes. NIS-4 found that, excluding incidences of sexual abuse, the single highest risk factor associated with child maltreatment is socioeconomic status. While NIS-4 showed an overall decline in child maltreatment, socioeconomic differences amongst racial/ethnic groups were related to the incidence of the occurrence of child maltreatment; and a higher incidence of maltreatment was noted for some populations of color. For example, higher rates of child 
maltreatment now exist for African Americans than Whites and other racial groups, even when controlling for poverty. Results from the NIS-4 have fueled the national dialogue and further challenged research to bring greater understanding of the role, function and intersection of poverty and race.

\section{Poverty}

Poverty, in a general sense, is defined as having little access to and/or the absence of life's basic necessities such as food, shelter, resources, health care, and other services; typically encompasses inadequate income, minimum education, experiences of inequality, limited opportunities, and restricted expressions/acts of freedom (Bradshaw, 2007; Delisle, 2008; Lister, 2004). During the 1960s, the federal government set in place a definition for poverty based upon the work of Social Security Administrator, Mollie Orshansky. Using population data from the U. S. Census and the food consumption data from the Department of Agriculture, Orshansky created the original formula whereby the cost associated with a diet having the least nutritional value is multiplied by three; establishing the Official Poverty Measure (OPM) (Hattery \& Smith, 2007; Iceland,2013). A family is considered as living in poverty if their gross earnings are below the OPM threshold (Iceland, 2013; Orshansky, 1963; Orshansky, 1965; Ruggles, 2008). Final revisions were made in 1969 and annually thereafter, allowing for inflation only. Orshansky's original formula has continued to be used to set each year's OPM (Hattery \& Smith, 2007; Iceland, 2013); Ruggles, 2008; Wight et al., 2014). Iceland (2013) explains that Orshansky's method, where comparisons are made of a family's earnings to an established poverty level that remains constant with the exception of considerations for inflation, is known as "absolute measure" for poverty and is used primarily by the 
United States. According to Iceland (2013), European nations typically use another approach, the "relative measure," whereby the poverty level is adjusted for cost of living increases and therefore rises, as opposed to remaining constant. Some scholars argue for an alternative to the absolute poverty measure that is currently used by the United States, arguing that it dates back decades and no longer is adequate (Iceland, 2013; Ruggles, 2008; Wight, et al., 2014). Some raise concern noting that Orshansky's initial approach used limited and/or obsolete data, partially due to a sense of urgency to develop a scale for defining poverty which was stimulated by the political agenda surrounding the war on poverty (Iceland, 2013; Ruggles, 2008). The current model is further criticized as it does not have the capability to reevaluate and reset benchmarks to accommodate policy needs and relevant changes happening within society (Bradshaw, 2007; Ruggles, 2008; Wight et al., 2014). Moreover, Orshansky's model fails to account for the multiple changes that have occurred with the federal taxes since 1969 as well as additional work and other expenses that today's families encounter (Bradshaw, 2007; Ruggles, 2008; Wight et al., 2014). According to Short $(2011,2012)$, the U. S. Census Bureau introduced the Supplemental Poverty Measure (SPM) in 2010 to address some of the shortfalls of the OPM. Short (2011) explains further that the SPM does not replace the OPM but serves “ to provide information on aggregate levels of economic need at a national level or within large subpopulations or areas and, as such, the SPM will be an additional macroeconomic statistic providing further understanding of economic conditions and trends" (pp. 2-3). Whereas, for example, Short (2011) notes the OPM unit of measure is limited to "families and unrelated individuals," the SPM unit of measure includes "all related individual who live at the same address..." including foster children, cohabiting 
individuals and their children (p. 3). Other distinctions between the SPM and the OPM, outlined by Short (2011), are that it includes in calculations for the poverty threshold expenditures on food, clothing shelter and utilities (FSCU) rather than the current calculation of "three times the cost of minimum food diet in 1963"; allows for geographic modifications for the cost of housing; averages FSCU over a five year period; and includes "in-kind benefits" in addition to the current calculation of gross income before taxes (p. 3). Scholars advise that, as was the case during Orshansky's era, the influence of political agendas continue to influence how poverty is defined and understood in the United States (Bradshaw, 2007; Lister, 2004; Ruggles, 2008). Views concerning poverty are formed socially and politically and have long standing historical roots.

\section{Historical Overview: Welfare as a Systemic Approach}

The approaches to assisting the poor during the early development of the United States were derived from those in Europe and England (Piven \& Cloward, 1971; Trattner, 1994). Piven \& Cloward (1971) note that particularly during the 16th century France, Germany, and England, for example, each had instituted policies, which prohibited begging and delegated the care of the poor to local parishes and communities. Views and actions associated with poverty and the early settlers were initially shaped by societal perspectives and social policies experienced in Europe, especially in England (Piven \& Cloward, 1971; Trattner, 1994). Thus, a brief historical overview of England's policies offers insight to the foundational premises guiding social welfare within the United States.

The Poor Law of 1601 of England, known as the Elizabethan Poor Law, was particularly influential. Resulting from numerous attempts by England to address poverty, 
the Elizabethan Poor Law established that government had a responsibility in assisting the poor and set in place parameters that have continued, to some extent, to guide current day social welfare policies and practices (Piven \& Cloward, 1971; Seccombe, 1999; Trattner, 1994). Prior to the Elizabethan Poor Law, England relied on the church and local communities to aid the poor. Dating back to England's 1349 Statute of Laborers policy there existed belief that assistance to the able-bodied encouraged laziness and supported unemployment thereby working against economic growth and robust labor market (Piven \& Cloward, 1971; Seccombe, 1999; Trattner, 1994). During this time those who were poor, yet healthy and presenting no acceptable reasons for being unemployed were viewed as unworthy of assistance, thereby setting the premise that some of the poor were deserving of assistance while others were not. Later in 1536, England's Act for the Punishment of Sturdy Vagabonds and Beggars, the Henrician Poor Law, would make it illegal and punishable by law for the able-bodied to publically beg. While discouraging begging by the able-bodied, the law also established that funds at the local level of government be used to offer employment to the able-bodied (Piven \& Cloward, 1971; Trattner, 1994). Trattner (1994) notes that policies of the day allowed for children between the ages of five and fourteen to received training of trades that would ultimately prepare them to secure wage earnings. During the second half of the 16th century, in addition to the already practice of soliciting volunteer contributions, England established tax assessments for all citizens to help with costs of caring for the poor. By the passage of the 1601 Elizabethan Poor Law, England had established a role for government in aiding all of the poor, granted some poor being deemed as more worthy than others.

Government was to provide work to the able-bodied with apprenticeships and servitude 
being common practices of the day. Furthermore, there was an expectation that parents would be responsible for the care of their children and grandchildren. In turn, children and grandchildren were to care for parents and grandparents.

The Elizabethan Poor Law then resulted from the earlier fragmented policies of the era. Trattner (1994) explains that the law brought congruency to the regulations of the earlier policies and most relevant, solidified local government as having financial responsibility for all of the poor rather than the obligation being solely with the church. The law, however, maintained societal beliefs which propagated that the conditions of the poor were self inflicted due to laziness or a failure to work hard enough and that poverty reflected an inherent character flaw of the poor, particularly the able-bodied. The ablebodied who were poor remained designated as unworthy/undeserving and were expected remedy their circumstances.

Those negative associations and punitive outlooks about the poor carried forward as Europeans immigrated to the newly forming American society. Those early attitudes and beliefs framed the foundation for later policies to aid the poor and have continued throughout the course of history to shape much of current day views concerning poverty. Just as had previously occurred in England, the United States placed responsibility for assisting the poor predominately with the private sector and primarily religious entities within local municipalities and communities. The conditions of the poor were believed to be self-induced and indication of an innate character flaw (Bradshaw, 2007; KrumerNevo, 2016; Seccombe, 1999). The thought that hard work, in particular, is adequate to achieve financial stability became common creed within American society. For example, Trattner (1994) acknowledges Massachusetts and Virginia as having policies against 
vagrancy or idleness. The able-bodied were expected to work or be placed into indentured servitude, arrested, and jailed or evicted from their local township. In essence it was a crime for the able-bodied to be unemployed. While most states during the early decades of the 20th century had developed policies to assist single mothers, the federal government was absent in the affairs of the disadvantaged.

Franklin (1970) notes that the first effort of the federal government to offer assistance to needy individuals was the enactment of an annuity system following the civil war to help veterans as well as the aged and disable. However, a robust intent of the federal government taking responsibility in aiding the poor did not truly occur in the United States until the period of the great depression. The Social Security Act of 1935 marked the beginning of the federal government having a designated role in providing financial support to assist the poor within the United States (Bradbury, 1962; Breckinridge, 1940; Lenroot, 1940; McGowan, 2005; Meyers, 2008). The initial provisions of the Social Security Act granted assistance for retirement insurance, unemployment and financial assistance for the blind, aged, and families with dependent children; establishing Aid to Dependent Children (ADC). The primary focus of ADC was to support needy children excluding any support to mothers (Lindsey, 2009; Piven \& Cloward, 1971; Seccombe, 1999; Trattner, 1994). Renamed Aid to Families with Dependent Children (AFDC) in 1950, the program's aim extended the inclusion of mothers and basically represented America's welfare system. AFDC remained in place until the passage of the Personal Responsibility and Work Opportunity Reconciliation Act (PRWORA) in 1996and the enactment of the Temporary Assistance for Needy Families (TANF). 
AFDC was designated to assist economically disadvantaged families where one of the biological parents was absent from the home due to being away from the family, death or disability. Children having an absent parent because of such circumstances were termed as dependent children. Most of these families were comprised of single mothers. Billingsley and Giovannoni (1972) reminds that AFDC while typically understood as having the purpose of addressing the needs of children, in reality AFDC only addressed a specific population of children whose needs were not met by due to particular circumstances of their parents and primarily fathers; the father is deceased, has a disability or has abandoned the family. In essence, the program was not for needy children in general. In addition, AFDC was to lend ability for low income single mothers to remain home with their children and not having to work as was the public sentiment of the era. However, this belief shifted in the decades that followed. Increasingly, women entered the employment market and any stigma associated with being a working mother overtime lessened. Concurrently, many states began to introduce policies promoting the advancement of job skills and training for welfare recipients encouraging women to work. The federal Work Incentive Program (WIN) in 1967 specifically targeted single female headed households where no children in the home were younger that six years requiring the mother participate in an occupational placement program. In 1988 WIN was discontinued when the federal Family Support Act developed the Jobs Opportunities (JOBS) program to increase participation of welfare recipients in occupational activities and enhance their employment skills. Additionally, the Family Support Act provided child care benefits to families for a year following their exit from public welfare due to becoming employed or having increased their wage earnings. Although several initiatives 
throughout the decades between the 1960s and 1990s sought to reduce welfare participation encourage and/or increase gainful employment and positively impact poverty, there was growing dissatisfaction with the welfare system. Public sentiments rose concerning increased numbers of welfare cases, beliefs that AFDC contributed to generational poverty and negative attitudes in general about welfare recipients. The cost of fiscally maintaining a system that failed to move individuals to gainful employment and established disincentives to working created considerably controversy. Additionally, although policy amendments had in 1961 Aid to Families with Dependent Children for Unemployed Parents (AFDC-UP) allowed eligibility for two-parent households where the main wage earner was unemployed; many held the perspective that AFDC rewarded single parenthood thereby promoting the absence of fathers. Furthermore, since 1935, welfare had been jointly funded between the federal government and states where the federal government set guidelines for eligibility and benefits requirements but also allowing for states considerable flexibility in the execution of the program.

Determinations of welfare eligibility and benefits, therefore, varied from state to state. By the latter years of the 20th century, welfare reform had become a politically charged topic creating the climate for welfare reform.

The PRWORA of 1996 introduced marked changes in the welfare structure making TANF considerably different than its predecessor and decreasing the authority of the federal government. Welfare became a block grant operated program rather than the federally matching of state funds leaving states discretion in the distribution of program funding. For example, no specifications were imposed designating a particular amount of the funds for cash assistance. The block grant funding could be used for day care, 
employment exploration, social services, and any other types of spending elected by the state. TANF, unlike AFDC, enforced a five-year time limitation on eligibility for receiving benefits. Usage of the former AFDC-UP was discontinued. The extension of benefits to two parent families was now at the discretion of States. In addition, TANF required minor parents to remain in school and in home/care of their parents.

Furthermore, the JOBS program ceased. However, an emphasis on securing and maintaining employment increased during this period. Under TANF, the federal government set requirements for employment efforts mandating that all states develop a program. Mandatory sanctions against welfare recipients for failing to meet the specified work and other programmatic requirements were a further requirement of TANF. TANF, as anticipated drastically reduced the numbers of open welfare cases and increase the numbers of individuals securing employment. The longstanding philosophical beliefs regarding work and self sufficiency influence current day operations of the public welfare system. The former prevailing attitude of minimal involvement from government in the affairs of families maintains today's controversy concerning the extent of government assistance programs for the poor such as TANF. Billingsley and Giovannoni (1972), in an earlier critique of the former AFDC, noted the public welfare system as underscoring long held ideals concerning the responsibility of poor individuals for their circumstances.

Pelton (2005) later calls attention to the inherent inequities resulting for needy children under TANF when compared to needy children receiving benefits via Social Security Income (SSI). Specifically noted is that although in each circumstance the child is determined as being in need, the child whose parent is deceased will likely receive greater financial benefits without any restrictions of time limits under SSI than the child 
receiving TANF benefits whose father is alive yet absent from the home. Additionally, locally in Oregon, welfare reform was met with similar criticisms and concerns. Morgen and colleagues (2010), in their local evaluation of welfare reform notes concerns regarding the shift in expectations of single mothers having to be more focused on seeking and becoming employed than parenting. This change is markedly different for mothers under the former AFDC regulations. Furthermore, while welfare reform has been marketed by some as successful due to large reductions in welfare recipients, jobs received are often inadequate to sustain the family's ability to remain absent any public welfare supports (Morgen et al., 2010; Seccombe, 1999). Children experience a greater potential to suffer when families endure ongoing financial instability. Ranjith and Rupasingha (2012) suggest that impoverishment for American children points to the ineffectiveness of welfare policies.

Some children are negatively impacted as child poverty undoubtedly is linked to the financial health, welfare, and stability of the family particularly adequate income and proper housing. Ranjith and Rupasingha (2012) indicate, for example, that inadequate family income is a primary contributor to poor health care, education, and malnutrition amongst children.

Characteristics such as family structure and age of parents are possible indicators of child poverty (Friedman \& Lichter, 1998; Lichter \& Crowley, 2004). Single parent homes, parent's education, and entering parenthood at an early age, for example, are strongly associated with child poverty (Chen \& Corak, 2008; Ranjith \& Rupasingha, 2012). While the majority of poor families are not neglectful or abusive towards their 
children, children from poor families are disproportionately represented within the nation's child welfare system.

\section{Poverty and Child Welfare}

Poverty as a contributing factor to child maltreatment has historical precedence as it was the underlying cause originally stimulating the national child welfare debate and has maintained the longstanding position as a primary indicator of child wellbeing. Sanctioned by the poor-laws of England which were adopted early in the development of the United States, the removal and placement of poor children outside of their biological homes to orphanages, almshouses and servitude was the norm during colonial times (Billingsley \& Giovannoni, 1972; Bremmer, 1970; Downs et al., 2004; Folks, 1900). Since its inception, philosophically, child welfare has maintained the premise that children should not be removed from their parent's care due to poverty alone. However, disengaging poverty from neglect has proved challenging. Child neglect is most often associated with poverty related issues such as inadequate income and housing; and few distinctions are made between the two conditions (Drake \& Pandey, 1996; Goodman et al. 2012; Pelton, 1981; Sedlack \& Broadhurst, 1996). Pelton (2015) further notes that defining or maintaining some consistency within the understanding of child maltreatment has not been static, but has met with significant variability over time. In addition, neglect, by definition, is enmeshed with understanding/explanation of child abuse as neglect and abuse comprise the meaning of child maltreatment. Further complicating the matter is that such circumstances often include additional characteristics afflicting families such as mental illness, addiction, and domestic violence (Goodman et al., 2012; Horowitz \& Wolock, 1981; Wilson \& Horner, 2005). The realities of poverty, then, become engulfed 
in multifaceted dynamics of child maltreatment making it more daunting to distinguish poverty separate and apart from other issues (Gadson, 1995; Roberts, 2002). Pelton $(1978,1999,2015)$ further criticizes that the view of neglect within the modality of the medical approach where matters are viewed as disease-treatment-cure paradigm fails to address socioeconomic/poverty and sociological concerns. Some scholars argue that poverty should be addressed independent of neglect and not be incorporated in defining neglect as related to child maltreatment, suggesting that child poverty merits its own degree of attention (Drake \& Pandey, 1996; Pelton, 1981). Noted concerns include, for example, that chronic poverty negatively impacts cognition, memory, performance in math and reading; and potentially leads to generational poverty (Brooks-Gunn et al., 1995; Danziger \& Danziger, 1995; Gadsden, 1995; Paxson \& Waldfogel, 2002). Research supports that decreases in income supports, such as TANF and increased poverty as being related to increases in child maltreatment (Beimers \& Coulton, 2011; Paxson \& Waldfogel, 2002). Klevens et al. (2015) in their examination of State policies, for example, report an association between increased child maltreatment investigations and inaccessibility to support and safety nets such as child care benefits/services and continuous eligibility for Medicaid benefits for children. However, the literature cautions that while there is a strong relationship between poverty and child neglect, this does not necessarily imply that poverty causes child neglect (Johnson-Motoyama et al., 2018; Pelton, 1999; Pelton, 2015). Comparable to Roberts (2002), Pelton (2015) maintains that the child welfare system, partially due to the broad definition of child maltreatment, approaches working with families from lens that looks for pathology or wrong doing and an investigatory style "...confuse poverty itself with neglect" (p. 35). The child poverty 
rate within the United States exceeds that of other developed countries (Children's Defense Fund, 2014; Ranjith \& Rupasingha, 2012). According to Smeeding and Thevenot (2016) child poverty within the United States from 2000 to 2011 was approximately $21 \%$, while the United Kingdom and Ireland had a child poverty rate of approximately $10 \%$ during this same period.

The Annie E. Casey Foundation (2019) notes that nationally the number of children living in poverty showed a decline in 2017 at $18 \%$; being 2.4 million fewer children from $22 \%$ in 2010 . While the decreased number of children experiencing poverty is good, this does not negate the adverse effects of poverty (Annie E. Casey Foundation, 2019; Campbell et al., 2016; First Focus on Children, 2018; Hoynes \& Schanzenbach, 2018; Ranjith \& Rupasingha, 2012). The literature cautions that growing up in poverty compromises child development, i.e. poor brain development, cognition, and health (Annie E. Casey Foundation, 2019; First Focus on Children, 2018; Ranjith \& Rupasingha, 2012). First Focus on Children (2018) further emphasizes the significance of potential harm to the development of very young children whose cognitive and physical growth is critical to overall healthy functioning. First Focus on Children (2018) reports that close to one out of five children who were less than six years of age experienced poverty during 2017. Furthermore, the literature suggests that consequently adulthood for impoverished children potentially results in continued economic struggles and poor health (Annie E. Casey Foundation, 2019; Hoynes \& Schanzenbach, 2018). According to Hoynes and Schanzenbach (2018), failure to properly address child poverty has lasting societal affects that have economic as well as moral implications. The authors note that the void created by not fully addressing child poverty consequently reduces the potential 
for future economic gains as the work force is weakened and structures such as health and mental health are strained.

Kim and Drake (2017) find that the length of time families live in poverty, and/or are eligible to receive benefits from public welfare programs is indicative of the number of reports for child maltreatment. Furthermore, the likelihood of a poor child being maltreated increases three times that of a child not living in poverty (Drake \& JohnsonReid, 2013; Maguire-Jack \& Font, 2017). Oregon, as reported by the Annie E. Casey Foundation (2019), currently has $22 \%$ of its children living in poverty.

According to Smock (2014), within Multnomah County (primarily Portland, Oregon, and a few surrounding towns) children are disproportionately represented amongst the poor. While children made up $21 \%$ of the general population, $28 \%$ of those experiencing poverty were children. The report further notes the increase of single-family households, poor women, decreased benefits from TANF and the former recession as contributors to increased children being poor. The numbers of poor children in Multnomah County has increased over the last two decades.

The Oregon Department of Human Services (DHS) Child Welfare Data Book (2018) reported that in fiscal year 2018, spanning October 2017 - September 2018, of the children reported for child maltreatment, neglect was reported more frequently than all other forms of abuse at $43.4 \%$. The second most frequent form of abuse reported during that same period was threat of harm at $39.9 \%$. Oregon is one of the few states with threat of harm included in the definition of child abuse and neglect.

Furthermore, the experience of childhood poverty for many children of color residing in Multnomah County is startling with African American, 52\%; American 
Indian/Alaska Native, $49 \%$; Hawaiian/Pacific Islander, 43\%; and Latino, 38\% (Department of County Human Services, 2014). Day (2000) notes an expectation of social welfare inherent to the American belief that opportunity is equitably available to all; and thereby influences the expectations held of clients, the assessment of their desire, and ability/means to change their circumstances. However, disproportionately represented amongst the poor and within child welfare are populations of color.

\section{The Impact of Poverty and Race}

Societal views concerning poverty typically lead to categorizing the poor as deserving/worthy or undeserving/unworthy, and ultimately inform the structures of government policies. Race, as has poverty, served to establish divisive properties within the core of American society. Likewise, race, as will be later discussed, is strategically used to influence accessibility to information and/or resources based on the creation of a hierarchy where White Americans hold superior status to populations of color or anyone not meeting the categorical criteria for being White. Thus, poverty and race each function as tools of divisiveness; sometimes independently, other times together, and many times in conjunction with gender (Lister, 2004; Morgen et al., 2010; Seccombe, 1999;

Seccombe et al., 1998). While not amply addressed in this writing, the face placed upon poverty is often gender based and most likely single females who are of color (Lister, 2004; Morgen et al., 2010; Seccombe, 1999; Seccombe et al., 1999). Research supports that the United States public welfare system ultimately stigmatizes women for having children outside the traditional norms and promotes gender inequality especially for poor women (Lister, 2004; Seccombe, et al., 1999). 
According to Hattery and Smith (2007) the majority of those receiving welfare benefits in America are White. Paradoxically, African Americans, and Latinos, for example, are disproportionately represented within the public welfare system. According to Damaske et al. (2017), Latino and African American female headed households are more likely than their Whites and Asian counterparts to be amongst the working poor. Additionally, beyond gender, Hattery and Smith (2007) explain that many African Americans constitute those who are working low wage jobs that are insufficient to sustain their economic needs, thus they remain poor. Bates et al., (2014), for example, report that in Multnomah County, Oregon, the "African-American family income is less than half that of White families and the poverty rate among African-American children is nearly $50 \%$ compared to $13 \%$ for White children" (p. 3). While there are likely many Whites, too, who are amongst those working, yet poor, they are not necessarily subjected to the stereotypes projected of poor people of color. For example, stereotypes of single unemployed female headed households of color, especially African Americans, i.e., the "welfare queen" exemplifying the African American woman as having children for the purpose of living off welfare; that African Americans are lazy; that African Americans are poor stewards of their money and other resources dominate the lens of much of American society (Bullock, 2008; Hattery \& Smith, 2007; Seccombe et al., 1998). Hattery and Smith (2007) advise that "there is a strong relationship among employment, underemployment, occupational segregation, and welfare receipt" (p. 221). However, Whites, especially the poor working class, struggle with the idea of privilege based upon race, awareness of the racially wealth divide, or that government programs have been for their advantage (Hattery \& Smith, 2007; Lui et al., 2006). This may be partially attributed 
to the long-time messaging and values promoting the hard work and pulling yourself up by the bootstraps concept (Bullock, 2008; Seccombe, 1999; Seccombe et al., 1999; Wilson, 2010). Bullock (2008) suggest that this ideology of individualism and self accomplishment rationalizes or validates inequitable treatment noting "the belief that anyone can advance, regardless of their family of origin, economic status, or ethnicity, is so central to our national identity that is the heart of the so-called American dream..." (p. $53)$.

During the 19th century, for example, the southern states especially upheld the view that hard work was the formula for financial success and, according to Franklin (1970), were resistant toward offering assistance to its poor. Franklin (1970) explains this position being primarily due to the south's efforts to maintain the institution of slavery and establish political power. It was not until after the Civil War that southern states acknowledged the need for public assistance. During the reconstruction period, public assistance throughout the south was minimal and primarily for Whites. It is worth noting that some populations of color have historically had high rates of poverty within their communities dating back to the $19^{\text {th }}$ century, particularly African Americans and American Indian/Alaska Natives. Trattner (1994) notes that American Indian/Alaska Natives and freed African Americans were seen as inferior to Whites and were mostly excluded from receiving public assistance.

The responsibility of members from these populations was solely left to their respective communities (Trattner, 1994; Ziibiwing Center of Anishinabe Culture \& Lifeways, 2011). Roberts (2005), in a historical review of how African Americans, specifically African American women, addressed child well-being during the latter years 
of the $19^{\text {th }}$ century and early years of the $20^{\text {th }}$ century recounts the emphasis placed upon preventive measures to support and strengthen poor families. For example, promotion of education and training to improve the skill sets of mothers, nurseries, kindergarten and private schools for children, and medical clinics that in addition to routine medical treatment offered tangible goods such as milk to offset the disparities/discrepancies in such service areas due to Jim Crow practices. Services such as nurseries and kindergartens were critical to families where mothers worked outside of the home, which similar to today, was a necessary reality for many African American mothers according to (Billingsley \& Giovannoni, 1972; Roberts, 2005). Billingsley and Giovannoni (1972) note that churches, schools/colleges, lodges, women's clubs, and philanthropy operating within the African American communities as being the primary, if not sole key resources assisting poor African American families and dependent children.

Furthermore, the Social Security Act failed to include provisions under its retirement insurance for those employed in agriculture and domestic services; thereby making most African Americans ineligible for benefits. Eligibility for the Unemployment Insurance (UI) offered under the Social Security Act, was also primarily limited to White males, excluding women and African Americans. Moreover, ADC when first implemented limited benefits to White widows; again, excluding mothers of color. Amendments made in 1939 included benefits to widows and children of former recipients of the Old Age Insurance (OAI); but again, eligibility to OAI had been structured primarily for Whites. Later, during the 1950s, practices primarily operating in the southern states called attention to inequitable processing of African American applicants for ADC benefits (Gooden, 2006; Pelton, 1981). Gooden (2006) notes that a number of 
southern states created eligibility requirements specifically for African American mothers. African American applicants were being denied benefits based upon determinations by public service workers that their homes were unsuitable. The suitability question concerning the homes stemmed from moral biases that children of the homes were born out of wedlock and regulations against having an able bodied man living in the home (Gooden, 2006; Lindhorst, \& Leighninger, 2003; Murray \& Gesiriech, 2004; Soss \& Schram, 2008). Illegitimate births of White and African American children were viewed differently by the public (Gooden, 2006; Neubeck \& Cazenave, 2001). Louisiana, for, example had terminated benefits of 23,000 children based upon such practices specifically garnering attention from the federal government. Subsequently, federal policy introduced the Fleming Rule in 1960 forbidding states to neglect caring for the needs of children based upon the suitability of the home, mandating that states provide services to the home or remove the child and offer financial assistance for the child (Lindhorst \& Leighninger, 2003; Murray \& Gesiriech, 2004). Consequently, the numbers of African American families receiving public welfare benefits increased. By the time of the passage of the 1964 Civil Rights legislation, the wellbeing of African Americans became the subject of much political debate.

The Negro Family: The Case for National Action (1965) also referred to as the Moynihan Report garnered considerable support as well as criticism. The report purported that family structure primarily single female headed households and illegitimate births was at the crux of issues facing African Americans (Cohen et al., 2015; Gans, 2011; Office of Policy Planning and Research/United States Department of Labor, 1965). The report met with considerable criticism at the time and Gans (2011) 
emphasizes that the report defined family structure through a Eurocentric lens and moral values that defined the African American as pathological, absent full consideration of realities such as low wages, unemployment and racism. Duncan et al. (2017) notes the importance of understanding the differing perspectives cultivated by circumstances surrounding families who live in poverty and distinguishing between the actions/behaviors of families of color versus their respective values. Marriage and having children raised in the home by both parents, for example, is valued by African American women but often seems unrealistic when considering challenges such as mass incarceration, high unemployment and other challenges occurring African American communities (Edin \& Kefalas, 2005; Wilson, 2010). Wright (1977) in an analysis of the impact of race on the disproportionate numbers of African Americans experiencing poverty, found a close connection between public sentiments about race and public welfare; and that racial bias impacted local state policies but did not necessarily indicate race influencing federal policies.

Racism and discrimination while unpopular and uncomfortable discussions, remain present in today's society; and engrained within the various government structures (Bullock, 2008; Lui et al., 2006; Neubeck \& Cazenave, 2001; Wilson, 2010). Neubeck and Cazenave (2001) note specifically call attention to racism and the public welfare system:

Welfare racism exists and persists because it serves three major social stratifications of social functions for racialized societies and their 'racial states.' Welfare racism provides: (1) social prestige for the general white population, (2) political and career power for its politicians and other elites and (3) economic 
acquisition for the nation's economic elite in the form of largely exploitable lowwage labor pool. (p. 12)

The United States has higher rates of poverty compared to other western nations (Homan et al., 2017; Lui et al., 2006; Smeeding, 2005). Lui et al. (2006) attributes this to racial divisiveness and advises that resolving the economic gaps caused by racism would be profitable to all. Beyond the focus on economic considerations, the influence of racism is thought to ultimately impact the plight of the nation's children of color who are impoverished (Annie E. Casey Foundation, 2019; Children's Defense Fund, 2017; Children's Defense Fund, 2019; First Focus on Children, 2018).

First Focus on Children (2018) specifically notes that children of color who "due to our country's long history of structural racism and discrimination, the poverty rate for Black and Hispanic children continues to be significantly higher than for White children" (p. 1). First Focus on Children (2018) also extends concern for children of immigrant households where "unique cultural and systemic barriers to obtaining economic security" exists (p. 1). According to the Annie E. Casey Foundation (2019), reportedly higher percentages of children of color live below the poverty line than White children. The percentages of African American and American Indian/Alaska Native children combined was 33\% which was three times higher than that of White and Asian and Pacific Islander children who combined was $11 \%$. The report further noted that $26 \%$ of Latino children were living in poverty which exceeded the national average.

\section{Race}

Lui et al. (2006) offers this portrayal of race, as constructed within the United States: 
Native Americans of all tribes faced genocide and displacement. Latinos of all nationalities ended up in this country after the United States government invaded, dominated and/or conquered their lands. Almost all African Americans are descendants of slaves and of survivors of segregation and mob violence. Asian Americans of all nationalities have been treated as perpetual foreigners and most European Americans of all ethnic groups have been treated (sometimes reluctantly) as citizens worthy of government assistance. (p. 25)

The role and function of race within the greater society has proven challenging and controversial, which subsequently impacts the understanding race within the child welfare discussion. Attributing to the challenge in the discussion of race is a lack of understanding in how it is defined. Confusion often results as sometimes the terms race, ethnicity and culture are all used interchangeably while seemingly having different meanings (Markus, 2008; Wells-Merritt \& Briggs, 2009). Thus, it is necessary to offer some explanation of the three terms, respectively, in order to unpack the role and function of race. Markus (2008) offers the following distinction as follows:

Race is a dynamic set of historically derived and institutionalized ideas and practices that (1) sorts people into ethnic groups according to perceived physical and behavioral human characteristics; (2) associates differential value, power and privilege with these characteristics and establishes a social status ranking among the different groups; and (3) emerges (a) when groups are perceived to pose a threat (political, economic, or cultural) to each other's world view or way of life; and/or (b) to justify the denigration and exploitation (past, current, or future) of and prejudice toward, other groups. 
Ethnicity is a dynamic set of historically derived and institutionalized ideas and practices that (1) allowed people to identify or to be identified with groupings of people on the basis of presumed (and usually claimed) commonalities including language, history, nation or region of origin, customs, way of being, religion, names, physical appearance and/or genealogy or ancestry; (2) can be a source of meaning, action and identity; and (3) confers a sense of belonging, pride and motivation" (p. 654). Culture refers "to patterns of ideas and practices associated with any significant social grouping, including gender, religion, social class, nation of origin, region of origin, birth cohort or occupation. (p. 653).

Markus (2008) explains that which groups are classified as a race versus ethnic or cultural has not been consistent throughout history noting that Latinos have not always fallen under the terminology of race; groups such as Italians, Irish, Asians, and Mexicans have sometimes been those having 'ethnicity and culture'; while Whites have primarily been excluded from either designation (p. 653 - 654). Markus (2008) further acknowledges that due to discrepancies in how history occurred, societal restrictions limiting resources/ease, and their membership to the majority race, some ethnic groups such as Italians and Irish worked against having any similarities or associations between White ethnic groups and those who were classified as minority races, (i.e., African Americans, American Indian/Alaska Natives, and Latinos); therefore, aligning with an identity of race rather than ethnicity.

Omi and Winant (1994) suggest that "race is a concept which signifies and symbolizes social conflicts and interests by referring to different types of human bodies" (p. 55). This explanation appropriately highlights the role of race within American 
society and its respective structures. Some of the social conflicts surrounding race within society is embedded within the longstanding debate of equality versus inequality (Day, 2000; Omi \& Winant, 1994; Malik, 1996). While the United States has from its origins expounded ideals of equality, inalienable or God given rights and a democratic society where privileges of class, wealth, etc. does not place one individual above another; the direct opposite exist for some and there is no guarantee of access to resources and opportunities (Davis \& Cloud-Two Dogs, 2004; Day, 2000; Malik, 1996). The Constitution, for example, initially extended citizenship to those with the ability to own property, predominantly white males, while people of color, women and poor European immigrants and people of color were excluded (Day, 2000; Gustavsson \& Segal, 1994; Malik, 1996). Malik (1996) argues that the idea of equality is not a natural phenomenon, but instead is socially constructed based upon the aspects of a given society.

Malik (1996) further suggest that society's uncertainty and particularly in the Western hemisphere, regarding equality is at the root of attitudes towards race noting that race emerged as an explanation for societal inequities. This is perhaps supported by the initial intent and efforts of scholars to promote the premise that race was a natural biological state accounting for differences and similarities within and amongst different groups of peoples. Formerly, scholars advanced the notion of race being as scientifically verifiable proof of an inherent biological basis for attributing superior and inferior traits to groups of peoples; and further purported this as reasoning and/or justification for inequalities (Jackson \& Weidman, 2004; Malik, 1996; Markus, 2008; Omi \& Winant, 1994). However, scholars have since agreed that race is socially constructed having no biological foundation. While race typically infers some reference to variation of 
phenotype characteristics, such as skin color, found amongst different groups of peoples, research now supports that the origins of race are not biological (Fields, 1990; Lopez, 2006; Markus, 2008; Omi \& Winant, 1994; Rattansi, 2007). Following Malik’s (1996) theory, one can argue which came first, the social construction of inequality as a given because of racial differences amongst humanity or the social construction of race as an explanation for certain inequalities. The latter, to some extent, leverages the position of race with other social constructs or statuses such as gender, ethnicity, culture and class. For example, some argue that racial disproportionality that manifests within the various societal structures, such as child welfare, is attributed economic status or class more so than race (Bartholet, 2009; Bartholet et al., 2011). Regardless, it is suffice to say that the role and function of race within American society has been critical in the designation of peoples and their respective position within society.

Race represents a construct created through social, historical, and legal premises designating different groups of peoples into specific hierarchical classifications embedded with exclusion and oppression of some (Fields, 1990; Lopez, 2006; Omi \& Winant, 1994; Rattansi, 2007). In American society, the White race has been designated as superior having dominant/majority status, while all other racial groups, African American, American Indian/Alaska Native, Latino, Asian, and Multi-racial have been deemed minority status (Flagg, 1993; Lopez, 2006; Omi \& Winant, 1994). Subsequently, the norm for understanding human behavior within American society has been set having the White race, (i.e., Eurocentric), as the standard. Markus (2008) adds, for example, that much of what has been presented by mainstream psychology “ $\ldots$ is specific to middle- 
class European American psychological experience" with the attention to others being practically “...invisible” (p. 653).

The hierarchical distinctions of race have been maintained and sustained legally, politically and socially throughout American history (Flagg, 1993; Lopez, 2006; Omi \& Winant, 1994). The designation of the White race, for example, has been a process historically vetted through the political and legal systems. Battalora (2013) references legislation from Virginia laying the foundation for specifically categorizing Whites as a group to be ...set apart from those labeled 'negro,' 'mulatto,' or 'Indian' (p. 34); and Maryland as first in passing legislations actually using the term White. Battalora (2013) further notes that prior to the Virginia and Maryland legislative acts those of European descent referred to themselves by their countries of origin, (i.e., British). The Naturalization Law of 1790 was the first congressional effort to limit citizenship in America to immigrants who were free and White (Battalora, 2013; Lopez, 2006; Omi \&n Winant (1994). Lopez (2006) explains that early Court decisions helped to establish race as a natural state, thereby positioning Whiteness as natural; with "Whites as those not constructed as non-White" (p. 20); and "Whites as citizens and others as aliens" (p.20). Lopez further concludes that such judicial determinations supported the concept of White as "pure" (p.20) as was evident in the United States regulation that a single drop of blood of African ancestry constituted being of the African American/Black race. Furthermore, race is associated with positive and negative attributes contingent upon which racial classification one is assigned. Lopez (2006) notes that the White race, for example, is framed having positive attributes such as “...industrious, knowledgeable, virtuous, and law-abiding" (p. 20). The manifestations of attributes associated with race have impacted 
the various systems governing the daily operations of society such as social services including child welfare, judicial, law enforcement, medical, educational, etc. According to Markus (2008) prejudice and discrimination founded upon race need not generate from a place of hostility or mal intent in order to create harm. She explains that “... racial stereotypes are often automatically activated and have powerful behavioral consequences both for those who hold the stereotypes and for those who are the target of them" (p. $653)$.

Longstanding stereotypes and values attributed to different racial groups have resulted today in adverse experiences and outcomes for many people of color when interfacing with societal systems. For example, racial and/or implicit bias is believed to contribute to the disparate treatment experienced by people of color when encountering these systems (Alexander, 2012; Egede, 2006; Markus, 2008; Wells et al., 2009).

Eberhardt, Davies, Purdie-Vaughns, and Johnson (2006) revealed that African Americans involved with the criminal justice system are more likely to receive the death penalty than Whites. Locally in Oregon, Bates and colleagues (2014) state that "AfricanAmericans in Multnomah County continue to live with the effects of racialized policies, practices and decision-making" (p. 2). Thus race directly or indirectly impacts the governance and operations of society, as evidenced by racial disproportionality and disparities within the systems of child welfare, judicial, law enforcement, health, mental health, housing, education, and so forth (Alexander, 2012; Bates et al., 2014; Billingsley \& Giovannoni, 1972; Markus, 2008; McRoy, 2004). One of the early references within the national dialogue concerning race comes from the 1968 Report of the National Advisory Commission on Civil Disorders: "What white Americans have never fully 
understood- but what the Negro can never forget - is that white society is deeply implicated in the ghetto. White institutions created it, white institutions maintain it and white society condones it" (p. 1).

Historically, child welfare, as one of societal structures, has shown itself to not be immune from societal political and social happenings surrounding race. Race, absent concerns for White children, did not enter the national child welfare dialogue during the early decades as children of color were marginalized within the greater society. While the acceptance of Jim Crow regulations/restrictions influenced the larger society, Roberts (2005) notes that the care of African American children fell primarily to their families and communities. Attention to interests of American Indian/Alaska Native children during this same time was stimulated by the desire to assimilate American Indian/Alaska Natives into American culture as demonstrated by the enactment of Boarding Schools and adoption of native children by White families (Family \& Children Services Division Minnesota Department of Human Services, 1995; Lidot et al., 2012; Lucero \& Bussey, 2012; Voyer, 2006). It was not until the 1930 White House Conference on Child Health and Protection that the interests and well-being of children of color was formerly addressed within the national child welfare dialogue (Folks, 1940; McRoy, 2004). According to Folks (1940) the discussion of race proved perplexing and troublesome noting that while there was consensus amongst the professional community regarding the negative impact of societal racism and discrimination; and that equitable treatment and service delivery should exist for all children, there was minimum understanding or knowledge on how to best achieve this for children of color. Throughout the years, child welfare continued to struggle to justly incorporate appropriate practices that adequately 
meet the needs of children and families of color (Billingsley \& Giovannoni, 1972; McRoy, 2004; Roberts, 2002). It would be several years following the introduction of race at the 1930 White House Conference on Child Health and Protection before the nation acknowledged the development of racial disproportionality within the child welfare system. Race, due to the positive and/or negative attributes associated with the various racial groups contributes to individual and structural/systemic biases operating within child welfare (Ards et al., 2003; Miller et al., 2013; Wells et al., 2009). Hill (2006) while cautioning against any drawing any subsequent conclusions regarding bias, confers that race definitely has a role in decision making along the child welfare trajectory. Furthermore, Hill (2010) specifically stresses the necessity of unpacking the influence of “institutional or systemic racism" when addressing racial disproportionality within the child welfare system to increase understanding in the context of the "public dialogue" (p. 104).

\section{Racial Disproportionality and Child Welfare}

The presence of racial disproportionality further exemplifies the challenges when attempting to make meaning of the role, function and intersection of poverty and race to the present-day definition of child maltreatment and goals of child welfare. Billingsley and Giovannoni (1972) called attention to the ongoing failure of the child welfare system to understand the cultural dynamics surrounding African American families and specifically identified racial disproportionality. Since that time, racial disproportionality, as defined by Hill (2006), is more often understood to mean the greater representation of children from certain racial/ethnic populations being found within the foster care system than their respective representation within the general child population. Disparity 
typically references unequal treatment and/or services experienced amongst the various racial/ethnic groups once involved with the child welfare system (Boyd, 2014; Font et al., 2012; Hill, 2006; Wulczn \& Lery, 2007).

Boyd (2014) explains that the distinction between racial disproportionality and disparity when referring to the child welfare system has been blurred with the two terms interpreted as one in the same. However, Boyd (2014) further advises against this practice stressing the necessity of clearly distinguishing between the two terms noting that "disparity is a between groups comparison for children in the child welfare system that does not depend on the group's percentage in the general population" (p. 16).

Wulczn and Lery (2007) further suggest that racial disproportionality is actually a result of disparity occurring at the entry and exit decision making points within the child welfare system. For example, disparate treatment for children of color has been identified throughout the child welfare trajectory beginning with the initial referral and investigation; being less likely to reunify with birth parents, more likely to experience reentry to foster care after reunification, and experience longer stays once in the foster care system; all of which possibly contributes to their ultimate overrepresentation in the child welfare system (Ards et al., 2003; Cahn \& Harris, 2005; Courtney, 1994; Courtney, 1995; Dettlaff, et al., 2011; Hill, 2006). Considerable research has been conducted exploring and explaining the existence of racial disproportionality nationally and within respective State public child welfare systems (Dunbar \& Barth, 2007; Miller et al., 2009; Miller et al., 2010; U.S. Government Accountability Office, 2007).

Prior to Sedlak and colleagues (2010) most recent National Incident Study of Child Abuse and Neglect (NIS-4) report, children of color were not reported as 
experiencing any higher rates of child maltreatment than their White peers. Sedlak et al. (2010) NIS-4 report found higher accounts of child maltreatment existing among African American children than other populations. Hill (2010) explains however, that in reality: The finding of no significant racial differences in NIS-3 is almost identical to the finding of no significant racial differences in maltreatment in NIS-4 -under the Harm Standard! Significant racial differences in NIS-4 were found - under the Harm Standard-only among the not low SES households (where black rates were higher than white rates) that experienced physical abuse. In sum the most important difference between the multivariate racial analyses in NIS-3 and NIS-4 is that the results in NIS-4 are more complex than the results of the NIS-3. While almost no significant racial differences in maltreatment were found in NIS-3, the presence or absence of significant racial differences in NIS-4 depends on the risk level (Harm or Endangerment Standard)and risk factors (household SES or family structure)... (p. 104).

Sedlak and colleagues (2010) recommend additional research to examine possible correlations between family characteristics such as socioeconomic status, employment status, family structure and acts of child maltreatment; and further exploration to determine if differences amongst racial groups for occurrences of child maltreatment maintain while controlling for risks factors. Hill (2010) further recommends that just as research explores risk factors associated with child maltreatment, greater attention should be the association between "protective factors or cultural strengths" that may decrease child maltreatment such as "type and frequency of mutual support between extended kin, extent of informal and formal child care by relatives, strong religious orientation, high 
self-esteem, etc.” (p. 104). Increased awareness of the benefits of protective factors/cultural strengths may prove especially beneficial for research concerning racial disproportionality.

\section{Theories Explaining Racial Disproportionality}

The literature offers varying theories and conceptual rationales to explain racial disproportionality such as (1) higher proportion of risks existing for families and communities of color; (2) individual and implicit biases existing amongst child welfare professionals; (3) systemic and structural biases within child welfare and other involved systems such as the juvenile court; and (4) multiple determinants implying that no one factor or set of factors can independently explain racial disproportionality (Ard et al., 2003; Bartholet et al., 2011; Dettlaff \& Rycraft, 2008; Johnson-Reid et al., 2009; Miller et al., 2012; Miller et al., 2013). Characteristics associated with individuals, families, and communities such as poverty, substance abuse, single parenting, mental health issues, violence, criminal behaviors, and the incarceration of parents are commonly designated as potential risks for child maltreatment (Coulton, Korbin \& Su, 1999; Drake et al., 2009; Sedlak \& Broadhurst, 1996). While much of the research acknowledges these or comparable explanations establishing a baseline of understanding, Boyd (2014) suggests that the literature lacks structure, explaining that current approaches are too varied in the presentation and categorization of the risk factors thought to attribute to racial disproportionality. Furthermore, the literature is unclear as to how these risk factors operate independently, collectively or through their interrelatedness to influence child maltreatment, particularly for children of color (Boyd, 2014; Font et al., 2012). Boyd's (2014) explanation is that the current framework fails to provide "justification for 
excluding or disproving alternative explanatory factors" (p. 17). Alternatively, Boyd (2014) better details and organizes the commonly recognized explanations offering clarity to domains that are innately overlapping and interrelated into five primary areas of concentration: (1) disproportionate need; (2) human decision-making; (3) agency-system factors; (4) placement dynamics; and (5) policy impact.

\section{Disproportionate Need}

The literature implies the prominence of certain risk factors amongst individuals, families and communities of color, particularly African Americans, is indicative of a higher need for services rendered by child welfare as reasoning for racial disproportionality (Bartholet, 2009; Boyd, 2014; Drake \& Pandley, 1996). According to Children's Defense Fund (2019), children are the poorest among America's population with children of color being disproportionally represented. The report indicates that every two out of three children of color lives in poverty with close to one out of three being American Indian/Alaska Native, and more than one of four African American and Latino being impoverished compared to one of nine White children. The experience of childhood poverty for many children of color residing in Multnomah County exceeds than the national average of 22\% with African American, 52\%, American Indian/Alaska Native, 49\%, Hawaiian/Pacific Islander, 43\%and Latino, 38\% (Department of County Human Services, 2014). This is corroborated to some extinct, for example, by child welfare data that reflects allegations of child maltreatment, especially neglect, are primarily attributed to poverty coupled with national data which shows that disproportionately African American children are living in poverty. 
Boyd (2014) purports three distinguishable sub-areas comprising the disproportionate need category: (1) poverty; (2) parent, child, and family characteristics; and (3) community dynamics potentially allowing for examination of each in greater specification. Poverty, already affirmed by the literature as a primary indicator of child maltreatment (Beimers \& Coulton, 2011; Courtney et al., 2005; Drake \& Johnson-Reid, 2011; Font, Berger \& Slack, 2012; Sedlak et al., 2010), is discussed in terms of individual poverty reflecting the economic status of respective households and structural poverty referencing the overall economic condition of communities and neighborhoods.

Bartholet (2009) concurs with the premise of disproportionate need suggesting that attention to racial equity by addressing the reduction of African American children to mirror that of White children potentially subjects African American children to increased safety risks while failing to acknowledge true child maltreatment threats. Others stress the importance of contextual understanding surrounding the experiences of individuals, families, and communities of color with certain risks such as poverty. Evans-Campbell (2008) illustrates that parents of color hold different views of what constitutes neglect than child welfare professionals and even White parents. Essentially, how poverty is understood by child welfare professionals conceivably lends to skewed assessments of families during initial investigations and may negatively impact any subsequent service delivery/plans thereby potentially contributing to racial disproportionality (EvansCampbell, 2008; Roberts, 2002). This assertion corroborates the suggestion by some that the child maltreatment definition, particularly neglect, creates inherent disadvantage for ethnic/racially diverse families as the definitions fail to acknowledge differences held by various cultural, ethnic and racial populations of what constitutes neglect (Evans- 
Campbell, 2008; Roberts, 2002) The misrepresentation or misunderstanding of poverty lends thought to a deeper understanding of the element of need with regard to poverty and its subsequent relationship with resource availability. Font et al. (2012) notes the literature is ambiguous when explaining the association between need and poverty experienced by families, noting that needs more extensively involves families' awareness, accessibility and understanding of available resources within their community; all of which are outside the realm of poverty alone.

Additionally, the research indicates that living in lower poverty levels results in child welfare involvement for families of color, whereas child welfare involvement for Whites occurs when living in higher poverty levels; meaning that families of color are likely to become involved with child welfare at poverty levels that are lower than that of White families (Drake et al., 2009; Korbin et al., 1998; Wulczn et al., 2005). PutmanHornstein et al. (2013), however, found that when controlling for socioeconomic factors, families of color living in lower poverty had decreased potential for becoming involved with child welfare. Similarly, Kim and Drake (2017) found poor African American families to be at a "lower risk" for reporting of child maltreatment than economically disadvantaged White families (p. 21). Thus, the research yields mixed findings. This discrepancy in becoming child welfare involved between poor families of color and poor White families possibly suggest potential bias in decision making possibly stemming from the influence of poverty and/or race.

Another confusing aspect of poverty points to the incongruence in how it impacts poor families becoming involved with the child welfare system compared to the presence of child welfare involvement amongst poor families who are involved with the public 
welfare system. Unlike the child welfare system, the public welfare system minimally has families who are receiving TANF benefits and also experiencing child maltreatment. The literature has yet to address the imbalanced representation between the small percentage of TANF recipients, regardless of race, who become involved with the child welfare system compared to child welfare's disproportionate high percentage of poor and disproportionately poor families of color who comprise the majority of the child welfare data base. Seemingly, it would be expected that higher numbers of poor families, especially those of color, in the public welfare system would be encountering child maltreatment. Font and colleagues (2012) further note that if high prevalence of poverty, individualized and structural is the explanation of racial disproportionality within child welfare "... then black/white differences in CPS involvement should be completely accounted for by differences in economic status and should therefore be statistically equivalent to zero in empirical models once economic factors are controlled" (p. 2190).

Similar to poverty, additional factors such as addiction, mental illness, domestic violence, family structure - for example, size and single female parented householdsand parental incarceration are believed to represent a disproportionate need for families of color with families' profiles typically exhibiting some combination of such characteristics. Families of color, in particular, are vulnerable to risks such as substance abuse, single parenting and mental health diagnosis prior to and during their involvement with the child welfare system (Chaffin et al., 1996; Kotch et al., 1999; Sedlak et al., 2010; Sedlak \& Shultz, 2005). Fluke et al. (2010) supports that poor communities, especially those of color often lack in available addiction and mental health resources. However according to Miranda and colleagues (2008), when controlling for socioeconomic factors 
such as poverty, race reflects minimal differences amongst families entering the child welfare system due to some mental illness diagnoses such as depression. Additionally, Courtney and colleagues (1996) report that African American mothers are more likely to be subjected to drug testing than Whites which may account for their higher rates of addiction Similar to poverty there remains clear understanding regarding how these various factors contribute to racial disproportionality.

The third aspect to disproportionate need involves community factors having negative effect on families such as poverty, crime, and an overall lack of resources (Dettlaff \& Rrycraft, 2008; Wilson, 2010). Research shows that inadequate resource availability to address sufficient housing, addition and mental health services negatively impact racial disproportionality (Dettlaff \& Rycraft, 2008; McRoy, 2011). Additionally, intact social ties and networks further strengthen communities' ability to offset or counter the negative impact of some adverse community factors and likely avert involvement with the child welfare system (Coulton et al., 1999; Roberts, 2002). Some argue that the high prevalence of child welfare's presence within communities of color inadvertently aids the deterioration of the communities' social strength (Cahn \& Harris, 2005; Roberts, 2002). Cause and colleagues (2014) note the negative effect of gentrification to the African American community of Portland, Oregon, resulting from the displacement of its population, restructuring of community resources, limited access and diminishing innate resources formerly in place through familial, neighborhood and church relations. Dettlaff and Rycraft (2014) supports this concern noting that the weakening of community social strength/cohesion attributes to increased representation of African American within the child welfare system. 


\section{Human Decision-Making}

The human decision-making category encompasses the influence of individual bias exerted by child welfare professionals. Bias has been evidenced when executing the various decision-making points along the child welfare continuum and is believed to contribute to racial disproportionality (Cross, 2008; Harris \& Hackett, 2008; Hill, 2006; Miller et al., 2010; Roberts, 2002). The literature terms bias as racial and likely implicit meaning that biases held by child welfare professionals may be racially motivated but are likely not overtly known/aware by the individual. Research supports that in some states such as Oregon and Washington, implicit bias affecting initial assessments where substantiations of allegations of child maltreatment are determined; decisions to remove and utilize out of home placement, service deliveries that support remedying initial causes for substantiation and/or foster care placement; and ultimately reunification (Harris \& Hackett, 2008; Miller et al., 2010). However, the literature also provides accounts where racial bias has not shown to have an influential presence as in the reporting of child maltreatment referrals from the general public or some key decision making points in Missouri and Illinois respectively (Drake et al., 2009; Rolock \& Testa, 2005). Regardless of these instances, Fluke and colleagues (2010) suggest that the literature has found sufficient representation of individual bias influencing racial disproportionality to support it as a contributing factor.

Further negatively impacting the decision making is that child welfare, as a compliance driven system, lends the potential that parents' actions/behaviors are misinterpreted as noncompliant, disinterest in adhering to case plan goals or services, or even hostile based on biases held by child welfare professionals (Cause et al., 2014; 
Miller et al., 2012). Possibly influencing the failure to accurately interpret messaging or intent of parents of color, as noted by Cross (2008), is the lack value competency by child welfare professionals in understanding the influence of culture. According to Cause and colleagues (2014) parents of color during a qualitative study in Oregon indicated their belief that White child welfare case workers' limited appreciation and awareness of culturally based parenting practices for various racial/ethnic groups as contributing to racial disproportionality. Furthermore, community members responses, including parents involved with the Oregon child welfare system, acknowledged different expectations held for families of color reflected as the continual modifications to requirements and/or expectations of parents; and an inability to acknowledge positive changes were achievable and/or accomplished by parents (Cause et al., 2014; Miller et al., 2010; Miller et al., 2012). Additionally, Rivaux, and colleagues (2008) found the child welfare professionals differently applying the threshold for risk based on race/ethnicity. Dettlaff and colleagues (2011) further demonstrated that when controlling for socioeconomic factors such as family income, race did not present as a contributing factor; but when controlling for the perceptions of risk held by case workers along with family income, race surfaced having greater influence; meaning that poor families may be assessed differently based upon their particular race. Closely aligned with individual bias is the influence of systemic/structural issues, including bias, within the child welfare system potentially contributing to racial disproportionality.

\section{Agency-System Factors}

Boyd's (2014) description of this category includes aspects affected by the infrastructure of the agency, systemic and structural bias by the agency, institutional 
racism, culture of the agency, service delivery, and a disconnect from the community served by the agency. Research supports various systemic elements such as inadequate staffing due to constant attrition and failure to develop a diversified workforce reflective of the communities served; work-load demands, culturally incongruent services and policies that inadvertently adversely affect families of color (Chibnal et al., 2003; Dettlaff \& Rycraft, 2010; Dettlaff \& Rycraft, 2011; Miller et al., 2012; Roberts, 2002). In essence, that which falls outside of the "norm" or doesn't fit with system values is seen by agency culture as abnormal; there may also exist fear by staff of operating outside the agency culture thus impacting policies and decision making (Cross, 2008, Harris, \& Hackett, 2008; Dettlaff \& Rycraft, 2008; Miller et al., 2010; Roberts, 2002). The significance of culturally specific services may be devalued and therefore lacking to appropriately meet the needs of families of color (Dettlaff \& Rycraft, 2008; Miller et al., 2010). Ultimately the disconnection of the agency with communities of color serves to deepen the underlying distrust held by many populations of color. The significance of improved relations with communities of color was highlighted, for example, in Miller and colleagues' (2010) research on racial disproportionality within Oregon's child welfare system, has noted the longstanding distrust and impaired relations with communities of color as contributing to racial disproportionality. Specifically acknowledged, is the impact to decision making surrounding placement when out of home care is determined to be necessary (Cause et al., 2014; Miller et al., 2014).

\section{Placement Dynamics}

Placement dynamics, according to Boyd (2014), manifests in decisions regarding the utilization of kinship care and adoption. Placement instability, although closely 
monitored through the CFSR process remains a challenge for child welfare. Multiple moves while in foster care have been suggested as influencing racial disproportionality, especially for African American children (Boyd, 2014; Foster et al., 2011). Additionally, while kinship care has received considerable attention over recent years resulting in increased utilization of relative placements when families of color become involved with the child welfare system, additional concerns arise regarding racial disproportionality. First, the old adage of the fruit doesn't fall far from the tree is believed to continue in some instances to deter child welfare staff from considering relatives as viable placement options (Cause et al., 2014; Miller et al., 2010). Meaning, that child welfare staff sometimes have misgivings about relatives based upon birth parents' characteristics such as addiction, criminal behavior, or former/ongoing child welfare involvement. Specifically emphasized in the literature is the belief that relatives are overlooked as placement options, and/or that licensing requirements rule relatives out as placement considerations (Cause et al., 2014; Harris \& Cahn, 2005; Miller et al., 2010). Additionally, kinship care sometimes results in extended time in care for children of color, thus inadvertently contributing to racial disproportionality. This is especially true for American Indian/Alaska Native populations as traditional values do not condone or acknowledge the legal severance of parental rights thus resulting in increased case plans of long term or permanent foster care placements for native children. Furthermore, despite the intentions of policies such as the Adoption and Safe Families Act (ASFA) and the Multi-Ethnic Placement Act and the Interethnic Placement Act (MEPA/IEPA) historically, children of color remain more likely to be in foster care for extended periods (Barth, 2005; Fluke et al., 2010). 


\section{The Potential Impact of Policy on Racial Disproportionality}

Federal policies, as noted by Boyd (2014), influences racial disproportionality, particularly for African American children. Beyond the Indian Child Welfare Act (ICWA), the literature notes the MEPA-IEPA as policies designed with the interest of race as a primary concern (Anyon, 2011; Boyd, 2014). Although intended to remove barriers to adoption for children of color and subsequently help prevent their potential lingering in foster care, Anyon (2011) acknowledges that neither policies, nor the promotion of trans-racial adoption, has served to deter racial disproportionality. Some further suggest that the concerns surrounding policies and impact to racial disproportionality is in reality a deficit of the impact of the MEPA-IEPA as specifically targeting race (Boyd, 2014; Center for Chapin Hall Center for Children, 2008).

Additionally, while the Adoption and Safe Families Act (ASFA) of 1997 mandated strict timeframes and financial incentives to promote permanency for children in foster care, Anyon (2011) notes that the policy has done little to positively impact racial disproportionality.

\section{Multiple Determinants}

The research supports multiple causes as influencing racial disproportionality and advises against any single determining factor attributing as the sole contributor (Dettlaff et al., 2011; Miller et al., 2010: Rivaux et al., 2008). For example, issues related to poverty, individual structural biases that may be racially induced as well as agency policies and legislation may all operate simultaneously or parallel to each other to influence the presence of racial disproportionality and disparity within the child welfare system. Baumann and colleagues (2011) further note the importance of understanding the 
ecology of decision making within child welfare and the role decision making when addressing racial disproportionality. Their Decision-Making Ecology Framework applied to child welfare decision making brings clarity to the interconnected and overlapping of particular decision-making elements that specifically influence racial disproportionality. For example, the interplay of the influence of external factors such as legislation, public concerns, and individual histories/experiences of caseworkers along with agency policy, and the climate/morale during key decision-making points along the child welfare continuum. Baumann and colleagues (2011) highlight the relevance of error occurrences within the child welfare decision-making processes when understanding racial disproportionality.

\section{The Existence of Racial Disproportionality within Oregon's Child Welfare System}

According to Miller, et al. (2010, 2012, 2013) racial disproportionality has been confirmed in Oregon's child welfare system particularly among African American and American Indian/Alaska Native children and families. Miller and colleagues (2010) report that African American and American Indian/Alaska Native families are twice as likely have involvement with Oregon's child welfare system and they are reported for allegations of child abuse/neglect at higher rates than White families. According to DHS American Indian/Alaska Native children make up 3.2\% and African American $4.8 \%$ of Oregon's foster care population while being $1.6 \%$ and $3.7 \%$ of the general population respectively during 2017. Miller and colleagues (2010), indicated that American Indian/Alaska Natives were nearly six times and African Americans were two times more likely to be represented in foster care in Multnomah County, Oregon's largest and most racially diverse region, than within the general population. 


\section{The Necessity of Including the Voices of Families in the National Discourse}

Families involved with both the child welfare and public welfare systems have had limited voice in the national discourse. Pelton (2011) acknowledges that perspectives of parents who become engaged with the child welfare system have historically been virtually absent. Over recent decades, however, scholars have reflected child welfare involved parents regarding topics such as family preservation (Coleman \& Collins, 1997), therapeutic foster care (Jivanjee, 1999), visitation (Haight, et al., 2002), child welfare interventions (Drumbrill, 2006;_Spratt \& Callan, 2004), loss and identity issues of parents (Schofield, et al., 2011) and experiences during and post foster care placement (Malet, et al., 2010).

Similarly, historically the research notes minimal input from welfare recipients regarding their experiences with and their views of the public welfare system (KrumerNevo \& Benjamin, 2010; Krumer-Nevo, 2016; Popkin, 1990; Seccombe, 1999; Strier, 2005). Some scholars have sought the perspectives of welfare recipients, particularly women, concerning their lived experiences (Butler \& Nevin, 1997; Morgen et al., 2010; Popkin, 1990; Seccombe, 1999; Seccombe et al., 1999; Williams 1998). However, Strier (2005) notes the literature as especially lacking regarding the perspectives of poor fathers. Goode (2012) further acknowledges the significance of highlighting gender differences when addressing financial challenges via the male voice. Men due to societal views surrounding masculinity that promotes beliefs of men as breadwinners more so that women, likely deter men from seeking financial support and assistance.

Furthermore, the literature has established that involvement with either or both the child welfare and the public welfare systems creates feelings of oppression, is degrading 
and is disempowering (Alpert, 2005; Anderson, 2001; Butler \& Nevin, 1997; Cause et al., 2014; Morgen et al., 2010; Pelton, 1981; Pelton, 1999; Pelton, 2015; Seccombe, 1999). Additionally, research supports that incorporating the independent perspectives of the lived experiences of families brings added value (Anderson, 2001; Cause et al., 2014; Pelton, 1981; Pelton, 2011; Pelton, 2015). Furthermore, research has firmly established that poor parents, those receiving or eligible to receive public welfare benefits, comprise the majority of those becoming involved with the child welfare system; and that poverty is singularly the greatest contributing factor posing risk for parents becoming involved with child welfare (Coulton et al., 1999; Drake et al., 2009; Howze, 2005; McLeigh et al., 2018; Sedlak \& Broadhurst, 1996). The research further acknowledges poor parents' as having value for parenting and that they care about the welfare of their children (Butler \& Nevin, 1997; Seccombe, 1999).

However, the literature is nearly silent regarding the views from poor parents who are welfare recipients who are at risk for becoming or are already involved with child welfare, concerning the influence of poverty on their parenting capacity as well as their ability to protect and meet the needs of their children. Frame and Berrick (2003) conducted interviews with parents of low socioeconomic status and subsequently suggested that parenting capacity should also be integrated into the dialogue concerning welfare. While welfare typically promotes return to work initiatives, the study concluded that attention also be given to supporting parent and/or child wellbeing. Considering the poverty related stressors experienced by parents, the immediate and long-term negative impact on child wellbeing outcomes, focusing primarily on employment issues by the public welfare system is inadequate. Ultimately, failure to infuse child wellbeing in the 
welfare conversation may potentially negative impact the child welfare system. Lister (2004) specifically recognizes qualitative research as valuable in capturing insightful meanings from the perspectives of lived experiences. Frame and Berrick (2003) further contend that solely addressing economic issues/challenges is inadequate in terms impacting overall child wellbeing and/or child welfare.

\section{Theoretical Framework}

Theories are essential in offering explanations that support the understanding of the concepts being explored and their potential meanings. Specifically, theory is useful in illuminating how poverty and race are conceptualized in the context of child maltreatment particularly concerning racial disproportionality. Additionally, Stark (2009) explains that theory helps avoid key concepts of poverty, race, and child maltreatment from becoming peripheral interests, maintaining them as focal points of the dialogue. This, too, strengthens the relevance of elevating the voices of disadvantaged families in the discussion. Based upon the research from the previously outlined literature review, two theories have been selected for this study: Theories of Poverty and Critical Race Theory. Combined, the two provide the framework necessary to examine the dynamics

involved in the intersections of poverty, race, and child maltreatment. Addressed first are the key five areas explaining the theory of poverty: individual, cultural, politicaleconomic structure, geographic, and cumulative and cyclical. The section concludes with a presentation of the components of critical race theory.

\section{Theories of Poverty}

The elements of the theory of poverty provide insight on the historical, political and policy aspects of how poverty has been addressed throughout time. Once more, an 
understanding of the theoretical explanations for poverty is best done through a historical lens. History reveals that the theories adopted at any given time have shaped the policies addressing poverty. The subsequent policies guiding the practices of the public welfare system in the past and current day have been largely shaped by the cumulative effect of history. Bradshaw (2007) offers five areas under the theory of poverty that have influenced anti-poverty efforts and the policies directing those actions: (1) Individual; (2) Cultural; (3) Political-Economic Structure; (4) Geographic; and (5) Cumulative and Cyclical. The following is an explanation of each.

\section{Individual}

The individual theory of poverty operates from the premise that poverty is caused at the individual level. As such each person is held accountable for his/her own fortune or misfortune. If one is unable to do adequately provide for their own individual means, the belief is that their shortcomings are due to flaws of their own. Under this belief, poverty is due to behaviors such as laziness, poor decision making or incompetence. In some instances, having a disability may also account for one living in poverty. Bradshaw (2007) explains, for example, those who were challenged with disabilities of vision, mobility, mental etc. were viewed by some religious faiths as being punished by God. The resulting belief being that there are those individuals who are worthy and those who are unworthy of support and assistance. Historically, the attitudes towards the poor have been primarily influenced from such thought. Hence, writings like the "Bell Curve" (1994) stem from such beliefs. Under this theoretical aspect, the worthy might be those who by no fault of their own land in poverty may be considered worthy. On the other 
hand, those who are considered to be able bodied and therefore capable of meeting their own needs are deemed to be unworthy.

Subsequently, the laws and policies addressing the needs of the poor have been greatly influenced by beliefs of who is deserving of support and who is not (Lin \& Harris, 2008; Seccombe, 1999). Thus, the poor have been stigmatized and shamed (Lin \& Harris, 2008; Lister, 2004; Seccombe, 1999). Gender associations are also sometimes applied under the individual theory of poverty. Seccombe (1999) notes that this view of poverty is not "gender neutral" (p. 18), implying that gender expectations bias views such that women are potentially marginalized. Seccombe (1999) suggest that women, according to societal conditions, have not positioned to be the breadwinners of the household and therefore are at a disadvantage. Similarly, this theory inadvertently supports certain racial attitudes and beliefs concerning who is more likely to be poor and who of the poor is deserving of assistance. For example, historically women of color, particularly African Americans, have inaccurately been thought as most likely recipients of public welfare benefits (Bullock, 2008; Hattery \& Smith, 2007; Seccombe et al., 1999; Seccombe, 1999).

Most often, conservative views are framed by the individual theory of poverty. This theory rewards competiveness and hard work. Otherwise it is punitive towards those who do not exhibit attributes associated with success. This theory has historical roots in Puritan or Calvinist teachings that view wealth akin to godliness or having favor with God (Bradshaw, 2007; Seccombe, 1999). The poor are seen as immoral and a risk to society. Operating from the individualistic theory of poverty, the public welfare system is 
criticized as reinforcing and/or rewarding bad behavior and poor choices of those who choose not to improve their circumstances.

\section{Cultural}

According to Bradshaw (2007), the cultural theory of poverty is based on the belief that the subculture embraces values and principles that are counterproductive and thus outside norms that are seen as promoting success. The cultural theory of poverty is often embraced politically by individuals with liberal leaning views. The underpinnings of this theory are seen in discussions that invoke "the culture of poverty" where poverty is believed to have occurred over generations, where beliefs, values, skills have transmitted from one generation to the next. The culture of poverty is sometimes connected to the theory of individual poverty although not thought to be linked to motivation of the individual. The culture of poverty is in essence a subculture of poverty. For example, the poor reside in barrios and ghettos; and there is a mindset that accompanies being a member of that subculture. Furthermore, as members of this particular subculture, individuals' exhibit learned coping behaviors in order to manage. However, such patterns then only perpetuate further misfortunes as even when circumstances change for the better the members of the subculture are unable to better their situation.

This theory is reflected in the belief many have that African American families are perpetually impacted by the dysfunctions of the family and communities where they live (Lewis, 1966; Lin \& Harris, 2008; Wilson, 2009). The theory is criticized by some arguing that the culture of poverty as a theory is misguiding, especially where people of color are concerned (Lamont \& Small, 2010; Lin \& Harris, 2008; Wilson, 2009). Some 
further suggest the richness of culture itself with diminished thereby misrepresented within this theoretical view of poverty (Lamont \& Small, 2010; Linn \& Harris, 2008; Wilson, 2009). Lin and Harris (2008), for example, posit alternative meanings and understandings of culture per se and its influence on behavior. Bradshaw (2007) further notes the importance of understanding the causal factors behind behavior. Lamont and Small (2010) argue, too, that culture does not necessarily dictate behavior and that social and political factors may also impact behavior.

\section{Political-Economic Structure}

The political-economic structure theory of poverty asserts that it is neither the individual nor sub-cultural contributors to being poor as the cause of poverty. In this lens, poverty is seen as the result of limited resources/opportunities and/or limited access to such resources/opportunities resulting from economic, political, and social structures. Systemic barriers obstruct access to education and other resources that might better one's circumstances. Discriminatory practices, for example, would explain why certain populations and individuals are impoverished. Another example would be single mothers whose earnings are at the minimum wage level and insufficient to sustain them economically so that they remain perpetually the working poor. In other words, a certain degree of societal structures are designed to induce poverty. For example, low/minimum wage jobs that are insufficient to sustain the economic needs of a family; fewer opportunities to gain education and skills to improve circumstances; systemic barriers within structures designated to assist the poor such as public welfare; racial discrimination; gender biases; and limited voice if any in political debates (Bradshaw, 2007; Lin \& Harris, 2008; Lister, 2004; Seccombe, 1999; Wilson; 2004). Finally, from 
this theoretical perspective, the poor lack the prowess to command political change to their advantage and are not empowered to affect change. Thus, this theory draws a distinct link between wealth and political power.

\section{Geographic}

The geographic theory of poverty maintains that poverty results from geographic separateness; the belief that social advantages and disadvantages are concentrated within geographic areas. That could be manifested in rural or urban regions based upon the extent of the disparities. Whether rural or urban certain characteristics negate the development of the area thereby dissuading growth. This theory purports issues such as disinvestment in communities/regions, outsourcing of jobs and inadequate social supports contribute to impoverished geographic areas. Lister (2004) notes, too, that high crime areas such as that of some urban communities do not attract business and economic growth. Similarly, Lister (2004) notes that rural communities, too, often do not attract businesses or companies that might strengthen economic development. Consequently, with both urban and rural areas the infrastructure necessary for economic growth is sometimes lacking. Knowledge and technology that would strengthen economic stability are absent and typically present in other communities that are more financially secure. Bradshaw (2007) notes that when infrastructure is lacking so is human capital. Another aspect of this theory is the notion of physically moving away from and out of those areas that are deemed economically stifling (Bradshaw, 2007; Wilson (2009). In such instances, individuals leave these communities and access educational or other opportunities, but they do not return-presenting another example of the resources leaving 
the community. While such action may advantage the individual, the same is not true for the area being left, adding to cumulative effect of poverty on that geographic area.

\section{Cumulative and Cyclical}

The cumulative and cyclical theory of poverty suggests that there are cumulative effects from problems such as inadequate earnings, poor housing and an individual's lack of confidence. It further notes that such elements are interdependent and strongly connected to the deficiencies and lack of resources in their community. In addition, these interactions and interdependencies come with their own complexities and are cyclical. Bradshaw (2007) speaks to the complexity of this theory, as it potentially integrates the aforementioned challenges of the other theories of poverty; the combination, therefore having a cumulative effect on the individual within their communal environment.

Bradshaw (2007) explains that this theory is founded in the discipline of economics. The premise is that the downfall in a given area potentially has a cumulative effect on the community, neighborhood or surrounding area. The theory is thought to explain the lack of development is some areas. For example, this theory is the cyclical dynamics sometimes occurring between education and employment, which combined discourage investors from engaging in the community. At the individual level unemployment prevents acts of self-investment such as education/training which ultimately could lead to employment. The cycle repeats resulting in discontent, depression and hopelessness, which lessens motivation and self-confidence.

\section{Relevance of the Theories of Poverty to this Study}

The theories of poverty align with what has been presented in the literature concerning poverty and offer insight regarding how poverty has been addressed 
throughout history. For example, based upon the individual theory of poverty, the values placed upon individualism within American culture links back to the religious views held by the early settlers that have carried forward to present times. Likewise, treatment toward some poor as worthy and others as unworthy is also explained through this theory. Additionally, the emphases of getting people employed as the primary means of addressing poverty as currently practiced today can be attributed to the mindset of individual theory of poverty. Similarly, each of the other theories of poverty reflects either some liberal or conservative perspective held today that impacts how poverty is addressed. The theories of poverty further enhance understanding of why the voices of the poor, such as the participants of this study warrant elevation and greater inclusion in the national discourse.

\section{Critical Race Theory}

Critical Race Theory (CRT) began during the mid-1970s following the historic Civil Rights Era within the discipline of law aimed to discredit liberal position of race neutrality and color blindness; and address oppression within society for the purpose of collective and individual transformation and social justice (Abrams \& Moio, 2009; Constance-Huggins, 2012; Crenshaw, 2011; Ortiz \& Jani, 2010). Ortiz and Jani (2010) explain that CRT does not assume the universality of truths or any all-encompassing narratives that orchestrate life. CRT operates from six major tenants: (1) Endemic reality of Racism is Not an Anomaly; (2) Race is a Social Construct; (3) Differential Racialization; (4) Interest Convergence; (5) Advancing the Voices of Individuals and Populations of Color; and (6) Intersectionality (Abrams \& Moio, 2009; ConstanceHuggins, 2012; Ortiz \& Jani, 2010). 


\section{Endemic Reality of Racism}

CRT states unequivocally that racism in the United States is not an anomaly for individuals and populations of color. Endemic within American society, racism is a usual, ongoing, reoccurring experience for those of color. Racism, while often unseen or unrecognizable particularly by members from the racially advantaged group, is prevalent and therefore not abnormal. The hidden aspect of racism ultimately sustains its existence (Abrams \& Moio, 2009; Constance-Huggins, 2012). Wilson (2009) explains that racism (1) perpetuates the notion of superiority of one race over another with one being inferior "biologically or culturally" (p. 15); and (2) that such rationales then dictate treatment of the race identified as inferior by society thereby determining its place within society both by position and "collective accomplishments (p.15). Consequently, at the core existence

of society is race giving meaning to and shaping individual and collective experiences of its peoples. Historically, then race and racism has played an intricate role in the shaping and development of American society (Lister, 2004; Neubeck \& Cazenave, 2001; Wilson, 2009).

\section{Race is a Social Construct}

CRT purports that race is a social construct. Race is understood to be a system designed for the structural categorization of peoples based upon visible physical similarities that have no biological premise. CRT acknowledges that race as a social construct permeates deeply throughout society having a powerful effect on individuals and peoples of color (Abrams \& Moio, 2009; Constance-Huggins, 2012; Ortiz \& Jani, 2010). 


\section{Differential Racialization}

CRT asserts that the privileged group holding the power modifies the criteria of race differently at different times contingent upon historical, social, and economical circumstances to their liking and specifications. Racialization of this nature is done for the benefit of the privileged group. The determination of who is included or excluded rest with the privileged group (Abrams \& Moio, 2009; Constance-Huggins, 2012; Ortiz \& Jani, 2010). For example, the Irish were at one time despised and not included in membership of the privileged group. Asians have been accepted differently at certain periods of history based upon their perceived economic usefulness at that given time. Delgado and Stefancic (2012) inform that differential racialization differs from one group to the next. They note, for example, that it is unlikely that African Americans will be told to go back where they came from or to go back home if they don't like life in the United States. Likewise, they further explain that is unlikely that those who appear to be Asian will be ridiculed for having abused the public welfare system and having children so that they can get welfare benefits. Furthermore Delgado and Stefancic (2012) cautions that the historical paradigm within the United States as seeing race as a binary "black-white" matter or any other such binary perspective where one group is pitted against the another diminishes possibilities of all people of color unifying together and/or benefiting from each other, potentially rendering greater dependency by each on the "white establishment" (p78.)

\section{Interest Convergence}

CRT maintains that those of the privileged group gain material and psychic benefits such that any interest that may advantage people of color only occurs when there 
is also something of merit for the privileged group. In other words, when interests converge to the point that there is gain for Whites as well as persons of color, oppression will be addressed. Bell (2000) suggests, for example, that historic acts like the Emancipation Proclamation and Brown vs. the Board of Education were pivotal in addressing inequitable treatment of African Americans, both “... served to advance the nation's foreign policy interests more that they provided actual aid to blacks" (p. 2). Likewise, Delgado and Stefancic (2012), state that prior to slavery “educated Europeans held a generally positive attitude toward Africans, recognizing that African civilizations were highly advanced with vast libraries and centers of learning” (p. 21). However, the need for labor and economic benefits of slavery altered such views. In another example the author's note that in the conquering of Mexico and the development of the Southwestern states, Mexicans' were deemed inferior. However, later Mexicans were brought to the United States when hard labor was needed.

\section{Advancing the Voices of Individuals and Populations of Color}

CRT acknowledges that the stories and truths of populations of color have been typically excluded from history as their voices have been routinely marginalized. CRT, therefore, asserts that individuals and populations of color are best suited to tell their own lived experiences. Through analysis and deconstruction, CRT often uses narratives/storytelling to present the voices and experiences of those oppressed (Abrams \& Moio, 2009; Constance-Huggins, 2012). Delgado (2000) explains that storytelling is powerful and a useful tool for the less dominant group to express their voices. In doing so they share meanings, build/strengthen relations and to have control over their own their narratives that potentially serve as a means to challenge reality creating counter realities. 
Additionally, as Delgado (2000) explains, stories and counter- stories effectively highlights inequalities and injustice. They prompt a review of so-called realities that have come into existence through repetition, habits and patterns that over time become believable and therefore acceptable. In essence the creation of counter narratives allows opportunity to see inequalities and injustice, some of which have had legal support; and to question their purpose and/or existence. Delgado (2000) further explains that the dominant group, too, has their own stories that often are about the less dominant groups typically maintaining their place of superiority as the norm and the less dominants' as inferior. Finally, Delgado (2000) suggests that "much of social reality is constructed. We decide what is, and almost simultaneously, what ought to be" (p. 62). The creation of counter-stories helps to deconstruct social reality that amounts to inequality, injustice and silenced voices.

\section{Intersectionality}

CRT recognizes the significance of the intersectionality with other variations of oppression such as gender, sexual orientation, religion, and class; and that failure to address the multidimensional aspects of an individual's experience minimizes effectiveness and potentially is in itself oppressive. CRT cautions against a singular framework and instead opts for an analytic approach that is multifaceted (Abrams \& Moio, 2009; Constance-Huggins, 2012).

\section{Relevance of CRT to this Study}

This study aims to introduce the perspective of poor families who are at risk for or are currently involved with the child welfare system, particularly those of color. CRT helps to explain how these particular voices, based upon a theoretical approach, brings 
understanding the role and function of race in American society. CRT also values the multilayered impact of race, class and gender, which is appropriate to help to explain the how and where the voices of many of the participants of this study, poor single women of color, have potentially formerly been compromised. The attention CRT gives to valuing the inclusion of voices such as those who participated in this study makes it well suited and an appropriate theoretical framework to utilize in addressing the absent voices of poor families who are at risk for or are currently involved with the child welfare system. 


\section{CHAPTER 3}

\section{Methodology}

This study introduces the voice of economically disadvantaged families who are at risk for or who have involvement with the child welfare system. The child welfare national discourse, while extensive, presents limited understanding regarding the intersection of poverty, race, child neglect, and racial disproportionality as the independent perspectives of families are minimally included and as a result are potentially compromised. Presenting the independent views of families can provide contextual meaning to the literature and an understanding that is unique to the direct experiences of families. Qualitative research aptly focuses its inquiry on particular human experiences, and/or social relations and the approaches the understanding of various elements of such encounters from those whose day-to-day events serve as living testimonials (Flick, 2006; Lister, 2004; Polkinghorne, 2005).

This qualitative study was conducted using a phenomenological approach. Phenomenology values the acceptance of the lived experiences of individuals (Polkinghorne, 2005; Richards \& Morse, 2007). Donalek (2004) explains that phenomenology incorporates participants' co-creation and collaborative work with the researcher in an examination process of their lived experience of a phenomenon. She further notes the researcher, through an inductive interpretation, presents subsequent emergent themes that describe the core elements of the phenomenon; and that the findings, while the responsibility of the researcher, may be reported back to the participants to strengthen the "rigor" of the study (p. 517). 
The current study focuses on the lived experience to provide meaning and context to the phenomena of poverty, race, and child maltreatment. Specifically, focus groups were utilized to obtain information concerning the lived experiences of welfare recipients who are at risk for or currently involved with the child welfare system. The literature supports focus groups as a means that amply allows for the emergence of families' firsthand experiences (Creswell, 2007; Flick, 2006; Morgan, 1997; Richards \& Morse, 2007). Additionally, Kamberelis and Dimitriadis (2005) note the usage of focus groups to support the redirection of power where dynamics of power differentials exist, such as that experienced by families when involved with the public welfare and child welfare systems.

\section{Study Design}

\section{Sample}

A series of four focus groups with 15 participants were conducted using purposive sampling. Purposive sampling was appropriate as the study aimed to reach a specific population of individuals who have the lived experience of being poor and at risk for or currently involved with the child welfare system. According to Polkinghorne (2005) accessing of the lived experience of participants should be deliberate and "...the selection should not be random or left to chance" (p. 140). Participants were recipients of Self Sufficiency benefits such as TANF and received case management services from a program called "Family Stability and Employment Unit" (FSEU). FSEU formerly operated as a specialized section focusing on child abuse prevention under the Oregon Department of Human Services (DHS), Self Sufficiency Program (SSP), District 2, Multnomah County. Individuals and families managed under FSEU were those who were 
identified as being at risk for becoming involved with the child welfare system based upon criteria that included but was not limited to having an excessive number of calls to the child welfare hotline, reporting domestic violence, struggling with addiction, presenting with mental illness, and/or exhibiting criminal behaviors. Some families, managed under FSEU, had open child welfare cases where the children were not removed but had remained in their parents' care. FSEU specialized in intensive case management and serviced families beyond the usual array of public welfare benefits (i.e., TANF/cash assistance, Medicaid). The role of the FSEU case manager differed greatly from the typical eligibility case worker and the experiences of families managed under FSEU were different than welfare recipients under other SSP units. For example, FSEU services included home visits from case managers and referral to community services addressing mental health, domestic violence, and addiction issues. When possible, some referral services were granted by providers who were capable of administering culturally specific services as warranted. In circumstances where families also had an open child welfare case, the FSEU collaborated with the child welfare worker to jointly co-manage the case. In such instances, FSEU workers attended court hearings and child welfare case staffing to represent the interest of the family.

FSEU offered case management services to approximately five hundred families, many of whom were families of color. All study participants were determined by the FSEU to be at risk for or had previous involvement with the DHS child welfare system.

\section{Recruitment}

Initial meetings occurred between the investigator and DHS managers responsible for the supervision/management of the former FSEU program to introduce and discuss 
the research project. A former FSEU caseworker was identified as a liaison for the department to assist with mailing of recruitment letters as no identifying information was divulged to the investigator. Informed consents, the recruitment letter and other related materials were reviewed by DHS. It should be noted that some modifications were made to the focus group guide based on input from DHS. Recruitment letters, providing an overview of the research and invitation to participate; as well as a sample of the informed consent, and the demographic survey were distributed via mail by the designated agency liaison. The recruitment letter provided a telephone number of the investigator with a request that all interested parties respond by telephone. The recruitment letter also specified that all participants would receive a $\$ 50$ gift card from Wal-Mart. Initially, three focus groups were scheduled. However, due to the low response from families of color a fourth focus group was scheduled for families of color only. Thus, a second mailing occurred to all families of color $(n=68)$. This second mailing included the same recruitment materials as indicated; the recruitment letter along with samples of the informed consent, and the demographic survey. The second mailing, again, was facilitated by the designated agency liaison.

The study targeted all families with an open case who identified as being formerly managed by FSEU $(n=244)$. The families were racially/ethnically diverse including African American ( $\mathrm{n}=93)$; American Indian/Alaska Native $(\mathrm{n}=14)$; and Pacific Islander $(\mathrm{n}=1)$. Additionally, there were some families that indicated racial/ethnic identity as unknown $(\mathrm{n}=10)$. Families who responded were provided a brief explanation of the study; given the opportunity to select one of three possible focus group sessions to attend including the date, time, and location of each. In addition, respondents were asked if they 
would like to receive a reminder call the day before the focus group they had selected. Reminder calls were provided to all who requested.

\section{Data Collection}

Due to the exploratory nature of the study, the focus group format was semistructured allowing for greater ease, flexibility, and flow of discussion. Focus groups were facilitated by a moderator and a co-facilitator who were both female. The moderator was African American, and the co-facilitator was White. They each took notes throughout all focus groups. The moderator functioned as lead facilitator of the conversations, allowing participants to operate as subject experts. The topic areas of poverty, race, and child maltreatment informed the questions of the focus group guide designed to aid facilitation of the focus group discussion. The moderator used the guide to introduce the topic areas and then refrained from interjecting comments, except when necessary to move the discussion along or to present a prompt question.

All focus groups were audio recorded and later transcribed verbatim by an independent party. Focus groups were conducted at the Regional Research Institute and the School of Social Work both located at Portland State University. Each focus group was scheduled for two and a half hours with two hours designated for discussion and thirty minutes allowed for introduction of the research, distribution and signing of the informed consent forms and the demographic questionnaires. Informed consent forms were reviewed and discussed at the beginning of each focus group session and participants were told that they could elect to terminate their involvement with the focus group at any time. Beyond the informed consent, each participant also completed a 
demographic questionnaire. The demographic questionnaire obtained information such as race, age, and family structure. Names were not recorded on the questionnaire.

Participants were assured of their anonymity. To help with securing anonymity the moderator used a variety of colored crayons. Each participant selected a crayon to use when identifying and/or announcing themselves throughout the discussion. For example, a participant who had selected the color orange when speaking would say, "This is orange ...." The color-coding approach helped to later distinguish participants' voices during data analysis. The particular crayon color selected by a participant was indicated on the demographic questionnaire and cross referenced as necessary during the data analysis. Cross referencing in this nature helped identify significant demographic characteristics of individual participants who brought seminal statements to the discussion that were used later as quotes in reporting the findings from the study. Finally, each focus group concluded with participants discussing their views of the focus group discussion. Incentives were distributed at the beginning of each focus group.

\section{Focus Group Guide}

Participants were asked the following focus group questions with follow-up probing questions as appropriate:

1. What challenges, if any, do you face? Would you say that money affects your parenting capacity? Please explain.

Probe: Sometimes parents have to make a choice when they do not have the financial resources. Can you give some examples of when you've had to make a choice that impacted your parenting?

2. How do you support your children's learning and healthy development? 
Probe: What do you do to support your child's overall wellbeing? What are your perceptions about race influencing families becoming involved with the child welfare system?

Probe: Racial disproportionality has been found to exist in Oregon's child welfare system for African America and Native American/Alaska Native children; meaning that these children have greater representation in the child welfare system than they do in the general population. What are your thoughts?

3. How do you see race, if at all, influencing families becoming involved with the child welfare system? Please explain.

Probe: Racial disproportionality has been found to exist in Oregon's child welfare system for African American and Native American children; meaning that these children have greater representation in the child welfare system than they do in the general population. What are your thoughts? What supports do you find valuable in alleviating challenges to parenting and helpful in preventing becoming involved with the child welfare system?

4. If so, do you see poverty and race influencing families becoming involved with the child welfare system? If so, please explain.

Probe: Some argue that poverty is sometimes confused with neglect and that results in children becoming involved with child welfare. What are your thoughts? 
5. What supports do you find valuable in alleviating challenges to parenting and helpful in preventing becoming involved with the child welfare system?

Probe: What supports do you find helpful in parenting?

6. How did it feel to participate in this study?

7. Is there anything else you would like to share?

\section{Data Analysis}

The previously presented theories of poverty and critical race theories each explain how today views' regarding poverty and race have been formed throughout history; how public welfare political and policy agendas have been shaped; and how poverty and race restricts access to information and resources. The data analysis process of this study was data driver and not guided per se by theory. While the relevance of the various theories of poverty and CRT to the study was reflected upon as the data analysis unfolded, the resulting findings were derived based upon their independent emergence from the raw data. Thus, the investigator maintained theoretical sensitivity throughout the data analysis process as suggested by Boyatzis (1998). As supported by Boyatzis (1998), thematic analysis was used as an inductive approach of uncovering key themes and concepts from the focus groups data. Boyatzis (1998) suggests that such an approach allows "previously silenced voices or perspectives inherent in the information can be brought forward and recognized" (p. 30).

The data analysis involved four steps: (1) Multiple reads of the data. Smith and colleagues (2009) emphasize the importance of multiple reads to "ensure that the participant becomes the focus of the analysis" (p. 82). The first reading of the transcript was done while listening to the audio tape to initiate engagement with the data and to 
identify any errors in the transcriptions and correct accordingly. The second review of the transcript was done absent the audio tape and involved reflective memoing to aid in sorting the researcher's initial reaction to the data and foster the ability for the researcher to remain true to the contents of the raw data. The third read again used memoing to identify similar or same phrases, words, and/or descriptions. The third read did not infer the thoughts and/or reactions of the researcher. (2) Line-by-line coding of similar or same phrases, words and or descriptions. Step two involved an examination of the text in an exploratory manner with particular concentration on how the participant discusses and explains the issues/topic areas, (i.e. poverty, race, child maltreatment); noting how the participants described their lived experiences by identifying, sorting, and recording chronologically important/main passages, words and/or phrases. (3) Grouping of the freestanding codes into linked associations and arranging them into descriptive clusters that then began the emergence of themes. This step involved data reduction, arranging the data into segments/chunks, while concurrently charting relatedness, patterns and connections. (4) Creation of themes from the descriptive clusters. This step involved drawing conclusions regarding how the clusters form into themes. Themes emerged based upon similarities, frequency, differences, and/or contextual meaning within the text. The four stages outlined are congruent with analysis as explained by Smith et al. (2009). In addition, the researcher kept an analytic journal to track notes and descriptions from the data that help to further the interpretive process and foster understanding of the participants' subjective views.

Upon completing the data analysis, the researcher attempted to meet face to face a final time with a representative of the group of research participants to review the results 
of the data analysis. A summary of the data was prepared to share with participants. Although agreeing to do so, no participants showed for this final meeting. In lieu of the face to face meeting the investigator was able to contact three of the participants via telephone to review and discuss the findings. The phone meetings included two female and one male participant. Participants suggested no modifications to the findings. This form of member checking is useful to assure trustworthiness of the data (Donalek, 2004; Linclon \& Guba, 1985). Smith and colleagues (2009) describe the dual role of the researcher as follows:

Trying to make sense of the participant trying to make sense of what is happening to them; and he/she is employing the same mental and personal skills and capacities as the participant, with whom he/she shares a fundamental property - that of being a human being. At the same time, the researcher employs those skills more self-consciously and systematically. As such, the researcher's sensemaking is second order; he/she only has access to the participant's experience through the participant's own account of it. (p. 3)

Donalek (2004) notes, too, the responsibility of the conclusions rest with the investigator. Should there be conflicting interpretations between the respondents,' and the investigator's interpretations both will be acknowledged. In this instance, there were no conflicts resulting from the member checking. In addition to the requirements necessary to fulfill the dissertation process, the researcher will provide a courtesy summary report of findings to DHS. Participants were made aware of study findings being shared with DHS. 


\section{Reflexivity}

Ritchie \& Lewis (2003) emphasizes the significance of positioning and maintaining awareness of the voice of the researcher in qualitative research. Finlay (2008) adds that operating from a phenomenological approach towards the research requires the "...researcher engaging in a sense of wonder and openness to the world while at the same time, reflectively restraining pre-understandings" (p. 2). Furthermore, she cautions that reflexivity is not an act of "suspending researcher suppositions" but "the researcher opens themselves [sic] to being moved by an Other where evolving understandings are managed in a relational context" (p. 3). In this instance, this researcher has several decades of professional experience within child welfare in multiple capacities ranging from case worker, policy manager, and administrator. In addition, the researcher on personal level, is a person of color and lived a childhood parented many years by an extended relative caregiver in a single parent home that received benefits from the AFDC program. Furthermore, the researcher was employed by DHS involved with both the child welfare and public welfare programs and familiar with the former FSEU program.

Participants were informed of the researcher's professional role with DHS at the time of the focus groups. The researcher stated that the research is an external endeavor and neither initiated nor under the management of DHS; and the researcher was not acting in the role or capacity of a DHS employee during the study. Due the affiliation with DHS, the researcher had anticipated the possibility of participants' unwillingness or lack of comfort in disclosing their personal stories. However, this was not the case. While one mother cried while sharing her story and all received their $\$ 50.00$ gift certificate to 
Wal-Mart at the beginning of each dialogue session, no one excused themselves from the focus group discussions.

The researcher maintained a reflective journal throughout the series of focus groups. The reflective journal was used by the moderator/researcher following each focus group to capture initial thoughts, observations, feelings and reactions to the focus group. Field notes of this nature are beneficial not only to identify/distinguish and sort the voice of the researcher in the research, but also is a useful aid later in data analysis (Marshall \& Rossman, 2006; Ritchie \& Lewis, 2003). This was especially true in the current study as the reflective journal was useful in recognizing and distinguishing the researcher's voice allowing more clearly the participants' voices to emerge unencumbered. Again, reflective memoing was used during the data analysis stage of the study.

\section{Trustworthiness}

This research employed two methods of addressing trustworthiness as outlined by Lincoln \& Guba (1985): (1) Member checking and (2) Audit Trail. First, as previously noted, member checking was done by telephone to review and discuss the findings with a sampling of the participants to confirm that the analysis adequately reflects interpretations of their lived experiences. Second, the researcher conducted an audit trail whereby a de-briefer was provided all field notes including the reflective and analytic journals, code book, formation of clusters and subsequent themes, analytic journal, and findings. The de-briefer had approximately 12 years' experience with qualitative research, and the facilitation of focus group discussions. No suggested modifications were made by the de-briefer. 


\section{CHAPTER 4}

\section{Results}

This study examined the role, function, and intersection of poverty and race, particularly as it influences child maltreatment. Presented herein is a description of participants, followed by the findings of the study detailing the resulting primary themes and sub-themes. The Chapter concludes with an explanation of the researcher's positioning.

A total of three primary themes emerged from the data: (1) Financial Strain Creates Significant Strain; (2) Concern for Children and (3) Dealing with the Systems: Public Welfare and Child Welfare. In addition, seven sub-themes were identified: (1) Single Parenting; (2) Race and Racism; (3) Limited Community Resources; (4) Mental Health; (5) Fear of Child Welfare; (6) Biases and Inconsistencies; and (7) Racial Disproportionality. Each theme and sub-theme is presented to offer an account of participants' lived experiences from their voice and perspectives. This framework is congruent with the phenomenological approach. An overview summarizing each primary theme and subsequent sub-theme is provided at conclusion of the final sub-theme.

\section{Descriptive of Participants}

The total number of study participants was fifteen. Each participant voluntarily completed a demographic questionnaire providing a descriptive of themselves and their households. The majority identified as persons of color: Black/African American $(n=7)$; Latino/Hispanic $(\mathrm{n}=1)$ and; Mixed Race $(\mathrm{n}=3)$. The remaining participants identified as White $(n=4)$. Most participants were female $(n=12)$. All participants were between the ages of 26 and 55 years of age with the majority being between 36 and 45 years old $(\mathrm{n}=$ 
6). Almost two-thirds of the individuals reported having pursued some form of post-high school education and/or training $(\mathrm{n}=9)$. Most participants indicated that they were single parents, never been married $(\mathrm{n}=14)$ and had their children living with them at the time of the study $(\mathrm{n}=12)$. Moreover, the majority indicated that their children were fairly young between zero to six years of age $(n=11)$. More than two-thirds of participants noted their income as less than $\$ 15,000$ annually falling below the 2019 federal poverty standards for households with two or more individuals $(\mathrm{n}=12)$. The 2019 federal poverty level for a household of two is $\$ 16,460$.

Lastly, most participants reported prior experience with both the public and child welfare systems ( $n=9$ and $n=13$ respectively), either during their childhood and/or adult lives. Table 1 provides a demographic profile of participants based upon of participant's self report.

Table 1. Participant Demographic Profile

\begin{tabular}{|c|c|c|c|c|c|c|}
\hline Gender & $\begin{array}{l}\text { Female } \\
(\mathrm{n}=12)\end{array}$ & $\begin{array}{l}\text { Male } \\
(\mathrm{n}=3)\end{array}$ & & & & \\
\hline Age & $\begin{array}{l}18-25 \\
(n=0)\end{array}$ & $\begin{array}{l}26-35 \\
(n=4)\end{array}$ & $\begin{array}{c}36-45 \\
(n=6)\end{array}$ & $\begin{array}{l}46-55 \\
(n=5)\end{array}$ & $56+$ & \\
\hline $\begin{array}{l}\text { Racial/ } \\
\text { Ethnic } \\
\text { Identity }\end{array}$ & $\begin{array}{c}\text { Black/ } \\
\text { AA }\end{array}$ & White & $\begin{array}{l}\text { Native } \\
\text { Amer. } \\
\text { Alaska } \\
\text { Native }\end{array}$ & Latino & $\begin{array}{c}\text { Mixed } \\
\text { Race }\end{array}$ & Other \\
\hline
\end{tabular}




\begin{tabular}{|c|c|c|c|c|c|c|c|}
\hline & $(\mathrm{n}=7)$ & $(n=4)$ & $(n=0)$ & $(\mathrm{n}=1)$ & $\begin{array}{c}\text { Amer. } \\
\& \\
\text { Alaska } \\
\text { Native } \\
(\mathrm{n}=3)\end{array}$ & $(\mathrm{n}=0)$ & \\
\hline $\begin{array}{l}\text { Highest } \\
\text { Level of } \\
\text { Ed. }\end{array}$ & $\mathrm{K}-5^{\text {th }}$ & $\begin{array}{l}6^{\text {th }}-8^{\text {th }} \\
(n=1)\end{array}$ & $\begin{array}{l}9^{\text {th }}-12^{\text {th }} \\
(n=4)\end{array}$ & $\begin{array}{l}\text { GED } \\
(\mathrm{n}=1)\end{array}$ & $\begin{array}{c}\text { Some } \\
\text { Coll. } \\
\text { No } \\
\text { Degree }\end{array}$ & $\begin{array}{l}\text { Coll. } \\
\text {.Grad } \\
(n=3)\end{array}$ & $\begin{array}{l}\text { Trade } \\
\text { School } \\
\text { or } \\
\text { Certifi- } \\
\text { cation } \\
(n=1)\end{array}$ \\
\hline $\begin{array}{l}\text { Marital } \\
\text { Status }\end{array}$ & $\begin{array}{c}\text { Never } \\
\text { Married } \\
(\mathrm{n}=9)\end{array}$ & $\begin{array}{l}\text { Married } \\
(\mathrm{n}=0)\end{array}$ & $\begin{array}{c}\text { Domestic } \\
\text { Partner } \\
(\mathrm{n}=1)\end{array}$ & $\begin{array}{l}\text { Divorced } \\
(\mathrm{n}=3)\end{array}$ & $\begin{array}{l}\begin{array}{c}\text { Sepa- } \\
\text { rated }\end{array} \\
(\mathrm{n}=2)\end{array}$ & & \\
\hline $\begin{array}{l}\text { House- } \\
\text { hold } \\
\text { Compo- } \\
\text { sition }\end{array}$ & $\begin{array}{l}\text { Spouse } \\
(\mathrm{n}=1)\end{array}$ & $\begin{array}{l}\text { Partner } \\
(\mathrm{n}=2)\end{array}$ & $\begin{array}{l}\text { Children } \\
(\mathrm{n}=12)\end{array}$ & $\begin{array}{c}\text { Friend/ } \\
\text { Room- } \\
\text { mate/ } \\
\text { House- } \\
\text { Mate } \\
(\mathrm{n}=0)\end{array}$ & $\begin{array}{l}\text { Extend. } \\
\text { Family } \\
(\mathrm{n}=1)\end{array}$ & & \\
\hline $\begin{array}{l}\text { Number } \\
\text { of } \\
\text { Children } \\
\text { Living in } \\
\text { Home by } \\
\text { Age }\end{array}$ & $\begin{array}{c}0 m-2 \\
(n=7)\end{array}$ & $\begin{array}{c}3-5 \\
(n=4)\end{array}$ & $\begin{array}{l}6-12 \\
(n=1)\end{array}$ & $\begin{array}{l}12-18 \\
(n=3)\end{array}$ & $\begin{array}{l}18-25 \\
(n=1)\end{array}$ & & \\
\hline
\end{tabular}




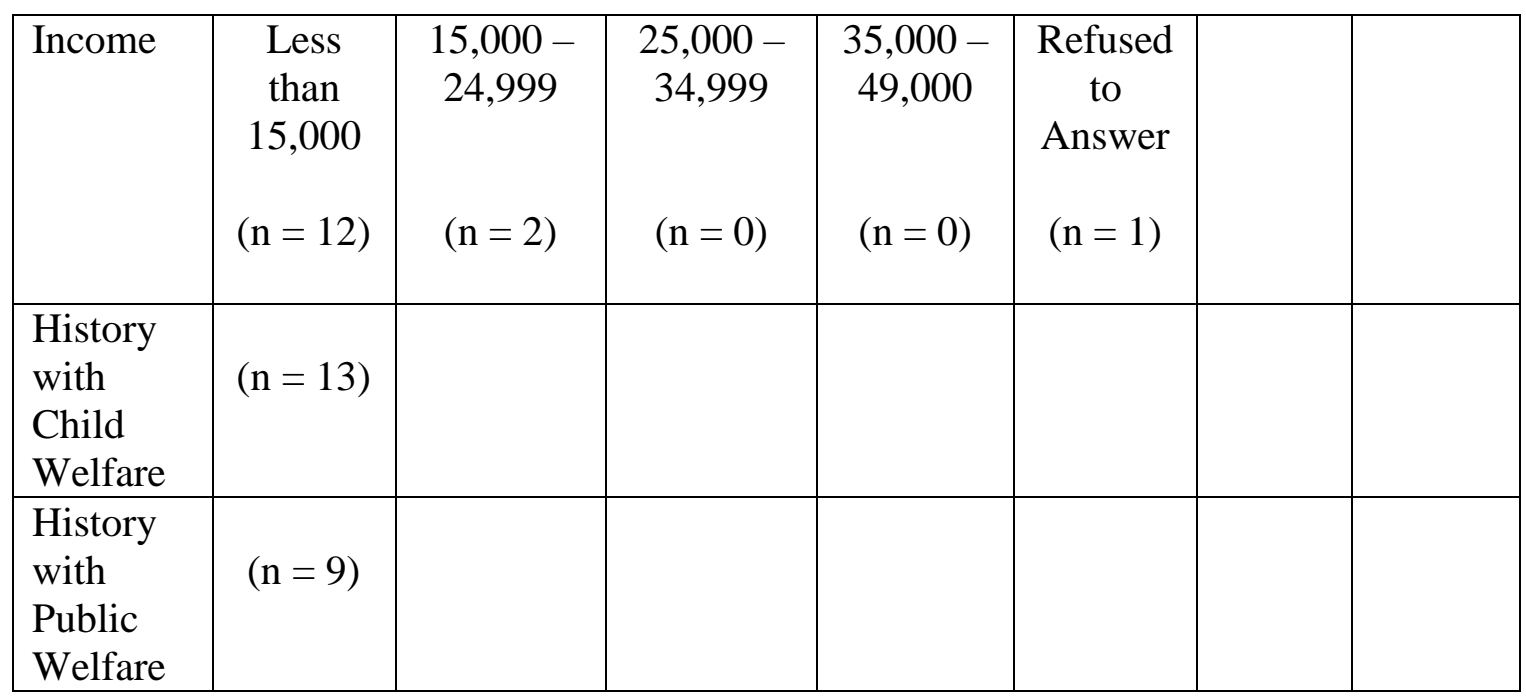

Participants responded candidly to the focus group guide speaking from their first-hand life experiences. Three primary themes and seven supporting sub-themes emerged from the data. The primary themes are: (1) Financial Strain Creates Significant Strain; (2) Concern for Children; and (3) Dealing with the Systems: Public Welfare and Child Welfare. Each theme presented with underlying sub-theme(s) that further describe participant's experiences in greater depth. These sub-themes are: (1) Single Parenting; (2) Race and Racism; (3) Limited Community Resources; (4) Mental Health; (5) Fear of Child Welfare; (6) Biases and Inconsistencies; and (7) Racial Disproportionality. Table 2 displays the primary themes and related sub-themes.

Table 2. Study Themes and Sub-Themes

\begin{tabular}{|cl|l|}
\hline \multicolumn{2}{|c|}{ Primary Themes } & \multicolumn{1}{c|}{ Related Sub-Theme(s) } \\
\hline I. & Financial Strain & 1) Single Parenting \\
& Creates & 2) Race \& Racism \\
& Significant Strain & 3) Community Resources and Limited Funding \\
& 4) Mental Health \\
\hline I. $\quad$ Concern for & 5) Fear of Child Welfare \\
& Children & 6) Biases and inconsistencies \\
\hline II. $\quad$ Dealing with the & 7) Racial Disproportionality \\
\hline
\end{tabular}




\section{Welfare and Child Welfare}

The resulting themes and sub-themes were determined by the frequency that each was referenced within the data. All themes and sub-themes held some degree of prominence throughout the focus group series, representing the views of participants across all focus group discussions. Table 3 shows the resulting themes and subsequent sub-themes indicating the frequency of occurrence found in response to the focus group guide.

Table 3. Data Clustering Results

\begin{tabular}{|c|c|c|c|c|}
\hline Focus Group Guide & $\begin{array}{l}\text { Primary } \\
\text { Theme }\end{array}$ & Frequency & Related Sub-Theme & Frequency \\
\hline $\begin{array}{l}\text { What challenges, if } \\
\text { any, do you face? } \\
\text { Would you say that } \\
\text { money affects your } \\
\text { parenting capacity? } \\
\text { Please explain. } \\
\text { Probe: Sometimes } \\
\text { parents have to make a } \\
\text { choice when they do } \\
\text { not have financial } \\
\text { resources. Can you } \\
\text { give some examples of } \\
\text { when you've had to } \\
\text { make a choice that } \\
\text { impacted your } \\
\text { parenting? }\end{array}$ & $\begin{array}{c}\text { Financial } \\
\text { Strain } \\
\text { Creates } \\
\text { Significant } \\
\text { Strain }\end{array}$ & 56 & $\begin{array}{l}\text { Single Parenting } \\
\text { Race \& Racism }\end{array}$ & 22 \\
\hline & & & $\begin{array}{l}\text { Mental Health \& } \\
\text { Disabilities }\end{array}$ & 21 \\
\hline $\begin{array}{l}\text { How do you support } \\
\text { your children's }\end{array}$ & $\begin{array}{c}\text { Concern } \\
\text { for }\end{array}$ & 51 & Mental Health \& & 21 \\
\hline
\end{tabular}




\begin{tabular}{|c|c|c|c|c|}
\hline $\begin{array}{l}\text { learning and healthy } \\
\text { development? } \\
\text { Probe: What do you do } \\
\text { to support your } \\
\text { children's overall } \\
\text { wellbeing? }\end{array}$ & children & & $\begin{array}{c}\text { Disabilities } \\
\text { Community } \\
\text { Resources \& Limited } \\
\text { Funding }\end{array}$ & 22 \\
\hline $\begin{array}{l}\text { How do you see race, } \\
\text { if at all, influencing } \\
\text { families becoming } \\
\text { involved with the child } \\
\text { welfare system? } \\
\text { Probe: Racial } \\
\text { disproportionality has } \\
\text { been found to exist in } \\
\text { Oregon's child welfare } \\
\text { system for African } \\
\text { American and Native } \\
\text { American/Alaska } \\
\text { Native children: } \\
\text { meaning that these } \\
\text { children have greater } \\
\text { representation in the } \\
\text { child welfare system } \\
\text { than they do in the } \\
\text { general population. } \\
\text { What are your } \\
\text { thoughts? }\end{array}$ & & & $\begin{array}{c}\text { Racial } \\
\text { Disproportionality }\end{array}$ & . \\
\hline $\begin{array}{l}\text { How do you see } \\
\text { poverty and race } \\
\text { influencing families } \\
\text { becoming involved } \\
\text { with the child welfare } \\
\text { system? Please } \\
\text { explain. } \\
\text { Probe: Some argue that } \\
\text { poverty is sometimes } \\
\text { confused with neglect } \\
\text { and that results in } \\
\text { families becoming } \\
\text { involved with child } \\
\text { welfare. What are your } \\
\text { thoughts? }\end{array}$ & $\begin{array}{l}\text { Dealing } \\
\text { with } \\
\text { system } \\
\text { issues: } \\
\text { Public } \\
\text { Welfare } \\
\text { and Child } \\
\text { Welfare }\end{array}$ & 50 & $\begin{array}{c}\text { Race \& Racism } \\
\text { Racial } \\
\text { Disproportionality } \\
\text { Bias and/or } \\
\text { Inconsistencies }\end{array}$ & $\begin{array}{l}22 \\
22 \\
21\end{array}$ \\
\hline
\end{tabular}




\begin{tabular}{|c|c|c|}
\hline $\begin{array}{l}\text { What supports do you } \\
\text { find valuable in } \\
\text { alleviating challenges } \\
\text { to parenting and } \\
\text { helpful in preventing } \\
\text { becoming involved } \\
\text { with the child welfare } \\
\text { system? } \\
\text { Probe: What supports } \\
\text { do you find helpful to } \\
\text { you in parenting? }\end{array}$ & $\begin{array}{c}\text { Limited Community } \\
\text { Resources }\end{array}$ & 22 \\
\hline $\begin{array}{l}\text { How did it feel to } \\
\text { participate in this } \\
\text { study? }\end{array}$ & $\begin{array}{c}\text { Appreciated the } \\
\text { opportunity to share }\end{array}$ & 15 \\
\hline $\begin{array}{l}\text { Is there anything else } \\
\text { you would like to } \\
\text { share? }\end{array}$ & & \\
\hline
\end{tabular}

Note: Frequency denotes total number of times that the comment or similar comments were used during focus group discussions. For example, while the table references the sub-theme race and racism multiple times in response to more than one of the focus group questions and as being associated with more than one of the subsequent primary themes; the number shown represents the total usage of the phrase/words and does not indicate duplication.

The following sections outline each primary theme and related subtheme as described by participants. In accordance with the phenomenological approach passages shown in quotations reflect the actual thoughts and opinions of participants reflecting the speaker's original words. The format presents each primary theme followed by each subsequent subtheme according to the respective order that each emerged within the data. Areas that address the subject matter of race and/or racism identify participant's voice by their respective racial identity to delineate any potential similarities and/or differences that may be based upon race of participant.

\section{Theme One: Financial Strain Creates Significant Strain}


Participants spoke earnestly about the ongoing stress and strain in their lives which they attributed to their socioeconomic condition. The most prominent descriptive emphasized about continually living with minimal means was that financial strain creates significant strain on their ability to manage basic life affairs. They expressed overall dismay about the everyday struggles/difficulties encountered when attempting to maintain fundamental living standards such as food, shelter, clothing and transportation. One mother expressed:

“There are times where I cry. I get really stressed out because at times you don't have the money to pay your bills and it's like [sic] a light bill that's due and if you don't have the money for it, they [utility companies] shut it off."

A father further explained the difficulties faced in managing on a daily basis:

"I think the challenges of everyday cost of living: transportation, washing clothes, going to the Laundromat, providing food, if cash based and not food stamp based [sic]. It is always a matter, so you've got to budget with how much you're working with and make sure you don't go pass that, you know, [sic] because taking care of things, a child, one, two... [sic] It's a lot, no matter the number. You have to make sure things are on an even basis and always no matter what, going month to month, month to month [sic]. So it's just like living from paycheck to paycheck, no matter how much you work, always somehow, it's never enough. So you have to stretch as best as you can to do what you can."

Another father echoed similar sentiment:

“I don't even know how I'm going to pay the rent next month. ... Yeah, I'm really struggling." 
Sharing her strategy for operating with little money, one mother explained:

"I have so many bills that are $\mathrm{X}, \mathrm{Y}$ and $\mathrm{Z}$ and only so much money to pay those $\mathrm{X}, \mathrm{Y}$ and $\mathrm{Z}$ bills. So, the first part of the month I'm trying to figure out, like okay, [sic] pay my electric bill this month but not next month. That way we can get the hygiene products in the house."

There was general consensus that the beginning of the month posed the greatest challenges for managing their finances. Another mother echoed:

"It's that first part of the month where I am like, okay, I've got to scramble and figure out like what has to be done this month? What can be put off, you know?" Other participants concurred, too, speaking of the chaos experienced as a result of trying to manage finances and be resourceful. One father notes:

"Then you have to go around and find all these resources, you know, people to help you pay bills and stuff and at times people don't have funding for it. So that stresses you out even more. Like [sic] everyday it's a daily challenge of you trying to figure out how you're going to get your bills paid."

Concurring, a mother shared:

"As a parent, my life is so hectic cause [sic] I'm out here trying to figure out how I'm going to pay bills."

Additionally, participants alluded to a certain degree of shame and discomfort associated with having to ask for help and engage with social service agencies. A father spoke of the additional stress he encounters when having to seek support or ask for assistance: 
"I think that stress is really a big thing because the first thing you think about when you've got to go in and talk to somebody is that they are going to look at you and they are going to judge you before you even get a word out of your mouth. Not knowing what the situation is but 'oh I know what this person probably is here for and what they are going to ask for.' So you got that stress already. ... Like [sic] my lights about to get cut off. I'm about to get an eviction notice on my door and everything. I feel that's stressful itself and now I've got to come and talk to you but you're going to make my stress even worse by what you're going to say."

A mother echoed similar thoughts noting the realities of limited available resources: "It's just so hard. ...I struggle. We go to food banks or whatever. Sometimes, you know as much as we can, but even then, like I said, there's just more people out there I think, as well, so it just really sucks..."

Acknowledgement of experiencing additional strain was referenced by one participant who described having to sometimes utilize strategies that could potentially jeopardized eligibility for receiving public welfare benefits:

"And when you're working with the system and you only got this much money and they see that because it's documented. You've got to go under the table sometimes which makes it a lot more harder because you've got to worry about this, that and are they going to find out."

Beyond not having enough money to meet their family's needs, participants talked about other dynamics which they attributed to the difficulty of parenting with limited financial supports. Specifically, four sub-themes emerged in this area: (1) Single 
Parenting; (2) Race \& Racism; (3) Limited Community Resources; and (4) Mental Health.

\section{Single Parenting}

Participants commented on the additional challenges brought on by single parenting, expressing that there was particularly a scarcity of resources to support single parent households.

One father stated:

"One of the things I noticed as a single parent is they [meaning public welfare] will tell you that there are lots of resources out there and they have packets this thick with lots of resources. We looked at it and they were all, you know, 'I'm sorry we're limited.' None of them work [sic]."

Agreeing, a mother noted:

"I do feel like there is a very big disparity with single mothers or single dads or just people with one child or five children. They [meaning the public welfare system] don't have the resources like day care to become self-sufficient or to find a job that's going to work with them."

Another mother explained:

“As a sole provider to my family I do what's needed to be done. I feel tired but at the end of the day, it's a do or die situation....I'm always on it! Father's absent [sic]."

Single fathers particularly observed their interactions with the public welfare system to be different than that of their female counterparts. They described experiences which they believed to be gender biased. One father commented: 
“It [public welfare system] won't help me because there's no help for single dad's that's got their kids. Maybe you need to go get an advocate for this or an advocate for that. I finally got me an advocate and she was African American. All of a sudden, doors got open for me because she's my talker. Me, I'm not just going to work. Anybody else out there can talk. So, let this lady do the advocating for me so I can at least get something to help my daughter. Because when I go they are going to tell me directly to my face they can't help me but the women sitting directly behind me, when she gets up to the counter, they are going to give her all this information. All of these places to go, all of these places that can help. No matter how many kids she's got [sic]. Me, there is nothing they can do for me so I have to step to the side and let them [meaning females] get up to the counter but no doors open for me..."

Another father spoke of his experience:

"Just like he said [referring to the previous speaker], from the first time I went to [State Agency], the system was designed for single moms and dads are no part of the situation. When the dad steps up and takes care of his child and goes to this system for help, they have nothing for him."

A single mother concurred:

“There really aren't any resources [referring to single fathers] and that's the reason why I now have custody of our brother's son. He had him for eleven years and the housing situation dropped and it slipped on him immediately and in a matter of thirty days he was homeless so I stepped up and now they're with me."

\section{Race and Racism}


Race and/or racism were noted by some participants as possible factors further impacting their challenges of living in poverty. The roles that race and/or racism have within society were described as creating additional burdens on the lives of the poor, particularly people of color. While participants' voice has, thus far, not been referenced by race, passages shared by participants throughout this section are indicated by the race of the speaker. This will hopefully help to illuminate any relevance that may be race related.

Strikingly, willingness to address race and/or racism varied among participants which seemingly may be due to race. For example, while many spoke candidly on the matter, some White participants offered little to no response. One White mother explained that as not being a person of color, she could not comment on the matter or acknowledge possible implications that race and/or racism may have for people of color:

"I'm not a person of color. Maybe they [referring to people of color] do have it harder. I feel like they have the same access I have. ...Maybe they are prejudiced [sic] but I feel like it's a lot more prejudice against me, than it's me against them or whatever [sic]. ...I just feel like there are as many poor White kids as there are Black [sic]. How would I know?

Another White mother acknowledged biases or differential treatment existing within society but attributed such actions to issues related to poverty rather than race and/or racism:

"Me particularly [sic], I don't really see a difference one way or the other in regards to race. I do see it a lot more on the financial part, especially with single parent homes or just people that are lower income than others [sic]." 
Another White mother concurred sharing her observation of encounters she witnesses from a particular outpatient center that she frequents:

"There is a mixed race of people that go there but to me it doesn't seem like, not necessarily determined by race that I'm hearing and seeing, but a lot more financial [sic]."

However, others spoke to the contrary as another White mother shared:

"I grew up very privileged. ...I didn't understand like the things that my peers [referring to people of color] went through because they weren't White until I had my son and once I had him, I got treated completely differently and it was just, it was difficult you know, I'm an adult and it was really hard to handle. ...But the way African American women, the way they grew up, they have this like a boulder looming over them their entire lives that they are treated differently [sic]. First of all because they are Black and second of all because they are a woman and there are all these assumptions of how Black women should act or do act or that they are crazy and they have all these things [sic]. They have oppression [sic]. ...They have these preconceived notions of how people are going to act based on melanin in their skin [sic]."

One White mother echoed:

"I think they [meaning the various societal systems] keep people at a certain level and they do certain thing within that community or within that to keep them suppressed so they can't achieve any higher [sic]. So they [meaning people of color] don't think they can achieve any higher, you know, like I think they [meaning the various societal systems] do a lot to say okay, you are only going to 
go this far and we will make sure that you only go this far because you can't get anywhere above that because we have to have the power and the control over all of that."

Another White mother spoke of her personal encounter with the child welfare system where she thought race was a factor in the removal and placement of her child.

“...I was White, so my son was placed with my mother. Women of color have their children taken away and placed in foster care [meaning non-relative or stranger care placements] for far less."

One White mother acknowledged:

"I think people sometimes tend to help people of their own race more than other people. I think it [race and poverty] makes it [managing life] more difficult. I think it makes it more possible for people that are of a different race or have a different financial level, [sic] whatever establishment they are dealing with...,[sic] if more than one person agrees that they are not suitable to take care of their kids, they [meaning the public and child welfare systems] could just railroad them [sic]. ...I think at times people take advantage of those kinds of things as well. Take advantage of somebody's level of financial and their race [sic]."

Although participants of color conveyed dismay concerning the additional burden race and/or racism placed on their lives, they showed no reservations to discussing such matters. One African American father firmly stated:

“Oh race plays into it [meaning life experiences]!"

Another African American father concurred: 
"It's the skin color that says no and they [meaning the various societal systems] say no."

One African mother explained:

“...you can’t go nowhere without somebody watching you or you go into a store [sic]and you got a security guard walking behind you... Why are you following me? I got money in my pocket and I'll hit my pocket real quick [sic]. Here's my wallet. Let me count these little dollars I got to spend or whatever [sic] but they are watching you for every little thing you do."

Another African American mother echoed:

Unfortunately, it [meaning race] does.... Unfortunately race plays a big part of the everyday world. Racism has never ended. Racism will never end. I have come to terms with that, so either join [meaning accept] it or resist it all your life and still have complications."

A Latino father shared:

“...It doesn't matter how much we can achieve, it's still race [sic]. We have to carry-on all the negative stereotypes and everything."

Again, an African American father explained:

"Yeah, the families [meaning families of color] give up. They are so broken that they think that financial wise [sic], being poverty stricken goes hand in hand with their situation. They [families of color] are more likely to give up and turn that [responsibility] over to someone else because they just feel like they [sic], that it's too overwhelming for them [sic]. They [families of color] don't look at the cost of living anymore, financial wise, poverty wise [sic]. So they figure if they're just 
out there alone doing what they do, they don't have to worry about it [managing racism and poverty] themselves [sic]. They [families of color] don't want to remove their own child from the equation and everything [sic], because [but] like I said, its [managing racism and poverty] just too overwhelming for them."

One White mother further noted her perception of how race and racism might be used by systems within society:

"I think they [meaning the various societal systems] keep people at a certain level and they do certain things within that community or within that to keep them [populations of color] suppressed so they can't achieve any higher [sic]. So they [populations of color] don't think they can achieve any higher, you know, like I think they [meaning the various societal systems] do a lot to say okay, you [populations of color] are only going to go this far and we will make sure that you only go this far because you can't get anywhere above that because we have to have the power and the control over all of that [sic]."

While participants discussed the influence that race and/or racism added to the difficulties of their lives, they also addressed any possible impact that race and/or racism might have upon their interactions with the public welfare and child welfare systems. The latter will be discussed further under the section addressing the third primary theme, dealing with the systems: public welfare and child welfare. Continuing the discussion regarding attributing factors complicating their daily lives, participants designated considerable attention to the role of private community supports upon their daily lives. Most pertinent was the expressed concern with the limited availability of community resources. 


\section{Limited Community Resources}

Participants named several private agencies within their respective communities designated to helping families/individuals to mitigate the negative impact of living with minimal finances. Several noted appreciation for the assistance received from such agencies both during times of crisis or immediate need and for ongoing support. They described the objective of community agencies as being to provide direct and/or indirect services such as housing, food, clothing, employment, health and mental health often through advocacy and/or case management. For example, one father further noted assistance his family received from a community agency during the Christmas holiday season:

"My people at [community agency] put my daughter on an Adopt a Family list there and we got adopted and I talked to the lady on the phone. She bought us a brand new chrome book laptop, everything they spent about $\$ 3500$. They came this Saturday to fill my entire tree up. So she [referencing to his child] is sitting under the tree counting all the presents."

While acknowledging the benefits gained from community agencies, participants also spoke to an overall shortage of resources leaving agencies unable to adequately fulfill their intended purposes. This general lack of resources was particularly noted as a point of contention for participants adding to their levels of stress. One mother described her experience of not being able to obtain assistance due to limited funding:

"I said this is what's going on and my back is against the wall. I just paid three or four hundred dollars on one bill the other day. My back is against the wall. I just 
called the resources [meaning private community agencies] and there is no funding out there. ... This is an issue."

Concurring, another mother adds:

“... They [meaning private community agencies] have so much money and they will help as much as they can. It just depends on what's available."

A father noted:

“... They [the public welfare agency and private community agencies] tell you that there are a lot of resources out there and they have packets this thick with lots of resources. We looked at it and they were all, you know, 'I'm sorry we're limited.' None of them work."

Insufficient housing assistance was noted as particularly troublesome by participants. Housing was acknowledged as being especially needed but unfortunately required long wait periods. Several shared having, at some point, experienced homelessness attesting to the benefits of housing assistance and also spoke to the excessive wait time to actually acquire housing. One father expressed frustration explaining the circumstances his family endured while living at a homeless shelter: "I've been on the wait list, number one, for five year. ... This is my cot. This is hers [meaning the participant's child]. These are the little boxes we have to put our clothes and stuff in to make everything seem reasonable. But when I came to you guys [community agency], you said there was nothing you could do for me. Not a hotel voucher to put me and my daughter in, not a Section 8 voucher, not even putting [sic] us on a wait list for the next available unit that might come open anywhere! 
He went on to share that he had finally acquired a place to live for he and his children: "Yesterday, I just signed my paperwork at [private agency]. So now my rent is $\$ 150$ a month in a brand-new building; two bedrooms, two full baths. So my daughters can have their own room; dishwasher, washer and dryer, everything [sic]."

One mother crediting her family's ability to secure housing to financial support provided by a community agency shared:

“...We were homeless for four years before we got into our place just two and a half years ago. So we were at shelters and all that but thank God for [community agency], though [sic]. I'm saying because they paid six thousand dollars for us to get into the place that we moved into. Yeah, I mean I couldn't have done it without them."

Another mother explained that her family was currently living apart from one another due to inadequate housing:

"Yeah, so where I am is just a two bedroom and we converted the garage into our bedroom. But if all three of my kids were with me, they would all be in one bedroom. When I got on these housing list and stuff, I did apply for three bedrooms because the idea was that they would all be living with me." In addition to financial support and housing assistance, mental health services such as counseling was another necessary benefit received via community agencies.

\section{Mental Health}

Mental health issues that existed either for participants themselves or their children raised additional concerns when discussing the difficulties of living in poverty. 
One participant speculated that her child's mental health diagnosis was caused by the family's living conditions:

“...That [meaning mental illness] seems to happen more for people that are on welfare or single parents or whatever. ... Same kind of dynamic or whatever but more so boys than girls where they have the insecure parent child relationship, lack of structure, lack of discipline, you know, all because like I said might have triggered it with the homelessness... [sic]"

Another mother shared having experienced a long-standing history of mental illness:

"I have been in major depression, yeah, for like twenty years. ...it's really easy to go down but it takes a lot to go up and so just struggling with that daily and I don't like what it feels like when I am feeling sorry for myself, because somebody has got to do it..."

One father echoed:

"I've been depressed for many years; emotionally depressed."

It was thought that greater attention be given to mental health issues for families experiencing poverty by the private and public agencies. One mother shared frustration with having to address mental illness:

"The first thing they [private and public agencies] say is did you talk to a counselor. For what? What can they do for me that I can't do for myself besides me telling them what's going on that they're going to repeat back to me after forty-five minutes at the end of the meeting [sic]."

The participant went further to express concern regarding the consequences of discussing mental health challenges with public welfare authorities or other service providers: 
"At the end of the day, if I come and tell you that I'm going through this and I feel this way and I feel like harming myself, the first thing you are going to do is say, ‘you got anybody helping you with your kids?'And when I tell you no; then want does that mean? Then they want to send the people [meaning child welfare] in. So what, I deal. I get up every day and sit in the porcelain tub in my bathroom and I cry and I talk to God about whatever it that I'm going through. Cause there ain't nobody [sic] else that can help me."

One father who was single parenting partially due to the negative impact that mental illness had on his child's mother, shared his observation of the impact of mental illness: "She [meaning the child's mother] was not the same person. ... It changed her. It seriously changed her and I thought it was a joke. You have got to be shitting me! It was the real deal and she wasn't using drugs. ... She got diagnosed with schizophrenia... I didn't know what was going on. I thought she was playing a game."

He went on to say:

“It's [meaning mental illness] a huge part. I've got a daughter and now that I know that genetic is in there...I got another generation to worry about. To wonder how she's going to react in this situation when she has kids. ...Also now I got counseling set up for my daughter you know. I have some awareness now."

A mother shared:

“... I also deal with like anxiety you know. I'm on anxiety medications which help, you know [sic]."

Another mother shared her own struggles: 
“... Since I've had this depression, I'm like holy shit, what is this? Where did it come from? [Participant crying] ...I remember saying good bye to my kids at one time because I was going to kill myself. I was just trying to think of a good clean way I could kill myself without leaving too much bad for my family. That's how bad it is [meaning mental illness] and I've been there more than once. So, that's like a really big struggle everyday so that alone I feel like its [meaning mental illness] just a major, major thing."

Multiple participants at different times acknowledged more attention and better understanding of the impacts of mental health. Several commented in agreement:

"There should be a better attitude toward mental health."

\section{Summary}

The first primary theme, Financial Strain Creates Significant Strain, exemplifies the ultimate reality of families living in poverty. Their lives are wrought with extreme difficulties and carry a certain degree of shame. Navigating the management of finances is a vicious cycle that appears to have no sustainable solution. The struggle to maintain and secure the very basic necessities of life such as food and shelter is relentless and results in a great deal of ongoing stress as participants describe little to no relief from the challenges of living without adequate means.

Regardless of their respective struggles, participants voiced particular concern for their children. Thus, the second primary theme, Concern for Children, while community resources and other supports may be available, acquiring such benefits subsequently creates even more stress. There can be much despair associated with finding the ample necessary supports to meet their family's needs as community resources and funding is 
often limited. Furthermore, characteristics such as single parenting, race and racism and mental illness further complicate the experiences of being poor.

Four sub-themes: Single parenting, race and racism, limited community resources, and mental health summarize the underlying issues that participants attribute to their lives being further strained. While participants discussed certain challenges experienced when parenting single handedly, those who were single fathers addressed unique difficulties that set them apart from single mothers. For example, single fathers felt that many of the public and private resources are targeted towards single moms. In addition, single fathers expressed encountering biases and discriminatory treatment against them that they believed to be gender based. Although all fathers participating were persons of color, gender related biases were distinguished separate and apart from racial biases.

The trials associated with race and racism did, however, result in additional stressors for poor families of color. Participants of color and some white participants, acknowledged that the continued existence of racism within society. Participants of color specifically highlighted this as a contributing factor to their lives being more complicated. In other words, issues of race and/or racism makes what is already a difficult life more burdensome. While some white participants attested to their peers of color having greater adversities solely due to race and/or racism, others expressed little to no empathy and were challenged in speaking on how race and/or racism might possibly create any impact upon the lives of their peers of color. Finding available resources was expressed by all, regardless of race, as especially onerous.

The private sector typically serves as to supplement public welfare benefits to the poor, but many times have limited availability. Furthermore, funding in general for 
private sector agencies as well as the public welfare agency is limited and often has restrictions. Participants described the shortage of community resources as adding to their stress. Once more, single fathers echoed despair in even fewer sources available for single fathers.

The cumulative strain of limited monies, single parenting, race and/or racism, and limited community resources perhaps partially exasperates mental health issues for some participants. Several explained that either they and/or their children suffered from mental illness. Some expressed fear of negative repercussions by public welfare if mental health diagnoses such depression were made known. Other's felt that little is understood about the total impact of mental illness upon the lives of the poor. In summary, all of the above stated issues culminate describing how financial strain subsequently creates significant strain upon the daily lives of poor families.

\section{Theme Two: Concern for Children}

Participants emphasized that while poverty might impede their ability to provide for their children's needs, their desire to parent as well as the parental responsibility they place upon themselves was not diminished. They sincerely care about their children. Thus, the second most primary theme emerging from the data was "concern for children." Participants expressed love for their children and maintained the needs/interests of their children as a major focus. Adamantly clarifying that her financial circumstances did not define her as parents, one mother stated:

"For myself [sic], having less money does not impact my parenting at all. My parenting, my ability to parent as a woman and a mom has no bearing on financial [sic]. Financial is just things that you can do to attain possessions or things like 
that [sic]. My kids value my time spent with them more than me taking them to spend money at a bunch of different places. They would prefer me to stay at home and snuggle and watch a movie or whatever just so we can like be together."

A father shared similar sentiment.

"Does money affect the way I raise my child? Does it affect my moral standards? No. When it comes to things that I'm able to have, it affects my ability to get material things."

Participants further openly discussed the necessity of buffering for their children as an effort to mitigate any possible adverse affects of poverty. They described taking active protective measures to ensure the wellbeing of their children.

One mother commented:

"I get very sensitive about my child when there is something that comes up out of the norm and I feel that there is, a responsibility on me as a parent to do more work and for me to ensure, you know, the best outcome for her. So I do my best to advocate for what it is that I could do as a mother and as a community member to improve or empower myself to ensure a better outcome for her."

One father shared an example how he advocates for his child:

"Well for me, being homeless, I went up to the school to let them know that we were considered a Title 10 . That's what they call it when you're homeless. That's the first thing I let them know. When you see that things are going on in the classroom that she's not participating or she's not really being focused, I'd like to be the first one informed."

Additionally, he suggested how he mitigates stress that may be affecting his child: 
"When you watch your child, you can see what their interest is and the things they like to focus on. My daughter loves art, so that's my way to let her blow off her steam or whatever. ... So if as long as I can keep her focused on other things and focused on other activities, I think that's the best way I can help her as a dad; is t relieve things so she doesn't have to see all the hoops we have to jump through, the people we have to go through and the things we have to continue to persevere through in order to make sure, like I said, the most important thing is to make sure we have a stable roof over our head, a comfortable bed to sleep in and a hot meal to eat. ...My daughter is in the [Community Agency]. She has her own counselor. That was the next thing that I did. Let me get somebody that she can talk to besides her dad and somebody that she can feel comfortable to besides her dad." Another father concurring that his daughter's best interest was also his priority stated: "I agree. I think that for my daughter as well. I think we are all here because we actually care about our children not because we don't care about our children. I sit down with my daughter at lunch and bring lunch's sometime [meaning at the child's school]. We sit down at lunch and we talk to see how the day is going, all she has done in the classroom..."

He went onto explain:

"We [meaning him and his child] try to bridge over things. We don't keep things from one another, but sometimes we try to bridge things over."

On the other hand, one mother thought it best to not share realities of the family's financial circumstances with her children: 
"Unfortunately, I hide things from my kids. I am the first to hide, my children are emotional. My children are emotionally attached to me. When I struggle, they struggle under every aspect of my life [sic]. When I struggle, they struggle I notice that.

... I had to tell myself a long time ago, it's okay to cry, it's okay to breakdown; just don't do it in front of them [meaning her children]. It sets them back, especially my youngest.”

Others spoke candidly of the resulting emotional turmoil placed upon parenting due to their continuously having to manage daily affairs with insufficient monies. They described the additional strain that this places on them and their children. One mother shared:

“...I shut down and my youngest really, the one that's almost eight, is the one that suffers from it. When I shut down, he acts out. It's to get my attention and I know this in my head but for like the first five days of the month I'm just like, okay bud you got to let mommy be, like I'm tired [sic]. I'm stressed out..."

Another mother added:

“... and I have a seven-year-old where it [meaning the mother's emotional state], he can tell when I'm stressing or when I'm going through a down, a down state to where I don't want to be bothered [sic]. He reacts, he will completely shut down [sic]."

Concurring, another mother spoke:

"If I don't have money, then it's a burden for my children because how am I going to care for them? Just providing for them in general; the cost of living, 
transportation, clothing; the food is definitely not enough for the amount of people that's in my household. So at the end of the day, money will always be a problem. ...yeah, there're these food pantries, you're right, [referencing another participant] but I'm talking about two thousand era kids. They don't want that. I'm fine with eating anything because I barely eat anyway, but I mean, when it's your child and your child is use to having something and then all of a sudden one day it's taken away and then you've got to go and tell that child they can't have it, that just doesn't make me feel bad, it makes them feel bad and that's not okay." Some participants acknowledged having disappointment, anger and shame about not being able to provide the material needs, wishes, and desires of their children. For example, the inability to do fun activities with their children such as recreation and games due to financial limitations was noted. One mother commented:

"I mean, I have these two beautiful children and I can't even provide the necessities they need at a time when they need it because of my financial, you know, hardships, because of my choices and my past. Like I just feel bad for them because they suffer from the choices that I made."

A mother added:

"I know a lot of families, a lot of women especially, who have said it's so much harder to be working making money and barely making ends meet. Yeah, I can pay my bills and put gas in the car, but I don' have enough money to go buy my kid's clothes. I don't have any money to take my kids somewhere on the weekend, even if it's the damn zoo. Not even going out of town for the weekend 
but just to go to do something fun with your kids for a day. It's really, really hard!"

A mother echoed:

"There are times when I get pretty stressed out because my oldest three kids, they want expensive things and they won't wear jeans from Wal-Mart. They won't wear none of that [sic]. It has to be from the mall."

While participants discussed the dismay surrounding their inability to meet their children's wants and desires, some commented on their resourcefulness as parents. They credited themselves for efforts made to accommodate their children having some luxury items such as electronic games, or brand label clothing. One mother explained searching for free or discounted items as a means to provide playful things for her children:

“...I'm pretty good at looking at other options on the Internet. I'll find cheaper prices or used. I do a lot of goodwill shopping or garage sale shopping."

One mother added:

"My boys are into games. Video games and stuff so I go to GameStop and you know they have pretty decent deals on stuff. You know I may not be able to get it brand spanking new but you [meaning her child] will have something like it." Underlying these various matters, i.e. concern for child's wellbeing and the ability to provide child's basic needs children, participants noted a general uneasiness about possibly becoming involved with child welfare.

\section{Fear of Child Welfare}

The majority of participants $(n=13)$ voiced fear and distrust of the child welfare system. Fear of child welfare emerged as a subtheme associated solely with the second 
primary theme, Concern for children. Exacerbating concerns about meeting the basic needs of their children/family while managing daily life affairs with very limited financial resources, participants conveyed distress about potentially becoming involved with the child welfare system. They were mindful of navigating life such that interfaces with child welfare could be avoided. One mother noted:

"You got to make sure you can make it from the beginning of January to the next beginning of February to make sure all your bills are covered because if you don't, one way or another the State is going to get involved and they are looking at you as being a bad parent; you spending your money on other things that you don't need to."

Another mother commented:

"So it's now in the back of my mind. I'm stuck in this stage. Well, what if child welfare is going to get involved again. I don't have time for that. I hate dealing with them, period!"

Sharing similar sentiment, one mother talked about her experience with the child welfare system and the ill feelings she and her children now hold:

"My kids was taken away from me for two months and put into the foster care system. I fought and fought. I had to go to drug classes. I had to go to mental health. I had to do all these things just to get my kids back. Once I got them back, my kids were so over child welfare to where now they would tell you they hate them [meaning child welfare]. They will not talk to them. So it's just like, I can't stand child welfare, period." 
Participants spoke of their looming distrust of child welfare. A father spoke of his experience with child welfare:

"Let me tell you. Two workers [meaning child welfare] showed up to talk with me. Child protective Services showed up and talked to me, went to my daughter's school and talked to my daughter. Now you coming to take my daughter from me cause I'm living in this shelter. I reached out to you guys more than once. You guys didn't do nothing [sic]. Now you guys here making me feel uncomfortable because you want to know my living conditions. But you're wondering if I'm a responsible dad taking care of my daughter the right way. You go up to the school to talk to her to make sure we are living okay inside of a shelter? I'm like this is the only time you guys show up? When you think that I'm not a fit parent. ...Wow, is this what it takes? A situation to go bad with a single dad and you think my child would be better off with people she don't know [meaning foster care]? ... Instead of saying let's see what we can do to help you. Let's see if we can sit down and talk and come up with some type of plan.... You didn't offer me none of that then you finally send me a letter saying you are closing the case and I don't even understand why it was open [sic]."

A father added:

"Yeah, you [referring to child welfare] expect me to trust you and yet if I tell you the real deal as far as what's going on you might think it's too much and might want to take my kids. I'm being honest with you, right? Can I be honest with you guys and tell you everything that's going on, right? You are going to take my kids, cause you don't know [sic]. They [meaning child welfare] might tell you to 
wait right here. Get up out of their [meaning child welfare worker] chair to go talk to someone. Someone [meaning child welfare] is at the school now to take your kids away and you are sitting there in the office [meaning the child welfare office] and don't know what's going in behind your back."

Participants mutually believed there to be an imbalance of power between themselves and child welfare workers. Many $(\mathrm{n}=10)$ expressed being disempowered. One mother expressed:

"Let me tell you they [meaning child welfare] have the power, no matter what you say. ...When it comes down to it, they have all the power you pretty much don't have any. ...I mean they should have a panel of parents, regular parents overseeing the CPS. Or maybe there should be some criteria to keep them in check."

Another mother shared that her public welfare worker came to her defense during a potential encounter with the child welfare system:

"I know that for a fact because I had a worker [State public welfare agency case worker] who knew what to do. He saw how many times [State child welfare agency] kept coming into my kid's life and my life for no apparent reason to where he took it to the extra step and went to the head of the CPS workers and was like, you know, you guys [meaning CPS] are messing with her too much. Let me put this in perspective, her kids are perfectly fine. I see them with her every time she comes in. Y'all leave her alone, y'all back down."

One another mother agreed, sharing her encounter with child welfare: 
“...I think it make it to where these case workers can be a little bit too aggressive or a little bit too judgmental on some of the other families that maybe really don't have that serious of a situation going on but yet they are going to nail you to the wall because they want to make sure that situation doesn't happen to any other families, you know. I had a specific female worker that came out a couple of times and I was like, I don't want her back in my house. She was just so rude and the way she talked to me. I was like, I don't know who the hell, I don't deserve [sic]. I don't care what I've done or what you think I have done, there's no way that I deserve to be talked to the way that you [meaning the child welfare worker] are talking to me right now, you know [sic]."

Coupled with their opinions about interfacing with child welfare workers, participants further shared thoughts about systemic issues within the child welfare and public welfare systems.

\section{Summary}

The second primary theme "Concern for Children" exemplifies the value parents have for their children. Participants voiced having value for their respective relationship(s) with their children. Regardless of adverse financial circumstances, they expressed love, admiration, care and sincere interest in the wellbeing of their children. Participants made concerted efforts to protect their children from the woes of poverty. Some explained their efforts to gingerly explain their life circumstances to their children. Others vehemently confirmed that their financial situation did not affect their relationship with their children. 
Participants described trying to maintain an emotionally safe and nurturing connection with their children. Even when faced with the stark realities such as homelessness, some described having the conscious intention to functionally parent to the best of their ability. One mother explained attempting to do homework via the telephone with children when living apart. Others talked of having ongoing one to one conversations with their children to mitigate any subsequent issues their children might experience that could be related to their financial situation. Some sought external resources such as counseling, recreational and other community resources as a means to offer alternative avenues for their children to release latent stress stemming from their home/family circumstances. While many spoke to the mounting stress, anxiety and in some cases depression, participants maintained the interests, protection, safety and wellbeing of their children as a primary concern. Similarly, the child welfare system holds comparable goals when addressing the welfare of children and their families. Ironically, participants did not express a universal view of child welfare as having the best interest of families in mind. Instead, child welfare was described with fear, distrust and dislike.

The subtheme "Fear of Child Welfare" illustrates the constant underlying anxiety looming over participants as they attempt to manage caring for their children. Most participants, regardless of gender and/or race, adamantly spoke child welfare as anxiety provoking and against becoming involved with the child welfare system. They expressed feeling disempowered by child welfare and losing control, believing child welfare to possess full authority over their lives. Hence, they acknowledged reverting to a sense of helplessness and hopelessness upon becoming involved with child welfare. 
Further complicating matters participants acknowledged also being angry about having to contend with the demands and expectations placed upon them by child welfare. Consequently they found themselves in the paradoxical predicament of trying to assert affective parenting while feeling despair about their ability to perform parental duties. While expressing sincere efforts to provide for their children and maintain family stability, they described having an ever present dread about child welfare intervening in their lives. Additionally, participants explained that whatever supports may come via child welfare, are often offered too late. They did not see child welfare as proactive in their efforts to serve families. While child welfare promotes safety and wellbeing for children as well as family stability, these were not the impressions of participants. Most of the participants of color, particularly Black/African American $(n=7)$ and some mixed race $(n=2)$, described child welfare as breaking up families. Ultimately, child welfare was viewed with trepidation.

\section{Theme Three: Dealing with the Systems: Public Welfare Program and Child}

\section{Welfare Program}

The third and final primary theme emerging from the data was "Dealing with the Systems: and Public Welfare Program and Child Welfare Program.” The public welfare program aims to sustain the family so that financial self sufficiency is achieved. Thus its main focus is to help families and individuals become self reliant, thereby not needing financial assistance from the government. Typically this is done through cash, food, housing and medical benefits. The child welfare program specifically provides support to families with the sole purpose of ensuring the safety, wellbeing and protection of children. While having different focal agendas whereby the public welfare program 
targets financial security and the child welfare program focuses on child safety, both programs similarly promote overall family stability.

Several participants acknowledged awareness of each program's designated goals as being to support and strengthen families. However to the contrary, participants questioned the intent of both programs in this regard indicating flaws within the public welfare and child welfare systems. They explained that this was not necessarily their respective experience when interfacing with either program. Sharing her sentiments regarding the public welfare system one mother commented:

“...The goal of the State [meaning public welfare] is again, for you not to depend on them so much and they figure the more they take from you, little by little by little it's going to encourage you to go out and do this. No it's not! Everybody's mind does not work that way; the strong yeah, because they want to be independent [sic].

Another mother expressed:

"I think there needs to be some kind of middle ground where you have gotten back into your place, you're getting on your feet and you have a job. But, they [meaning the public welfare program] are not just going to completely cut you off of everything cold turkey and make it such a struggle again. Finally you're getting back on your feet. It's a really overwhelming feeling to know it's all on your shoulders. And if you don't make it, you don't make it."

A father reiterated:

"It's just plain and simple, people need help and they take things for granted thinking they understand how everything works in the system [meaning the public 
welfare], what they [meaning the public welfare] can and they [meaning the public welfare] can’t do. When I say help, I mean genuine help and they [meaning the public welfare] are not doing it. The system is designed, like I don't know how that system is designed, but it's not designed to help. It could be because of the cases [meaning caseload size] they carry but I tell you what, there was a whole lot less people on the system in 1985 than what there is right now and the system has not changed. Something has got to change and I don't think its case loads."

Almost half $(n=7)$ of participants suggested that some of the policy and /or practice flaws within the public welfare system could be attributed to biases and inconsistencies.

\section{Biases and Inconsistencies}

Participants noted concerns regarding policies and practices that they believed existed due to biases and inconsistencies existing within the public welfare system. For example, some participants expressed confusion regarding benefits and eligibility determinations suggesting that decisions were possibly punitive. One mother spoke of her experience with receiving food stamps:

"I get food stamps. My daughter and I for the two of us get less than what two adults or two other people get. I'm saying they [other families] get almost a $\$ 190$ or whatever. We get like $\$ 50$ less than they do. That's how they [meaning public welfare] figure it. I don't understand how they [public welfare] figure it cause kids eat a lot [sic]. Why should we get less because she is a child instead of an adult?"

A father described his situation: 
"I was at my worst, you know, borrowing money from churches, getting money from churches and people in the community that would help because they felt sorry for me. You now, I learned the system by them closing doors on me, too.... I got an eviction notice... and here I'm sitting with a program that has section 8 vouchers [referring to a type of housing assistance] and I'm going why can't I get a Section 8 voucher? It's just a temporary voucher. I mean you're [meaning public welfare] helping me with resources for these other things, why not housing? And the lady [referring to the public welfare worker] says well unfortunately you are already in a housing unit and you're not evicted and living on the streets. They [meaning public welfare] won't give one [referring to the housing voucher]. Never mind that I'm trying to keep a place for my daughter. Why is the program here, to help families? You know you have to be in a shelter or they won't help you."

Another mother added:

"Everybody should have the same opportunity."

Speaking about the application process, one mother explained:

"Just like on those applications that they give you to see if you're going to be homeless within the next six months or whatever. Some people check the box. Yeah, they [meaning public welfare] don't look at it as if you're going to be homeless or you are homeless. They don't look at that. They say well do you have any TANF left? It's like well I have to use all that money to pay for where I'm staying, pay for if my kids need anything, pay to get on Tri-Met [public transportation system]... You got a lot of different things. They don't look at that 
or if you've got a shut off notice. They ask you all this in your application and then they don' take it into consideration. They just reissue your benefits if it's time for you to renew and that's it. You're out the door. You are still stuck." All participants implicated the public welfare system having contradictory goals and expectations for recipients. For example, one father offered his example of having to choose to remain on public assistance or return to school as a means of potentially improving his ability to establish better earnings:

"When I asked if I could go to school, try some stuff, get a career [sic]; they told me if I tried for or even filed to go to school, they would cut off my TANF, my food stamps and medical."

Similarly, a mother shared:

"But when you tell these folks at [public welfare agency] that you are in school; that you are doing something; doing one of the three things that you want to do to be able to keep the little piece of change they are giving you. Even though they tell you its [meaning income] not counted, it is. But when they see that, then they say we [public welfare agency] don't have to step up. You got an income [sic]." Furthermore, participants suggested that the public welfare system failed to provide adequate supports to ensure ongoing stability to sustain welfare recipients when exiting the program. For example, one mother shared:

"When a mother, like a single mother goes from, you know, being on TANF to then actually being in her own place and getting a job. It's like they reduce your help and your services to such an extent that sometimes you are better off not getting a job and staying on the system.” 
Expressing similar experience, another mother stated:

“I am making \$180 on TANF since I'm not working, looking for a job or something. If I start to work, they take every dollar I make from that job and they take away from the $\$ 180$ I get from TANF."

Concurring, a mother interjected:

"Yeah, they [public welfare] dropped me off so now I have to figure out how to get the accommodations for my son because he has ADHD and him [sic] and his brother can't do anything."

While participants expressed concerns regarding biases and inconsistencies operating within the public welfare system, similar views were expressed regarding the child welfare system. Furthermore, biased and inconsistent practices within the child welfare system were believed by participants as influencing families of color disproportionately becoming involved with the child welfare system, thereby impacting racial disproportionality.

\section{Racial Disproportionality}

Participants specifically suggested the operation of racially motivated decision making and the existence of biases/ inconsistencies within child welfare practice as attributing to punitive treatment toward families of color. Additionally, societal views regarding race and racism were also believed by participants to promote negative implications for poor families of color further attributing to their difficulties upon engagement with the child welfare system. It should be reiterated, too, that regardless of 
race, participants further described their experiences with child welfare as being disempowering, leaving them fearful and distrustful of the child welfare program. Such sentiments were emphatically echoed by most participants of color. Fear and distrust of child welfare coupled with concerns regarding race and racism imply that participants question child welfare motives and actions concerning families of color. Analogous with the aforementioned subtheme section addressing race and/or racism, the race of the speaker will be noted when discussing racial disproportionality to denote possible contextual significance. Acknowledging the general influences of societal views concerning race and racism, an African American mother reiterates:

"Unfortunately race place a big part of the everyday world. Racism has never ended. Racism will never end. I have come to terms with that. So either join it or resist it you're your life and still have complications."

When discussing suggested biases that may exist within the child welfare system, another African American mother added:

"How I think the child welfare system is really involved in anything with African Americans [sic], they put us down so much to where we are thinking that we are all criminals or we are all bad people because of our color."

One White mother offered this thought:

"Well, being a White woman and I have these kids that are Black, I guess racism is very much alive. Back in the day Black people were slaves. Even though everything has changed since then, there is still a lot of people who are very much racist and the Blacks or Hispanics, they [meaning child welfare] will go in and maybe there are communication problems and they [meaning child welfare] will 
just take the kids. Whereas white people, you know, kinda [sic] get away with more I think. "

Concurring, an African American father added:

"Because if a White mom is on drugs or alcohol, they are going to let her keep her child but they are going to put her in a program until she's clean. So she can keep her child with her while she's in rehab or the twelve step program to try to correct what's wrong so the State can go back to the courts and say 'Okay, this is what this mom is doing. If it's an African American woman, a Native woman, we [meaning the child welfare system] are going to take the child out of the equation and put them in the foster care system. Now it's up to you to get yourself together. Get yourself in a program to get clean, come back to the courts to prove that you are a fit parent now and getting your life in order; and we'll see if we'll give you your child back. That's a double Standard as far as I'm concerned all the way down the line. Because if you're not going to take one, but are you are going to take the other, what makes that fair? Because you are helping this race over here but you're not helping this race."

A White mother suggests that perhaps individuals are judged based upon their race:

"I think, I think I consider judgmental is being a little bit mixed in with racism because you look at others and you may judge somebody without knowing them [sic]."

Another African American father concurs: 
"They [meaning the child welfare system] broke her [meaning the African American mother] and they [meaning the child welfare system] make it really hard and you're not going to get them back [sic]."

Participants further suggest that such treatment of families of color by the child welfare system as inadvertently contributing to the weakening and/or breakdown of family structure for families of color. Again, one African American father reiterates:

“...Don't take the child away from the mom. Let the child and mom stay together. Work with the structure [meaning the family structure] so they can stay together. Then you won't have so many Blacks and Native Americans caught up in the system."

Concurring, an African American father explains:

"He [referring to another participant] makes a good point because when I look at it overall too, I look at the structure [meaning the family structure], right? So if you look at the structure of Angle-Saxons, I hate to say this but in my opinion, they've got a lot of aunts and uncles and things. They've got nice houses and thousands of dollars [sic]. You don't have that in the community [meaning the African American community]. Black families don't have a lot of structure, anymore like what it used to be in the Black communities. We've [meaning African Americans] got a lot of single parents and they've got an uncle but he's not stable enough to take or watch the kids while she gets clean. So they [meaning child welfare] take the kids and put them in foster homes and they make it hard for her to be able to get them back. It hurts the families even more than disparities. That's why you see a lot of discouragement. The foundation is so little 
and the structure is so little in Black communities. It's maybe and I don't know what's happened... I think drugs have a lot to do with that and that's one of the reasons why the State's able to come in and take the kids. You've got people there because of the stigma. It makes it a little bit harder. The numbers are high. If they [meaning African American parents] give up, the first thing they are going to do is be like, I don't want to give my son or daughter to a family member, I'll just give them to the State. Let them take them."

A White mother commented:

"First of all, maybe the reason why there is a higher number of those cultures or races in the foster care system. ...Who's to say that that isn't what's keeping the number of White kids out of the eyes of the system as opposed to maybe a different culture. ....But maybe the numbers are higher because they [meaning African American parents] are willing to say I can't take care of these children so I need to let somebody else do that because I can't. I can't."

One White mother adds:

"You know, I'm not exactly sure why that [meaning racial disproportionality] is, because I've known more people that are Caucasian to give their kids away before any other culture and that's what I've witnessed...."

A White mother concurs:

"I just have seen a lot of Caucasian people be not very family oriented or don't value their family as much as they should. That's just my opinion."

\section{Summary}


Participants concurred that biases and inconsistent practices partially attributed to their experiences of difficulty when involved with the public and/or the child welfare system. Participants offered examples of what they perceived to be inequitable distribution of benefits. For example, such beliefs were substantiated by participants' description of inconsistent decision making surrounding eligibility benefits. Similarly, they felt that the program often administered competing goals for welfare recipients such as promoting educational pursuits and employment that jeopardized benefits eligibility. Securing employment was particularly viewed as contentious as this often yielded minimum wage salaries that were insufficient to sustain a household yet possibly compromise public welfare benefits. Participants further indicated that the public welfare system was punitive in their actions toward welfare recipients. This was noted as participants explained inadequate support services for families when transitioning out of the program. Participants' perspectives of bias and inconsistent practices extended to the child welfare program.

Specifically, racially motivated biases and practices were attributed to the existence of racial disproportionality within the child welfare system. This was particularly expressed when referencing investigation actions confirming allegations of abuse and/or neglect, removal and placement decisions. Participants also alluded to such practices as contributing to the disruption of African American families and possibly inadvertently partially attributing to the deterioration of African American families over recent decades. Such sentiments were expressed among half of the participants; African American $(n=5)$, Latino $(n=1)$, and White $(n=2)$ respectively. Some participants noted that perhaps the disproportionate investigations on families of color serve to avert 
attention from White families that could possibly require child welfare involvement. Other White participants felt that families of color to be more family oriented than Whites, somewhat questioning the excessive engagement of child welfare with families of color.

\section{Researcher's Positioning}

This body of work was initiated from personal and professional interest. I am an African American woman who grew up with humble means. Similar to the study participants' households, my family received welfare benefits. However, I was not fully aware of my family's economic circumstances until my adult years. Thus, during childhood, I never saw myself, my family, or my community as poor. While there were families who, like ours, were on welfare, there was no presence of child welfare in my community. There were households where children were being parented by someone other than their biological parent, but there was no presence of child welfare. The question I've asked myself is why? Why, considering the strong connection between poverty and child maltreatment, did the overrepresentation of children of color in the child welfare system seem not to exist during my childhood?

Beyond my personal childhood experiences as a former welfare recipient, I chose to pursue a social work career with my professional interest being predominantly focused within the area of child welfare. Thus, I have considerable knowledge, understanding, and work experience within the child welfare system. Several steps were taken to ensure that objectivity was maintained throughout the recruitment, data collection and data analysis processes. 
Efforts were made to help ensure my ability to remain close to the data while appropriately acknowledging my reactions to the data. During the focus group sessions, participants were made aware of my professional background and specifically my former position with DHS. None expressed concern and seemed to be at ease throughout the sessions. A debriefing occurred following each focus group session with the cofacilitator. Additionally, a reflective journal was kept throughout the focus group series. Each of these activities aided my ability to filter my reactions to the data as it was being collected. During the data analysis period I kept an analytic journal. This process helped in the management of the data as it unfolded. Following the data analysis, the results were shared with representatives from the focus groups to verify accurateness. An audit

trail was also done whereby the reflective journal, analytic journal, code book, clustering of themes and results were forwarded to another person to debrief and review. The reviewer has familiarity and experience with qualitative research. This final step, in addition to the member checking was done to ensure that the study results reflected the views of participants and achieved trustworthiness. Overall, I do not believe my personal and/or professional positions influenced the results of the study.

\section{CHAPTER 5}

\section{Discussion}

This study examined the role, function, and intersection of poverty and race on the risk for child maltreatment. Specifically, perspectives were drawn from economically disadvantaged families having received services from the former FSEU of DHS/SSP. Qualitative data was collected via focus group discussions allowing for the elevation of 
families voices with the intent of enhancing the research knowledge purely from their lived experiences.

This investigation aimed to explore: (1) the extent to which parents perceived their economic situation affecting their parenting capacity; (2) the extent to which parents perceived race as a factor to becoming involved with child welfare; (3) the extent to which parents perceived the intersection of poverty and race influencing child welfare involvement; and (4) which supports found valuable to alleviating challenges to their ability to adequately parent and prevent child welfare involvement. Attention was given to differences and/or similarities that potentially stemmed from participants' racial identity. The study participants included Black/African American ( $\mathrm{n}=7)$; Latino/Hispanic $(\mathrm{n}=1)$; mixed race $(\mathrm{n}=3)$; and White $(\mathrm{n}=4)$, respectively.

Each study aim is addressed below through a discussion of the study results detailing the primary themes and sub-themes in the order that they emerged from the data. In total there are three primary themes and seven sub-themes. The primary themes are (1) Financial Strain Creates Significant Strain; (2) Concern for Children; Dealing with the Systems: Public and Child Welfare. The sub-themes are (1) Single Parenting; (2) Race \& Racism; (3) Community Resources and Limited Funding; (4) Mental Health and Disabilities; (5) Fear of Child Welfare; (6) Biases and Inconsistencies; and (7) Racial Disproportionality. Throughout the discussion of themes and sub-themes relevance will be given to the current literature. While the study was not theory driven, the Theory of Poverty and Critical Race Theory (CRT) are also referenced as warranted. In addition, limitations of the study as well as potential implications for policy, practice and future research will also be addressed. Finally, the discussion closes with concluding thoughts. 


\section{Theme One: Financial Strain Creates Significant Strain}

The stark realities of being poor cannot be overstated (Edin \& Lein, 1997; Ghate \& Hazel, 2002; Pelton, 1989; Pelton, 2015; Pfeiffer, 2018; Russell et al., 2008; Seccombe, 1999; Strier, 2005). Daily life for the poor is extremely difficult as exemplified by the most dominant theme, Financial Strain Creates Significant Strain. All participants described struggling to budget such that their funds would cover their family's needs throughout a given month. They spoke, too, of the challenges of navigating limited community resources to adequately secure basic needs such as food and shelter. Regardless of race, gender, and age participants repeatedly addressed the relentless stress associated with managing their lives with meager financial means (Campbell et al., 2016; McLeigh \& Melton, 2019; Seccombe, 1999). Seccombe (1999) dispels the belief by many that public welfare recipients, especially single mothers, are lazy, incompetent, and aim to manipulate the system. Several participants described their circumstances as "it's hard." Chase and Walker (2012) explain that the use of the descriptive 'it's really hard' is not atypical for those who experience the economical adversities (p.742).

Consistent with the literature, participants explained that their daily lives as were complex; having to creatively plan and strategize, in order to minimally fulfill their family’s basic needs (Kalil, \& Ryan, 2010; Pandley et al., 2004; Seccombe, 1999). Concurring with the literature, several expressed this was a task that often proved to be overwhelming (Campbell et al., 2016; Kalil, \& Ryan, 2010; McIntyre et al., 2003). Some noted the resulting emotional turmoil brought on by additional challenges further complicating their lives, such as mental health issues. Almost all discussed feelings of 
shame, depression, and anger with having to constantly rely upon external supports to navigate life. Frustration and/or dismay were blatantly apparent as some participants visibly displayed their feelings through tears during the focus group dialogues. Participants, in spite of such feelings, also presented with some degree self pride. They disliked always having to seek and ask for help. Likewise it seemed that some participants were equally bothered with having to put on a façade that all was well in their lives. According to Chase and Walker (2012), the inability to express of shame and other such feelings gravely impacts poor families as they try to navigate life with some resemblance of pride and dignity. McIntyre et al. (2003) criticizes the literature for not giving ample attention to how the poor feels about their circumstances. According to McIntyre et al. (2003) it is equally as important to acknowledge the emotions of those living in poverty as their lived experiences.

Mixed with their emotions, participants expressed frustration about being judged because of their inability to fully provide for their families. Some harshly judged themselves accepting blame for their circumstances. This act aligns with the theory of individual poverty which explains that the circumstances of the poor are due to their own shortcomings, such as poor decision making and laziness. Participants' reactions further exemplify the acknowledgement by the literature that poverty impacts one's sense of dignity and self worth (Chase \& Walker, 2012; Davis \& Wainwright, 2005; KrumerNevo, 2016; Pelton, 1989; Seccombe, 1999).

The consensus across the literature is that those not personally impacted by impoverishment typically have views differing from those whose lives are shaped by poverty (McIntyre et al., 2003; Pelton, 1989; Pfeiffer, 2018; Russell et al., 2008; 
Seccombe, 1999; Strier, 2005). The general public, political figures and those public and private entities designated with servicing poor families underestimate what being poor truly entails (Pfeiffer, 2018; Seccombe, 1999; Strier, 2005). This degree of detachment may be partially attributed to residual views of worthy verses the unworthy that remain deeply embedded within American psyche.

Results from the study support the continuing influence of longstanding expectations and ongoing messaging in American society/culture stemming for the pull yourself up by the bootstraps beliefs (Bullock, 2008; Rosenbaum, 2018; Seccombe et al., 1998; Wilson, 2010). Participants, through expressions of feeling judged by others and self blame demonstrated their acknowledgement of such principles. Namely, as noted by Rosenbaum (2018), those individuals who are deemed as able-bodied and therefore capable, are supposed to adhere to being self reliant regardless of family background, socio economic status, race or ethnic. This belief aligns with the individual level of the theory of poverty. The general consensus being that the American dream is attainable with hard work (Bullock, 2008; Seccombe et al., 1998). Additionally individualism, which also serves as an intricate aspect of American values, further reflects participants' feelings of shame. Outside of not having enough money, the sober realities of single parenting; dealing with race and racism; insufficient community resources; and managing mental health issues emerged as a sub-theme adding to the pressures of living in poverty.

\section{Theme Two: Concern for Children}

The study sought to examine the extent to which parent's perceived their economic situation affecting their capacity to parent. Clearly poor parents struggle with providing material goods for their children and to some extent their basic needs. 
However, participants did not perceive this as impacting the value that they placed upon parenting and their ability to remain emotionally connected to their children. While the literature supports that poverty is an indicator for families possibly becoming involved with child welfare, participants did not speak of their financial circumstances as impacting their parenting capacity. They seemingly made a distinction between their inability to provide material means for their children and their expressions of love toward their children. For example, one mother spoke of feeling bad about not being buy things for her children but spoke passionately about the quality time she spent with her children such as cuddling and watching movies. Another mother spoke of feeling bad about not being able to take her children for outings such as the zoo but made time to do homework with her child via the telephone while they lived apart. A father spoke of the attention he gave to meeting his child's emotional needs and her personal interests during the time that they lived in a homeless shelter. All participants, regardless of race and gender, further described efforts to motivate and encourage their children to perform well in school as well as engage in activities of interests.

Some participants shared their efforts to protect their children from the scars of poverty through candid conversations with their children about their circumstances. For example, two White mothers, two African American mothers and one African American father referenced having such discussions with their children. One African American mother, contrarily, shared that she chose secrecy as a means to shelter her children. Regardless, actions such as these demonstrate participants' concern for their children as well as their intentions and active efforts to adequately parent. These examples somewhat support the suggestion by scholars that poverty does not necessarily cause neglect 
(Pelton, 1989; Roberts, 2000; Russell et al., 2008). Russell et al. (2008) points out that while the emotional and psychological effects of poverty have been unquestionably been acknowledged within the literature, "poverty is either dismissed or ignored" (p 93).

Scholars do, however, suggest that poverty should be distinguished from neglect in child welfare matters (Pelton, 1989; Roberts, 2000). Pelton (1989) further reminds that child welfare has not been properly equipped to address poverty related issues. Child Welfare often uses the term "capacity" in their assessment of parent's ability to care for and meet the needs of their children. Perhaps under the circumstances of economically disadvantaged families, perhaps any concrete needs that are compromised due to poverty be fully addressed to abate the potential negative effects that poverty may have upon their parenting capacity. Indeed, this aligns with the concerns of the early aforementioned White House conferences on child wellbeing.

The 1909 conference addressed the stark poverty many families faced and created financial supports to families. This conference further specifically established child welfare practice that denounces the removal of children from the care of their parents solely due to poverty. Yet, today there exist this strong connection between poverty and child neglect resulting in many families coming to the attention of child welfare. Furthermore, subsequent White House conferences promoted holistic views and approaches on achieving child wellbeing giving attention to the educational, recreational, emotional, physical, and mental state of children; included the voices of parents and youth; and became more inclusive addressing concerns for all children regardless of race. For example, the 1950 White House conference addressed concerns regarding the impact of Jim Crow practices and racism on African American children. In spite of this early and 
continued attention, poverty, as does the impact of racial biases illustrated by racial disproportionality, negatively impact family's potential involvement with the child welfare system. In addition, as important as it may be to fulfill concrete needs when servicing poor families, equally as critical is the full awareness and understanding by child welfare of the multiple complexities of poverty.

\section{Theme Three: Dealing with the Systems: Public Welfare and Child Welfare}

Public welfare policies over the decades have been generated from tenants of self reliance. The Social Security Act's initiation of ADC, TANF's predecessor, established the government's intent to support the economic needs of children. Unfortunately, seemingly, the values promoted by the individual theory of poverty; the structural theory of poverty; and public expectations of self reliance potentially conflict with the program goals. The public welfare system, while designated to support poor families inadvertently places families in juxtapose dilemmas adding to their hardships. For example, participants discussed frustrations similar to Rosenbaum (2018) with having to make conflicting choices such as taking the risk taking a low-wage job or perhaps further their education to improve their financial circumstances or remaining reliant upon the public welfare system. Participants noted feeling penalized. The political-economical structure theory of poverty explains that such situations illustrate how structural barriers pose limitations upon poor family's ability to rise out of poverty. In actuality, the trials of the poor in American society seem not to be fully appreciated. While explicitly spoken by some and indirectly by others, participants alluded to feelings of shame and some degree of disgrace by having to constantly seek assistance and sometimes being met with biases and inconsistencies. Participants further shared their thoughts regarding the child welfare 
system. However, these perspectives are addressed later in the subsections Fear of Child Welfare and Racial Disproportionality.

\section{Sub-Theme One: Single Parenting}

Most of the participants were single parents $(n=14)$ at the time of the study. Two of the three male participants and thirteen of the female participants indicated that they were single parents. Regardless of race, male and female participants alike noted that this further strained their ability to manage life. Research supports the added hardship placed upon single parents (Campbell et al., 2016; McIntyre et al., 2003; Seccombe, 1999; Seccombe et al., 1998). Russell et al. (2008) acknowledges the societal view that single parenting is a "personal choice," and an individual responsibility (p. 84). Again, these views align with the individual theory of poverty whereby the plight of the poor is of their own doing. Most often, the thought is that primarily poor females are typically parenting alone. However, while the literature supports the absences of fathers being particularly difficult for mothers it further acknowledges that fathers, too, comprise the population of single parents and (Kalil \& Ryan, 2010; Russell et al., 2008; Seccombe, 1998; Strier, 2005). Fathers of the study emphasized their plight being equally as challenging as that of single mothers. For example single fathers expressed that they, too, are faced with issues concerning housing, food and mental health needs. Additionally, single fathers pointed to blatant discrepancies in resources available to them compared to those for single mothers. One father spoke of utilizing a female private agency worker to advocate on his behalf as he felt his voice could not be heard. Although the research concerning poor single fathers is minimal, there is consensus that greater attention is warranted concerning the needs of poor single fathers (Goode, 2012; Strier, 2005). It is 
also worth noting that the single fathers participating were all men of color. Two of whom were parenting daughters, which potentially raises other unique challenges. Race and racism were acknowledged as creating additional challenges for some participants.

\section{Sub-Theme Two: Race \& Racism}

The topics of race and racism brought interesting responses. Two of the four White participants appeared to be either totally unaware and/or completely shocked that racism actually existed. Another White participant alluded to people being with others like themselves and suggested that some groups of people may be treated disparately based upon cultural differences that might set that group apart from the general population. However, she did not feel that she could speak on the subject of race or racism. One White participant, who indicated that her children were African American, spoke more candidly about race and racism. She admitted, however, that she did not become aware of racial issues and racism until the birth of her children. Thus, most of the White participants expressed that they did not feel that they were capable of discussing either race or racism. Hence, they were virtually silent on either matter. The literature supports this perceived ignorance is not uncommon particularly by poor working-class Whites when they are faced with considering that government programs have been established primarily for their benefit (Hattery \& Smith, 2007; Lui et al., 2006). Please recall, for example, that ADC was initially established to benefit poor White children and that concerns regarding the needs of people of color were virtually absent from the Social Security Act (Neubeck \& Cazenave, 2001; Seccombe, 1998).

It should be noted that while the co-facilitator of the focus groups was White, the lead facilitator was a person of color. This may have influenced the degree to which 
participants chose to speak on this subject. Again, the one White participant who chose to engage in discussion shared that she only gained insight to the realities of racism after entering into personal relationships with people of color and/or the birth of her mixedrace children. In other words, it appears that outside of those few personal encounters with people of color, Whites participants lived in some degree of isolation.

People of color, on the other hand, spoke with candor. There was a general acceptance concerning the challenges of race and/or racism and how either or both impacted their lives. Issues of race and/or racism were expressed as a natural part of their lives. This acknowledgement that racism exists and is fully interwoven in the fabric of American society coincides with the first tenant of CRT. It also further implicates the second tenant where race is viewed as a social construct intended for the separation of people into racial categories. The seemingly isolation of some White participants perhaps attests to this concept. Additionally, two of the White participants and those who identified as people of color, acknowledged the negative impact of race and racism whereby privilege exists for the benefit of Whites based upon an imposed racial hierarchy. Participants of color spoke, too, about the intersectionality of other elements of oppression such as class and gender as further exasperating their challenges with poverty. Again, each of these later sentiments aligns with CRT. For example, fathers talked about the impact of gender and race upon their ability to navigate resources for their families. The two African American fathers described experiencing a lack of available resources for them that they believed was due to their gender with most community resources being allocated for women. They each expressed feeling judged because of their gender and race when seeking assistance from community resources. The Latino father, too, 
expressed feeling that his race, due to negative societal stereotypes, hampered his ability to navigate life.

\section{Sub-Theme Three: Community Resources and Limited Funding}

While scholars over the decades acknowledge the necessity of ample public and private resources to facilitate the ability of poor families to adequately function economically, this remains today a major challenge (Kalil \& Ryan 2010; Larner, Stevenson \& Behrman, 1998; McLeigh et al., 2018; Pelton, 1998; Seccombe, 1999). The dilemma posed a major challenge for participants as several spoke about the shortages of community resources. Participants, males and females; people of color and Whites, mutually spoke of challenges such as securing adequate housing, utility assistance, and food. They explained having to know where resources were within the community, the extent to which the resources were actually available and how to access them for their respective families. The literature supports that this level of functioning is no small feat and potentially very draining on poor families (Russell et al, 2008; Seccombe, 1999; Seccombe et al., 1998). Such circumstances required tenacity and skill on their part, somewhat comparable to actually having a job. Larner, Stevenson, and Behrman (1998) acknowledged Oregon and Alabama attempt to address the issue of limited funding whereby the two States allowed non-restricted funds. Non-restriction allowed case workers to allocate funds as warranted in support of families with poverty related issues. Such practices somewhat respond to Pelton's (1998) criticism that child welfare's failure to address poverty related matters due to their inability to properly respond. Conceivably, greater attention to poverty concerns for the poor who become engaged with child welfare could potentially reduce the number of neglect related cases. Additionally, 
mental health, and disability issues posed further challenges for poor parents and/or their families.

\section{Sub-Theme Four: Mental Health and Disabilities}

Mental health and disabilities of either or both participants and their children was referenced throughout focus group discussions. Eleven of the fifteen participants shared that they and/or their children suffered with mental illness and/or some other form of disability. One White mother and one African American father each shared living themselves with a disability. Four participants mentioned that they are parenting children with diagnoses of autism, bi-polar, ADHD, and/or Oppositional Defiance Disorder. One mother shared that she suffered with anxiety. Three other mothers and one father indicated that they were diagnosed with depression. Some felt that their living in poverty was partly the cause of mental health challenges for their family as recognized by Goodman and colleagues (2012). Depression, for example, was particularly prevalent in the lives of several participants. Some admitted never experiencing deep depression until they fell into poverty or illness. One mother expressed believing that her daughter's mental illness was the result of the family becoming homeless. Comparable to the literature, participants discussed the added shame of mental illness to their already feeling disgraced by their economic situation (Chase \& Walker, 2012; Goodman et al., 2012). Several further expressed discomfort in sharing their mental health concerns with authorities of the public welfare and child welfare systems for fear of being judged incapable of parenting as noted by Chase and Walker (2012). Some noted other forms of disabilities as further complicating the lives of them and/or their children. One father shared how his disability made the challenges of poverty even greater. Thus, the 
additional strain brought on by mental health and/or other disabilities should not be overlooked or underestimated. Participants were especially concerned for the wellbeing of their children. Some discussed openly sharing their family's financial deficits with their children in an effort to abate any potential negative mental health and emotional issues.

\section{Sub-Theme Five: Fear of Child Welfare}

Ultimately, beyond the previously mentioned concerns that participants expressed about caring for their children, they discussed having looming worry of their family possibly being called to the attention of child welfare. Participants, some Whites and those identifying as people of color, were candid about their fear of child welfare. They talked about feeling powerless once involved with child welfare and being prejudged by child welfare regardless of the reasons for investigation. One White mother and one African American mother expressed, too, that their children also feared child welfare.

Other issues felt to influence negative interactions with child welfare included lack of trust with child welfare case workers and the system at large, race, racism, gender, and mental illness. Regardless of the race of the participant, the discussion of not trusting child welfare and being misunderstood due to mental health issues arose. Participants did not believe child welfare staff to fully understand the implications of mental health but felt criticized and penalized by child welfare when mental health presented in their lives. Goodman and colleagues (2012) support the need for helping professions to gain greater insight on how to best serve economically disadvantaged families who struggle with mental illness. 
All participants of color, males and females further expressed concerns regarding racial stereotypes and structural racism as elements possibly influencing perceptions of them as well as their parenting ability. Additionally, male participants felt that gender also biased interpretations of their parenting skills, treatment by workers and that fewer resources were available to them as fathers. Collectively, participants expressed greater trust dilemmas and relations in general with child welfare as opposed to private sector agencies. Ironically, many of the private agencies aiding families held contractual agreements with child welfare and to some extent acting on child welfare's behalf. This speaks to the need for better education and improved communication by the department with staff, contract providers and the families.

\section{Sub-Theme Six: Biases and Inconsistencies}

Some participants identified biases and inconsistencies existing within both the public and child welfare systems. Three White mothers, two of the African American mothers and the two African American fathers discussed discrepancies within the public welfare system. For example, public welfare was deemed to have fewer resources available for male recipients than for female. As previously mentioned, the public welfare agency was believed to enact conflicting policies positioning clients with the choice of remaining on welfare or actively pursuing educational opportunities to better their opportunities.

While the public welfare system is designated to offset financial struggles for low income families, several spoke to discrepancies in the amount of cash assistance and/or other benefits. Decisions seemingly varied from one worker to another and at times were felt to be subjective. For instance, participants' spoke of questioning decisions resulting 
in approval of differing monetary amounts for similar households. One father shared not understanding the denial of necessary housing vouchers to avoid homelessness for his family during a time when he felt the assistance was unquestionably warranted. The agency was further perceived to hold recipients as responsible for their own economic circumstances as asserted by the individual theory of poverty. To address such concerns, public welfare may consider an in-depth review of policy coupled with advanced training of staff. Both the policy analysis and staff training should include client participation as a means of advancing client voice.

Likewise, the child welfare system was thought to also hold biases and exhibit inconsistent practice. Participants, particularly those of color, expressed how racial biases and inconsistencies within the child welfare system contributed to racial disproportionality.

\section{Sub-Theme Seven: Racial Disproportionality}

Similar to the discussion of race and racism, participants of color offered more to the conversation than their White counterparts. Three of the White participants explained they lacked knowledge regarding racial disproportionality. Therefore, they felt illequipped to speak on the matter. One White participant, however, shared belief that perhaps the focus on families of color took attention away from White families who might warrant the attention of child welfare.

Participants of color expressed no discomfort speaking easily about the subject. Some of their thoughts suggested racial bias by the child welfare system when engaging with families of color, especially African American families. For example, they felt that child welfare workers were more likely to offer services that might possibly mitigate the 
need to remove and place a White child into foster care. Contrarily, they felt that families of color would most often have the child removed and paced into foster care. Some African American participants explained further their perception that routinely separating African American children from their parents as partially attributing to the breakdown African American family structure. Additionally, some African American participants expressed belief that the removal of African American children from their parents contributed to mental health issues such as depression for African American parents. This belief was especially concerning for African American mothers, such acts further attributed to them losing hope and feeling defeated.

The study supports other scholarly concerns implying child welfare's inability to properly distinguish between neglect and poverty related issues; and that they are ill equipped to address poverty (Pelton, 1998; Roberts, 2002). It further concurs with the premise of Krumer-Nevo (2018) calling for a new paradigm in social work practice regarding services to impoverished families that potentially strengthens linkages between theory and practice.

\section{Study Limitations}

The purpose of this study was to increase the input from economically disadvantaged families in the examination of the role, function and intersection of poverty and race, on the risk for child maltreatment. While the study met this intent, it is not without some limitations. The sample size totaled fifteen participants but only three of the participants were male thereby limiting the inclusion of father's perspectives. Furthermore, although many of the perspectives rendered are congruent with the 
literature, they may be limited to regional influences. Two of the African American mothers referenced the Northwest region being different in comparison to other parts of the country. One White mother and one African American mother spoke of how their experiences in the Northwest differed from areas of the South where they each had previously lived. Finally, due to participants being recruited from a specialized branch of public welfare services, their views may not necessarily be representative of the general population of public welfare recipients. That said, much of the information gained from the study aligns with the existing literature and offers thoughts for future policy, practice, and research.

\section{Implications for Future Policy}

Based upon study findings six concerns are noted as implications for future policy. The implications suggest focusing attention on: (1) single fathers, (2) prevention, (3) poverty awareness, (4) program collaborative, (5) historical trauma, and (6) policy review by community members.

The development of policies within the public welfare and child welfare systems specific to servicing the unique needs of single fathers is warranted. While there are many poor mothers who are parenting alone, there are also poor fathers who are single parents. The study highlights inadequacies of the public welfare and child welfare systems in addressing the needs of male single parent households. Single fathers of the study expressed frustration with the inability of public welfare and child welfare to properly address their family's needs. An example of limited service/treatment resources for fathers is with referrals for residential placements for drug/alcohol treatment. When referring single mothers for residential drug treatment services, it is reasonable practice to 
utilize facilities whereby children can remain in the care of their mother, avoiding separation of the family. Such treatment facilities are equally as important for single fathers, but typically are not as readily available. One female participant echoed the concerns of the single fathers sharing that her brother and his children were residing in her home due the lack of community resources and supports for single fathers. Single fathers of the study further expressed feelings of being judged because of their gender. While some single mothers in the study also expressed feelings of shame, frustration, and being judged such feelings are potentially amplified for single fathers. Each of the two single fathers of the study was parenting daughters. One father expressed gratitude towards a FSET worker who took the time to respectfully talk with him and his daughter concerning some of her gender specific needs.

Policy development directing child abuse/neglect prevention services through the public welfare system is also warranted. Poor families who are determined to be at risk for child welfare involvement or have already become involved with child welfare potentially benefit from specialized case planning within the public welfare system that goes beyond the typical array of services. Considering that many of the families who become involved with the child welfare system are either recipients of public welfare benefits or eligible for such benefits, it seems appropriate that child abuse/neglect prevention efforts be implemented by public welfare. Such actions potentially minimize the length of time that child welfare is involved with families or negate the need for child welfare intervention. However, the provision of child abuse/neglect prevention services is currently beyond the scope of traditional public welfare systems. 
The development of child welfare policies that require ongoing training and education regarding how to best service impoverished families who engage with the child welfare system is also needed. Often, when addressing the needs of the poor, the usual approach is to attend to the lack of tangible goods and finances. While addressing these areas is important, attention to the resulting feelings associated with poverty is also vital. Study participants spoke to the negative feelings they experienced because of their financial circumstances. Failure to acknowledge the full effects of poverty lessens the probability of fully understanding the multiple complexities faced by families. This is especially important when investigating allegations of neglect for families of color; inadvertently resulting in negatively impacting racial disproportionality. Roberts (2002) suggests that child welfare investigations of poor African American families often fail to distinguish between poverty and neglect. Furthermore, Poverty Aware Social Work Paradigm (PAP) as described by (Krumer-Nevo, 2018) supports the need for a new approach in servicing poor families. This new paradigm underpins the need to create policy guidelines that truly value the expertise learned from the lived experiences of poor families, particularly those of color.

Policy alignment that directs collaboration of the public welfare and child welfare programs when the two mutually serve poor families, especially those families of color. This study suggests that absent policies that promote poverty awareness, the current deficit model approach will continue the misunderstanding and misinterpretation of circumstances concerning the poor. Policies that propose joint efforts may help avoid conflicting and/or contradictory practices by public welfare and child welfare systems. 
This will help to abate confusion and misdirection of families dually involved with both systems.

The design and implementation of policies that require ongoing anti-racism training for the public welfare and child welfare systems is imperative. This is important and necessary to fully understand the significance of historical, as well as, intergenerational trauma associated with race and racism. Such policies potentially serve to mitigate any continuance of structural racism and biases that may be embedded within the public welfare and child welfare systems. Participants of color illustrated this need when describing their daily personal experiences with race and racism, but also with perceived biases when engaging with the public welfare and child welfare systems.

The development of policies directing the inclusion of community members from populations of color in the development and periodic review of policies could be useful in strengthening trust and relations with communities of color. This may help to minimize any inadvertent negative impact to families of color and their communities; and potentially avert mistrust of government systems historically embedded within communities of color, further deterring racial disproportionality within the child welfare system. The inclusion of community members in this manner should also require policies that support financial compensation to community members for their time and expertise.

\section{Implications for Future Practice}

The study results further imply five areas to be addressed in practice. The practice implications include: (1) focused attention on single fathers as prevention services; (2) poverty awareness; (3) specialized training for public and child welfare workers; (4) 
cross-training between public welfare and child welfare program areas; and (5) historical trauma.

Practice improvement strategies warrant attention when servicing poor fathers engaging with the public welfare and child welfare systems. The two African American fathers perceived gender biases based on how they felt treated and the limited number of resources available for fathers. In addition to inadequate resources, the study noted potential deficits in properly engaging with fathers. Effective client engagement is important in any case planning effort and perhaps requires gender specific awareness when working with single fathers. One single father shared that he felt his voice was minimized and that absent a female advocate his concerns would not be heard.

The development of ongoing trainings targeted at improving service delivery for single fathers, especially those of color, due to historical societal expectations of men as providers and protectors of the family may prove useful. When having to seek assistance male participants described being shamed, judged and further burdened by their inability to minimally provide for their children. Unaddressed, such feelings may impact the parenting capacity of fathers, exacerbate or lead to mental health issues, and ultimately negatively impact racial disproportionality within child welfare.

Specialized training for public welfare workers that goes beyond benefits determination when servicing poor families who are at risk for or become involved with child welfare. This potentially enhances practice areas regarding client assessment, client engagement, historical trauma, culturally sensitivity, community referrals etc. While no longer in operation, this specialized unit operated from a prevention lens that seemingly averted families from child welfare involvement and aided child welfare in servicing the 
poverty related issues for those families who had already come to their attention. Based upon study results, models such as FSET warrant consideration when working with economically disadvantaged families who are or may be at risk for child welfare involvement.

Specialized training is needed for public welfare and child welfare workers. The study results indicate the need for increased awareness, knowledge and skills when servicing families who live in poverty. Trainings specifically focused on increasing sensitivity to the feelings associated with living in poverty for the public welfare and child welfare systems. The study highlighted the negative impact of feelings such as shame and guilt potentially having a negative impact on the functioning capacity of poor parents as such emotions further exasperates poor parents' ability to navigate the multiple challenges affecting their lives. The study, therefore, supports the (PAP) model introduced by Krumer-Nevo (2018). PAP presents a standard of social work practice whereby practitioners are intricately involved in the ongoing adversities of public welfare recipients. The PAP model entails assisting families in the navigation of matters such as eviction notices, food shortages and other life challenges. This suggests, for example, that public welfare workers and child welfare workers coordinate benefits and other services such that resources are truly tailored to the client's needs.

Cross trainings and joint meeting between public welfare and child welfare to draw upon the expertise and experiences of staff from both program areas are also beneficial. This may potentially strengthen practice and help mitigate inconsistencies, biased practices, and potentially positively impact the overrepresentation of certain populations of color becoming involved with the child welfare system. Cross training 
Ongoing trainings are necessary for public welfare and child welfare addressing the impact of historical trauma. The histories of enslavement, attempted genocide, forced assimilation, marginalization, and ongoing discrimination for African Americans and American Indian/Alaska Natives respectively cannot be devalued or understated. Historical trauma has long lasting negative impact on these populations that extend from one generation to another. This is partially evidenced by the illness such as hypertension and heart ailments that are prevalent amongst African Americans. In addition, this history has resulted in deep seeded mistrust of government entities thereby posing further challenges in establishing trust and engagement when public welfare and child welfare attempt to service families of color.

\section{Implications for Future Research}

Results from the study designates seven areas if interests implicating the need for future research. Future research should consider: (1) further exploration regarding establishing better distinctions between poverty and neglect; (2) improved service capacity to meet address poverty needs; (3) increased awareness regarding needs of single fathers; (4) minimizing power imbalance; (5) elevation of parent voice; (6) impact of historical trauma; and (7) the relationship between gender and race. Such research is essential to guiding the aforementioned policy and practice implications.

Future research should address how to better distinguish between poverty and neglect. There is a failure to fully identify what neglect looks like when it relates to poverty. It seems apparent, based upon the results of this study, that parents make extraordinary efforts to not be neglectful of their children in spite of their economic circumstances. Therefore, it is potentially counterproductive and somewhat punitive to 
ignore the distinctions between poverty and neglect. Doing so, seemingly takes away from the arguably necessary independent focus upon addressing poverty (Pelton, 1999, 2015; Roberts, 2002). Likewise, when weighing the detrimental effects of poverty, it appears logical that the inability to properly care for children due to poverty related issues be isolated from acts of willful neglect (i.e., intentionally failing to care for children). Thus, this study concurs that poverty warrants its own attention has relevance (Pelton, 1999, 2015; Roberts, 2002). Furthermore, it has been a decade since the recommendation of Sedlak and colleagues (2010) for further research to examine risk factors such as socioeconomic status upon child maltreatment. Perhaps it is time that research revisits the inclusion of poverty related issues as neglect when examining child maltreatment.

Greater understanding is needed to better ascertain how to better prepare child welfare to service poor families, especially those of color. The study concurs with the concern of Pelton $(1999,2015)$ and Krumer-Nevo (2018) that child welfare professionals should be better equipped to address poverty related issues for families who are suspected of abuse and/or neglect. The study also concurs with Roberts (2002) that child welfare inaccurately distinguishes between poverty and neglect when conducting investigations of families of color, particularly African Americans.

Attention call for the need for increased awareness and understanding concerning the experiences of poor single fathers. Such research may increase understanding in how to best serve and provide equitable supports to single fathers. Fathers in this study believed they were at a disadvantage in amply meeting the needs of their children due to the lack of available resources. Fathers also expressed experiences of gender bias. While 
much attention has been given to the existence of racial bias within the child welfare system, future research might focus on gender biases.

The study further suggests greater examination of the relationship between gender and race. In addition to the challenges expressed by participants of color regarding race and racism, two of the three male participants describe experiencing gender biases. While this study certainly addressed the intersectionality of poverty and race, it raises the need to further understand the dynamics existing between gender and race.

It is essential that future studies focus on and/or deeply consider the imbalance of power between themselves and families. Participants discussed the negative impact of the power imbalance between themselves and public welfare and child welfare staff. Research that can better inform the academic training and subsequent professional supervision of social workers in this respect will serve to improve practice and advance the profession. In addition, there is a need to continue to allow opportunities for the elevation of parents' voices. Families of this study expressed appreciation and feeling of empowerment with having a forum to share their lived experiences. The close of each focus group discussion resulted in participants lingering to share additional thoughts. This further exemplifies the need, importance and value of such forums. Thus, the study aligns with principles of CRT promoting the voices of individuals, especially people of color. Exploration regarding the impact of historical trauma on service intervention outcomes for families of color may better prepare public welfare and child welfare workers. All participants of color candidly addressed their challenges in dealing with race, racism and the ongoing impact of historical trauma. Failure to acknowledge 
historical trauma by the public welfare and child welfare systems further exacerbates such issues, impeding client engagement, service intervention, and service outcomes.

\section{Conclusion}

This study sought to explore the role, function, intersection of poverty, and race upon child maltreatment. Operating from a phenomenological approach, information was gathered directly from economically disadvantaged families speaking from their firsthand lived experiences. Consideration was given to the variation in responses based upon the participant's racial identity.

Poverty as experienced by families poses a direct conflict with neglect as defined by the child welfare system. Neglect as described by study participants has less to do with their actions to care for and meet the needs if their children, and more to do with how neglect is defined by the child welfare system. When relating this distinction to matters concerning poor parents, especially those of color, devastating consequences are posed when interfacing with the child welfare system. Participants of the study were well aware of this as demonstrated by their constant fear of child welfare.

In spite of the latent anxiety stemming from their fear of child welfare, as well as the significant strains experienced due to poverty, poor parents exhibit acts of love that display the degree to which they are able to parent, (i.e., their parenting capacity). Thus, the study affirms previous research indicating that poor parents value parenting and care about the well-being of their children (Butler-Nevin, 1997; Seccombe, 1999). The response of one White mother and one African American father when asked how their financial circumstances impacted their parenting capacity, was that their circumstances was an implication of their economic situation but not an indication on their ability or 
desire to parent. Poor parents actively work toward the fulfillment of providing the basic needs of their children such as food, shelter and clothing not solely out of necessity, but because they love and care for their children. They further demonstrate protective parenting as shown by their efforts to shield their children from the negative effects of poverty; giving attention to their children's emotional and mental health. Actions such as seeking assistance, while experiencing feelings of shame, guilt and frustration, further assert poor parents efforts to remedy their circumstances. In addition, poor parents' efforts to pursue gainful employment are also to no avail in rectifying their circumstances partially due to low/insufficient wages and contradictory policies within the public welfare system. They seek housing, for example, but experience long wait periods did one African American father, due to shortages of resources.

Ultimately, the parents of this study did not describe themselves as neglectful in their parenting duties, but as parenting with a lack of financial means and other resources. In other words, they are poor parents, not neglectful parents. However, child welfare, based upon their definition of neglect views the circumstances of the poor as potentially neglectful. This paradox could be addressed partially by better describing when and how the lack of means results in willful acts of neglect.

This study concurs with Pelton $(1999,2015)$ that poverty requires independent examination that is separate and apart from neglect. This study further illuminates the conclusions of Pelton (1999; 2015), Roberts (2002) and Krumer-Nevo, 2018 that the dynamics of poverty warrants greater understanding by child welfare in order to adequately serve, engage and address the needs of poor families. Based upon the current structure and its explanation of neglect, how is child welfare an adequate solution for 
poor families? Results from this study suggest otherwise. Until child welfare adopts policies and practices aligned with theoretical premises such as that of PAP, it is woefully inappropriate to serve poor families. Albeit, well intentioned child welfare workers, the child welfare system cannot adequately resolve issues of poverty experienced by poor families due to the system's lack of understanding regarding the complexities and multiple dynamics of poverty. For example, the relationship between poverty and mental health, and/or the impact of feelings such as shame on poor parents.

In addition the failure to acknowledge through policies and practice, the impact of race on poor families of color in American society compromises child welfare's effectiveness when servicing poor families of color. Similar to the level of understanding regarding poverty, as suggested by Krumer-Nevo (2018), it is equally important that child welfare understand the present and cumulative impact of racism on poor individuals and families of color. This calls for an examination and understanding of the historical trauma experienced by African Americans and American Indian/Alaska Natives. Failure to do so potentially gravely impacts families, children, and communities of color as demonstrated by the prevalence of the overrepresentation of children of color within the child welfare system, (i.e., racial disproportionality).

The intersectionality of poverty and race, therefore, potentially negatively influences investigations, and perhaps other decision making points along the child welfare continuum, when interfacing with poor families of color. The result is that economic situations surrounding these families dictate determinations of neglect rather than "situational poverty." Poverty can be resolved. 
Another characteristic impacting the lives of some participants beyond poverty was gender related. Fathers, all of whom were men of color, expressed experiencing discrepancy in treatment compared to their female counterparts. All fathers conveyed the intersection of race and poverty uniquely impacting their experiences seemingly due partially to societal views held about men of color. In addition, they especially felt that insufficient resources were available to accommodate their needs and that most were tailored to single female headed households. Although fathers expressed concern about the lack of available resources, they appreciated efforts made by the public welfare agency to accommodate their needs.

All participants acknowledged the efforts of public welfare to assist and support their needs. Likewise, they especially valued the assistance received via various community resources. Interestingly, while many of the community resources held contractual agreements with DHS, families did not seem to draw connections between the state agency and the private sector. When discussing what supports they found to be most helpful in supporting them and preventing child welfare involvement, participants credited the assistance they received from the community resources.

Finally, it is worth noting the value of soliciting the perspectives of economically disadvantaged families. All participants expressed appreciation for having the opportunity to share their respective views. They were thankful to have a platform from which to speak. Many expressed hope that their stories could possibly effect systemic changes to better the lives of poor families and their children. 


\section{References}

Alpert, L.T. (2005). Research review: Parent's service experience—a missing element in research on foster care case outcomes. Child and Family Social Work, 10(4), 361366.

Alpert, L.T., \& Britner, P.A. (2009). Measuring parent engagement in foster care. Social Work Research, 33(3), 135-145.

Anderson, S. G. (2001). Reports from welfare reform. Welfare recipients' views about caseworker performance: Lessons for developing TANF case management practices. Families in Society: The Journal of Contemporary Human Services, 82(2), 165-174.

Annie E. Casey Foundation. (2019). 2019 kids count data book. State trends in child well-being. Retrieved from: https://www.aecf.org/resources/2015-kids-countdata-book.

Annie E. Casey Foundation. (2019). 2019 kids count data book. State trends in child well-being. Retrieved from: https://www.aecf.org/resources/2019-kids-count$\underline{\text { data- }}$ book/?msclkid=aa8cef7d580514a40653b1f025e480bb\&utm_source=bing\&utm_ medium =cpc\&utm_campaign=2019\%20Data\%20Book\&utm_term=kids\%20coun t\%20data\%20center\&utm_content=2019\%20Data\%20Book\%20\%20Kids\%20Count\%20keywords.

Annie E. Casey Foundation. (2019). 2019 kids count data center. Child population by race in the United States. Retrieved from: https://datacenter.kidscount.org/data/tables/103-child-population-by- 
race\#detailed/1/any/false/37,871,870,573,869,36,868,867,133,38/68,69,67,12,70, $\underline{66,71,72 / 423,424}$.

Ards, S. D., Myers, S. L., Malkis, A., Sugrue, E., \& Zhou, L. (2003). Racial disproportionality in reported and substantiated child abuse and neglect: An examination of systemic bias. Children and Youth Services Review, 25(5/6), 375392.

Arowolo, D. (2010). The effects of western civilization and culture on Africa. Afro Asian Journal of Social Sciences 1(1).

Ashton, C. M., Haidet, P., Paterniti, D. A., Collins, T. C., Gordon, H. S., O’Malley, K., Petersen, L. A., Sharf, B. F., Suarez-Almazor, M. E., Wray, N. P., Street, R. L. (2003). Racial and ethnic disparities in the use of health services. Bias, preferences, or poor communication? Journal of General Internal Medicine, 18, 146-152. Retrieved from: https://www.ncbi.nlm.nih.gov/pmc/articles/PMC1494820/pdf/jgi_20532.pdf.

Atwater, R. M., Greenburg, M. D., Muckenfuss, R. S., Patterson, R. S., Porterfield, J. D., \& Rosen, G. (1950). The White House conference on children and youth. American Journal of Public health and the Nation's Health, 40(11), 1437-1439.

Banerjee, M. (2002). Voicing realities and recommending reform in PRWORA. Social Work, 47(3), 315-328.

Barth, R. (2005). Child welfare and race: Models of disproportionality. In D. Derezotes (Ed.), Race matters in child welfare. The overrepresentation of African American children in the system (pp. 25 - 46). Washington. D.C.: Child Welfare League of America. 
Battalora, J. (2013) Birth of a White nation. The invention of White people and its relevance today. Houston, Texas: Strategic Book Publishing and Rights Co.

Bartholet, E. (2009). The racial disproportionality movement in child welfare: False facts and dangerous directions. Arizona Law Review, 51(4), 871-932.

Bartholet, E., Wulczn, F., Barth, R. P., \& Lederman, C. (2011). Race and Child Welfare Chicago: Chapin Hall at the University of Chicago. Retrieved from: https://www.chapinhall.org/sites/default/files/publications/06_27_11_Issue\%20Br ief_F.pdf.

Bates, L., Curry-Stevens, A., \& Coalition of Communities of Color. (2014). The AfricanAmerican community in Multnomah County: An unsettling profile. Portland, Oregon: Portland State University.

Baumann, D. J., Dalgleish, L., Fluke, J., \& Kern, H. (2011). The decision-making ecology. Washington, DC: American Humane Association. Retrievedfrom: https://www.publicpolicy.com/upload/pdfs/Juvenile\%20Justice\%20documents/Ra ce\%20Equity\%20Coalition/Decision_Making_Ecology.pdf.

Beimers, D., \& Coulton, C. J. (2011). Do employment and type of exit influence child maltreatment among families leaving temporary assistance for needy families? Children and Youth Services Review, 33, 1112-1119.

Billingsley A., \& Giovannoni, J. M. (1972). Children of the storm. Black children and American child welfare. New York Chicago, San Francisco, Atlanta: Harcourt Brace Jovanovich, Inc.

Boyatzis, R. (1998). Transforming qualitative information: Thematic analysis and code development. Thousand Oaks, California: Sage Publications Inc. 
Boyd, R. (2014). African American disproportionality and disparity in child welfare: Toward a comprehensive conceptual framework. Children and Youth Services Review, 37, 15 - 27.

Bradbury, D. E. (1962). Five decades of action for children. A history of the Children's Bureau U. S. Department of Health, Education and Welfare. Social Security Administration, Children's Bureau.

Bradshaw, T. (2007). Theories of poverty and anti-poverty programs in community development. Community Development, 38(1), 7-25.

Breckinridge, S. P. (1940). Government's role in child welfare. The Annals of the American Academy of Political and Social Science, Nov, 42-50.

Bremmer, R. H. (1970). Children and youth in America. A documentary history. Volume I: 1600 - 1865. Cambridge, Massachusetts: Harvard University Press.

Brooks-Gunn, J., Klebanov, P., Liaw, F., \& Duncan, G. (1995). Toward an understanding of the effects of poverty upon children. In Fitzgerald, H. E., Lester, B. M., \& Zuckerman, B. (Eds.), Children of Poverty. Research, Health and Policy Issues, (pp. 3-1). New York, New York: Garland Publishing, Inc.

Bullock, H. E. (2008). Justifying inequality: A social psychological analysis of beliefs about poverty and the poor. In Lin, A. C. \& Harris, D. R. (Eds.), The Colors of Poverty, (pp. 52-72). New York, New York: Russell Sage Foundation.

Butler, M. (2012). "There" is home: A case study of the colored orphan asylum in New York City. Retrieved from UMI Dissertation Publishing.

Butler, S. S. \& Nevin, M. K. (1997). Welfare mothers speak. Journal of Poverty, 1(2), $25-61$. 
Butterfield, A. K., Scherrer, J. L., \& Olcon, K. (2017). Addressing poverty and child welfare: The integrated community development and child welfare model of practice. International Social Work, 60(2), 321-335.

Cahn, K. \& Harris, M. (2005). Where have all the children gone? A review of the literature on factors contributing to disproportionality: Five key child welfare decision points. Protecting Children, 20(1), 4-14.

Carstens, C.C., Folks, H., \& Murphy, J. P. (1933). Section IV - The handicapped: Prevention, maintenance, protection. Committee on socially handicapped Dependency and neglect. Dependency and neglected children. Report of the committee on socially handicapped - Dependency and neglect. The White House conference on child health and protection. D. New York Appleton - Century Company Incorporated. Retrieved from: http://babel.hathitrust.org/cgi/pt?id=mdp.39015009499107;view=1up;seq=344.

Cause, A., Miller, K., \& Cahn, K. (2014). Where are our voices in the child welfare racial disproportionality discourse? : Elevating parents' independent voice. [Unpublished manuscript].

Chase, E., \& Walker, R. (2012). The co-construction of shame in the context of poverty: Beyond a threat to social bond. Sociology, 47(4), 739- 754.

Chibnall, S., Dutch, N.M., Jones-Harden, B., Brown, A., Gourdine, R., Smith, J., Boone, A., \& Snyder, S. (2003). Children of color in the child welfare system: Perspectives from the child welfare community. Washington, DC: U.S. Department of Health and Human Services, Children's Bureau. Retrieved from: http://www.childwelfare.gov/pubs/otherpubs/children/children.pdf. 
Child Trends Data Bank. (2016). Children in poverty. Indicators of child and youth wellbeing. Retrieved from: https://www.childtrends.org/wpcontent/uploads/2016/12/04_Poverty.pdf.

Child Trends Data Bank, (2019) Children in poverty. Key facts about child poverty. Retrieved from: https://www.childtrends.org/indicators/children-in-poverty. Child Welfare Information Gateway. (2011). About CAPTA: A legislative history. Washington, DC: U.S. Department of Health and Human Services, Children's Bureau. Retrieved from: https://www.childwelfare.gov/pubPDFs/about.pdf.

Child Welfare Information Gateway. (2013). What is child abuse and neglect? Recognizing the signs and symptoms. Washington, DC: U.S. Department of Health and Human Services, Children's Bureau. Retrieved from: https://www.childwelfare.gov/pubPDFs/whatiscan.pdf.

Child Welfare Information Gateway. (2016). Racial disproportionality and disparity in child welfare. Washington, DC: U.S. Department of Health and Human Services, Children's Bureau. Retrieved from: file:///G:/Dissertation/RacDisCWArticles/racial_disproportionality(2016)CW-Info-Gateway.pdf.

Children's Bureau. (2019). The AFCARS report. Retrieved from: https://www.acf.hhs.gov/sites/default/files/cb/afcarsreport26.pdf.

Children's Bureau, U. S. Department of Health, Education, and Welfare Social and Rehabilitation Services. (1967). The story of the White House conferences on children and youth.

Children's Defense Fund. (2015). Ending child poverty now. Retrieved from: http://www.cdfca.org/library/publications/2016/ending-child-poverty-now.pdf. 
Children's Defense Fund. (2017). The state of America's children 2017. Retrieved from: https://deaconess.org/sites/default/files/files/CDF\%202017-soac.pdf.

Children's Defense Fund. (2019). Ending child poverty now. Retrieved from: https://www.childrensdefense.org/wp-content/uploads/2019/04/Ending-ChildPoverty-2019.pdf.

Children's Defense Fund. (2020). The state of America's children 2020. Retrieved from: https://www.childrensdefense.org/policy/resources/soac-2020-introduction.

Chudacoff, H. P. (2007). Children at play. An American history. Retrieved from http://www.nytimes.com/packages/pdf/books/ChudacoffChapter1.pdf.

Constance-Huggins, M. (2012). Critical race theory in social work education: A framework for addressing racial disparities. Critical Social Work, 13(2), 2-6.

Cook, J. F. (1995). A history of placing - out: The orphan trains. Child Welfare, LXXIV(1), 181- 197.

Coulton, C. J., Korbin, J. E., \& Su, M. (1999). Neighborhoods and child maltreatment: A multi-level study. Child Abuse \& Neglect, 23(11), 1019-1040.

Coulton, C.J., Korbin, J. E., Su, M., \& Chow, J. (1995). Community level factors and child maltreatment. Child Development, 66(5), 1262-1276.

Courtney, M. E. (1994). Factors associated with the reunification of foster children with families. Social Service Review, 68(1), 81-108.

Courtney, M. E. (1995). Reentry to foster care of children returned to their families. Social Service Review, 69(2), 226-241. 
Courtney, M. E., Barth, R. P., Berrick. J. D., Brooks, D. Needell, B., \& Park, L. (1996.) Race and child welfare services: Past research and future directions. Child Welfare 75(2), 99-137.

Crawford, S. (1992). The slave family: A view from slave narratives. Retrieved from: http://www.nber.org/Chapters/c6967.pdf.

Creswell, J. W. (2007) Qualitative inquiry \& research designs: Choosing among five approaches. Thousand Oaks, California: Sage Publications Inc.

Cross, T. (2008). Disproportionality in child welfare. Child Welfare, 87(2), 11-20.

Cross, T. (2011). A mission not impossible. Understanding and reducing disparities and disproportionality. National Indian Child Welfare Association. 2011 System of Care Community Training. Tribal and Urban Systems of Care Grantee Meeting. Retrieved from: http://www.nicwa.org/Indian_Child_Welfare_Act/documents/DisparitiesinNative ChildWelfareNICWA2011CompatibilityMode_000.pdf.

Curry, S., \& Abrams, L. S. (2015). They lay down the foundation and then the leave room for us to build the house: A visual qualitative exploration of young adults experiences of transitional housing. Journal of the Society for Social Work Research, 6(1), 145-172.

Damaske, S., Bratter, J. L., \& Frech, A. (2017). Single mother families and employment, race, and poverty in changing economic times. Social Science Review, 62, 120133.

Danziger, S., \& Danziger, S. (1995). Child poverty. Public policy and welfare reform. Children and Youth Services Review, 17(1/2), 1-10. 
Davis, K. E., \& Iron Cloud-Two Dogs, E. (2004). Oppression of indigenous tribal populations and Africans in America. In K. Davis \& T. Bent-Goodley (Eds.), The Color of Social Policy (pp. 3-20). Washington, D.C.: Council on Social Work Education.

Davis, K. E., Kim, E., \& Romero, J. (2004). The color of social policy: Mexicans, Chinese and Japanese in America. In K. Davis \& T. Bent-Goodley (Eds.), The Color of Social Policy (pp. 21-36). Washington, D.C.: Council on Social Work Education.

Day, P. J. (2000). A new history of social welfare. ( ${ }^{\text {rd }}$ Edition). Boston, Massachusetts: Allyn and Bacon.

Derezotes, D. M., Poertner, J., \& Testa, M. F. (2005). The overrepresentation of African American children in the system. Race matters in child welfare. (D.M. Derezotes, J. Poertner \& M. F. Testa, Eds.). Washington, D.C.: Child Welfare League of America.

Dettlaff, A.J., \& Rycraft, J.R. (2008). Deconstructing disproportionality: Views from multiple stakeholders. Child Welfare, 87(2), 37-38.

Dettlaff, A.J., Rivaux, S.L, Baumann, D.J, Fluke, J.D., Rycraft, J.R., \& James, J. (2011). Disentangling substantiation: The influence of race, income, and risk on substantiation decision in child welfare. Children and Youth Services Review, 33(9), 1630-1637.

Donalek, J. G. (2004). Demystifying nursing research. Phenomenology as a qualitative research method. Urologic Nursing, 24(6), 516-517. 
Donnelly, A. G. (2005). The context of child welfare law. America's children. In M. Ventrell \& D. N. Duquette (Eds.), Child welfare law and practice. Representing children, parents and State agencies in abuse, neglect and dependency cases (pp. 1-13). Denver, Colorado: Bradford Publishing Company.

Downs, S. W., Moore, E., McFadden, E. J., Michaud, S. M., \& Costin, L. B. (2004). Child welfare and family services. Policies and practice. Boston, Massachusetts.: Pearson Education, Inc.

Drake, B., Lee, S. M., \& Johnson-Reid, M. (2009). Race and child maltreatment reporting: Are blacks overrepresented? Children and Youth Services Review, $31(4), 309-316$.

Drake, B., \& Jonson-Reid, M. (2013). Poverty and child maltreatment. In J. Korbin, \& R. D. Krugman (Eds.), Handbook of child maltreatment. Vol. 2,(pp. 113-148). New York, New York: Springer.

Dumbrill, G.C. (2006). Parental experience of child protection intervention: A qualitative study. Child Abuse \& Neglect, 30(1), 27-37.

Duarte, C. S., \& Summers, A. (2012). A three-pronged approach to addressing racial disproportionality and disparities in child welfare: The Santa Clara County example of leadership, collaboration, and data-driven decisions. Child Adolescence Social Work Journal, 30, 1-19.

Duncan, G. J., Magnuson, K., \& Votruba-Drzal, E. (2017). Moving beyond correlations in assessing the consequences of poverty. Annual Review of Psychology, 68, 413434.

Duran, E. (nd). Return from the black world [Unpublished manuscript]. 
Eberhardt, J. L., Davies, P. G., Purdie-Vaughns, V. J., \& Johnson, S. L. (2006). Looking deathworthy: Perceived stereotypicality of Black defendents predicts capitalsentencing outcomes. Psychological Science, 17(5), 383 - 386.

Egede, L. E. (2006). Race, ethnicity, culture, and disparities in health care. Journal of General Internal Medicine, 21(6), 667-669. Retrieved from: https://www.ncbi.nlm.nih.gov/pmc/articles/PMC1924616/pdf/jgi0021-0667.pdf.

Eskin, M., \& Kravitz, M. (1980). Child abuse and neglect. A literature review and selected bibliography. National Criminal Justice Reference Service. U. S. Department of Justice. National Institute of Justice.

Evans-Campbell, T. (2008). Perceptions of child neglect among urban American Indian/Alaska Native parents. Child Welfare, 87(3), 115-142.

Farrell, A.F., Lujan, M. L., Britner, P.A., Randall, K.G., \& Goodrich, S.A. (2012). I am part of every decision: Client perceptions of engagement within a supportive housing child welfare program. Child and Family Social Work, 17(2), 254-264.

Fargas-Malet, M., McSherry, D., Larkin, E. Kelly, G., Robinson. C., \& Schuboltz, D. (2010). Young children returning home from care: The birth parent's perspective. Child and Family Social Work, 15(1), 77 - 86.

Family and Children's Services Division. (1995). Orphanages: An historical overview. A discussion of the role of orphanages in child welfare policy. Minnesota Department of Human Services.

Federal Poverty Level. (2019). Income chart. Contiguous 48 states and D.C. Retrieved from: file:///E:/Lexar/2019-Federal-Poverty-Level-Chart-in-all-states.pdf. 
Fields, B. J. (1990). Slavery, race, and ideology in the United States of America. New Left Review, 95-118. Retrieved from:

http://t.studythepast.com/4333_spring $12 /$ materials/fields $\% 20$ slavery $\% 20$ race $\% 20$ and\%20ideology.pdf.

Finlay, L. (2008). A dance between the reduction and reflexivity: Explicating the "phenomelogical psychological attitude." Journal of Phenomenological Psychology, 39(1), 1-32.

First Focus on Children. (2018). A snapshot of children living in poverty: 2017.

Retrieved from:

https://irstfocus.org/wp-content/uploads/2018/09/Children-Living-in-PovertyFact-Sheet-Sep-2018.pdf.

First Focus on Children. (2019). A snapshot of children living in poverty: 2018.

Retrieved from: https://firstfocus.org/wp-content/uploads/2019/10/FF_2018Snapshot-of-Children-in-Poverty.pdf

First Focus on Children, (2019). Children's budget 2019. Retrieved from: https://firstfocus.org/resources/report/childrens-budget-2019

First Focus on Children, (2019). First focus on children report: Child poverty remains high while federal spending on children declines. Retrieved from: https://www.chn.org/voices/first-focus-report-child-poverty-remains-high-whilefederal-spending-on-children-declines/

First Focus on Children, (2019). We know we can cut child poverty in half, so why aren't we? Retrieved from: https://firstfocus.org/blog/we-know-we-can-cut-childpoverty-in-half-so-why-arent-we. 
Flick, U. (2006). An introduction to qualitative research. Thousand Oaks, California: Sage Publications.

Fluke, J., Harden, B. J., Jenkins, M., \& Ruehrdanz, A. (2010). Research synthesis on child welfare disproportionality and disparities. Retrieved from: http://www.cssp.org/publications/child-welfare/alliance/Disparities-andDisproportionality-in-Child-Welfare_An-Analysis-of-the-Research-December2011.pdf.

Folks, H. (1900). The care of destitute, neglected, and delinquent children. Charleston, South Carolina: BiblioBazaar Reproduction Series.

Folks, H. (1940). Four milestones of progress. The Annals of the American Academy of Political and Social Science, Nov, 12-17.

Font, S. A., Berger, L. M., \& Slack, K. S. (2012). Examining racial disproportionality in child protective services case decisions. Children and Youth Services Review, 34, 2188-2200.

Frame, L. (1999). Suitable homes revisited: An historical look at child protection and welfare reform. Children and Youth Services Review, 21(9/10), 719-754.

Frame, L., \& Berrick, J. D. (2003). The effects of welfare reform on families involved with public child welfare services: Results from a qualitative study. Children and Youth Services Review, 25,113-138.

Franklin, J. H. (1970). Public welfare in the south during the reconstruction era, 1864 80. Social Service Review, 44, 379-92.

Gadsden,V. L. (1995). Literacy and poverty: Intergenerational issues within African American families. In H. E. Fitzgerald, B. M. Lester, \& B. Zuckerman (Eds.), 
Toward an understanding of the effects of poverty upon children. Children of Poverty. Research, Health and Policy Issues (pp. 85-124). New York, New York: Garland Publishing, Inc.

Gans, H. J. (2011). State of the discipline. The Moynihan report and its aftermaths. A critical analysis. Du Bois Review, 8(2), 311-127.

Garner, T. I., Gudrais, M., \& Short, K. S. (2015). Consistency in supplemental poverty measurement: Adding imputed in-kind benefits to thresholds and impact on poverty rates for the United States. Government Statistics Section. Retrieved from: https://www.bls.gov/osmr/pdf/st150120.pdf.

Glasser, M.A.(1950). Fact finding for the White House conference on children and youth. Social Security Bulletin, 13(11), 15-16.

Goode, J. (2012). Brothers are doing it for themselves? Men experiencing getting in and getting out of debt. The Journal of Socio-Economics, 41, 327 - 335.

Goodman, L. A., Pugach, M., Skolnik, A., \& Smith, L. (2013). Poverty and mental health practice: Within and beyond the 50-minute hour. Journal of Clinical Psychology, 69(2), $182-190$.

Grahn-Farley, M. (2011). The U. N. convention on the rights of child and the forgotten history of the White House children's conferences, 1909-1970. Transitional Law \& Contemporary Problems, 20, 307-376.

Green, D., Belanger, R., McRoy, R., \& Bullard, L. (2011). Challenges of racial disproportionality in child welfare. (D. Green, K. Belanger, R. McRoy, \& L. Bullard, Eds.). Washington, D. C.: Child Welfare League of America. 
Gustavsson, N. S., \& Segal, E. A. (1994). Critical issues in child welfare. Thousand Oaks, California: Sage Publications Inc.

Hacsi, T. (1995). From indenture to family foster care: A brief history of child placing. Child Welfare, LXXIV(1), 163-180.

Haight, W. L., Black, J. E., Mangelsdorf, S., Giorgio, G., Tata, L., Schoppe, S. J., \& Szewezyk, M. (2002). Making visits better: The perspectives of parents, foster parents and child welfare workers. Child Welfare, 81(2), 173-202.

Harris, M. S., \& Hackett, W. (2008). Decision points in child welfares: An action research model to address disproportionality. Children and Youth Services Review, 30(2), 199-215.

Hattery, A. J., \& Smith, E. (2007). African American families. Thousand Oaks, California.: Sage Publications Inc.

Health Publications Institute. (1951). Mid-century White House conference on children and youth 1950. A healthy personality for every child: A digest of the fact-finding report of the mid-century White House conference on children and youth.

Herring, D. (2001). The Puritan concept of parenting and childrearing: An historical inquiry. Master's Thesis, Gordon-Conwell Theological Seminary. Retrieved from: http://www.davesexegesis.com/wp/wpcontent/uploads/2006/07/Puritan\%20Parenting.pdf

Hill, R. (2006). Synthesis of research on disproportionality in child welfare: An update. Casey-CSSP Alliance for Racial Equity in the Child Welfare System. Retrieved from: http://www.cssp.org/reform/child-welfare/other-resources/synthesis-of$\underline{\text { research-on-disproportionality-robert-hill.pdf. }}$ 
Hill, R. B. (2010). Research recommendations. In J. Fluke, B. J. Harden, M. Jenkins, \& A. Ruehrdanz (Eds.), Research synthesis on child welfare disproportionality and disparities (pp. 103-112). Retrieved from:

http://www.cssp.org/publications/child-welfare/alliance/Disparities-andDisproportionality-in-Child-Welfare_An-Analysis-of-the-Research-December2011.pdf.

Hirshberg, D., \& Sharp, S. (2005). Thirty years later: The long-term effect of boarding schools on Alaska Natives and their communities. Retrieved from: http://iser.uaa.alaska.edu/Publications/boardingschoolfinal.pdf.

Holt, M. I. (2010). Children as topic no. 1: White House conferences focused on youth and societal changes in postwar America. Prologue Quarterly of the National Archives and Records Administration, 42/2, 18-26.

Homan, P., Valentino, L., \& Weed, E. (2017). Being and becoming poor: How culture schemas shape beliefs about poverty. Social Forces, 95(3), 1023-1048.

Horowitz, B. \& Wolock, I. (1981). Material deprivation, child maltreatment and agency interventions among poor families. In L. Pelton (Ed.), The social context of child abuse and neglect, New York, New York: Human Sciences Press. (pp. 137-184).

Howze, K. A. (2005). Cultural context in abuse and neglect practice: Tips for attorneys. Child welfare law and practice. Representing children, parents, and state agencies in abuse, neglect, and dependency cases. In M. Ventrell \& D. N. Duquette (Eds.), Child welfare law and practice. Representing children, parents and state agencies in abuse, neglect, and dependency cases (pp. 95-111). Denver, Colorado: Bradford Publishing Company. 
Iceland, J. (2013). Poverty in America. A handbook. Berkley and Los Angeles, California: University of California Press.

Igbion, B. O. (2011). Colonialism and African cultural values. African Journal of History and Culture, 3(6), $96-103$.

Jambor, H. (1958). Theodore Dreiser, the "Delineator" Magazine and dependent children: A background note on the calling of the 1909 White House Conference. Social Service Review, 32(1), 33-40.

James, J., Green, D., Rodriguez, C., \& Fong, R. (2008). Addressing disproportionality through undoing racism, leadership development and community engagement. Child Welfare, 87(2), 279-296.

Jiang, Y., Ekono, M., \& Skinner, C. (2016) Basic facts about low-income children. Children under 18 years, 2014 fact sheet. National Center for Children in Poverty. Retrieved from: http://www.nccp.org/publications/pdf/text_1100.pdf.

Jindani, S. G., \& Murdock, V. (2009). Toward client-centered service: Asking clients for their views of TANF, food stamps, child care, and Medicaid services. Journal of Social Service Research, 35, 364-379.

Jivanjee, P. (1999). Parent perspectives of family involvement in therapeutic foster care. Journal of Child and Family Studies, 8(4), 329-341.

Johnson-Motoyama, M., Moore, T. D., Damman, J. L., \& Rudlang-Perman, K. (2018). Using administrative data to monitor racial/ethnic disparities and disproportionality within child welfare agencies: Process and preliminary outcomes. Journal of Public Child Welfare, 12(1), 23 - 42. 
Jones, M. B. (1993). Decline of the American orphanage. Social Service Review, 67(3), $459-480$.

Kamberelis, G., \& Dimitriadis, G. (2005). Focus groups: Strategic articulations of pedagogy, politics and inquiry. In N. K. Denzin \& Y. S. Lincoln (Eds.), The Sage handbook of qualitative research (pp. 887-907). Thousand Oaks, California: Sage Publications Inc.

Kang, N. (2009). Puritanism and its impact upon American values. Review of European Studies, 1(2), 148-151. Retrieved from: www.ccsenet.org/journal.html.

Kapp, S.A., \& Vela, R. H. (2004).The unheard client: Assessing the satisfaction of parents of children in foster care. Child and Family Social Work, 9(2), 197-206.

Katola, M. T. (2014). Incorporation of traditional African cultural values in the formal education system for development, peace building, and good governance. European Journal of Research in Social Sciences, 2(3), 31-39.

Kim, H., \& Drake, B. (2017). Duration in poverty-related programs and number of child maltreatment reports: A multilevel negative binomial study. Child Maltreatment, $22(1), 14-23$.

Klevins, J. Barnett, S. B., Florence, C. Moore, D. (2015). Exploring policies for the reduction of child physical abuse and neglect. Child Abuse \& Neglect, 40, $1-11$.

Krumer-Nuvo, M. (2016) Poverty-aware social work: A paradigm for social work practice with people in poverty. British Journal of Social Work, 46, 1793-1808.

Lamont, M., \& Small, M. L. (2010). Cultural diversity and anti-poverty policy. UNESCO: Blackwell Publishing. 
Leary, J. D. (2005). Post traumatic slave syndrome. America's legacy of enduring injury and healing. Milwaukee, Oregon: Uptown Press.

LeMaster, M. M. (2001). "Thorough-Paced girls" and "cowardly bad men": Gender and family in Indian-White relations in the colonial Southeast, 1660-1783. Baltimore, Maryland, Bell \& Howard Information and Learning Company.

Lenroot, K. F. (1940). Child welfare 1930-1940. The Annals of the American Academy of Political and Social Science. Nov, 1-11.

Lidot, T., Orrantia, R., \& Choca, M., J. (2012). Continuum of readiness for collaboration, ICWA compliance and reducing disproportionality. Child Welfare, 91(3), 65-87.

Lincoln, Y. S., \& Guba, E. G. (1985). Naturalistic inquiry. Beverly Hills, California: Sage Publications Inc.

Linn, A. C., Harris, D. R. (2010). The colors of poverty. Why racial and ethnic disparities persist. New York, New York: Russell Sage Foundation

Lister, R. (2004). Poverty. Malden, Ma.: Polity Press.

Lopez, I. H. (2006). White by law. The legal construction of race. (10th Edition). New York, New York: New York University Press.

Lucero, N. M., \& Bussey, M. (2012). A collaborative and trauma-informed practice model for urban Indian child welfare. Child Welfare, 91(3), 89-112.

Lui, M., Robles, B., Leondar-Wright, B., Brewer, R., \& Adamson, R. with United for a Fair Economy. (2006). The color of wealth. New York, New York: New Press.

Lewis, O. (1966). The culture of poverty. Scientific American, 215(4), 19-25.

Magruder, J., \& Shaw, T. V. (2011). Children ever in care. In D. Green, K. Belanger, R. McRoy, \& L. Bullard, L. (Eds.), Challenging racial disproportionality in child 
welfare. Research, policy, and practice (pp. 53-66). Washington, D.C.: Child Welfare League of America.

Maguire-Jack, K., \& Font, S. A. (2017). Intersections of individual and neighborhood disadvantage: Implications for child maltreatment. Children and Youth Services review, 72, 44-51.

Marshall, C., \& Rossman, G. B. (2006). Designing qualitative research. Thousand Oaks, California: Sage Publications Inc.

Marts, E.J., Lee, E.O., McRoy, R.G., \& McCroskey, J. (2011). Point of engagement: Reducing disproportionality and improving outcomes. In D. Green, K. Belanger, R.G. McRoy \& L. Bullard (Eds.), Challenging racial disproportionality in child welfare: Research, policy, and practice (pp. 167-178). Washington, DC: Child Welfare League of America.

Mazonde, I., N. (n.d.). Culture and education in the development of Africa. Retrieved from:

http://citeseerx.ist.psu.edu/viewdoc/download?doi=10.1.1.469.8503\&rep=rep1\&ty pe=pdf.

McGowan, B. G. (2005). Historical evolution of child welfare services. Child welfare for the $21^{\text {st }}$ century. In G. P. Mallon \& P. M. Hess (Eds.), A handbook of practices, policies, and programs (pp. 10-46). New York, New York: Columbia University Press.

McIntyre, L., Officer, S., \& Robinson, L. M. (2003). Feeling poor: The felt experience of low-income lone mothers. AFFILIA, 18(3), 316-331 
McLeigh, J. D. McDonell, J. R., \& Lavenda, O. (2018). Neighborhood poverty \& child abuse and neglect: The mediating role of social cohesion. Children Youth and Services Review, 93,154-160.

McRoy, R.G. (2004). The color of child welfare policy. In K. Davis \& T. Bent-Goodley (Eds.), The color of social policy (pp. 37-64). Washington, D.C.: Council on Social Work Education.

McRoy, R. G. (2011). Contextualizing disproportionality. In D. Green, K. Belanger, R. McRoy \& L. Bullard (Eds.), Challenging racial disproportionality in child welfare. Research, policy and practice (pp. 67-71). Washington, D.C.: Child Welfare League of America.

Miller, K.M., Cahn, K., Anderson-Nathe, B., Cause, A., \& Bender, R. (2013). Individual and systemic/structural bias in child welfare decision-making: Implications for children and families of color. Children and Youth Services Review, 35(9), 16341642.

Miller, K.M., Cahn, K., Cause, A., Bender, R., \& Cross-Hemmer, A. (2010). What we know about disproportionality and disparity in Oregon's child welfare system: Decision point analysis qualitative report. Child Welfare Partnership, Portland State University. Retrieved from https://multco.us/file/31361/download.

Miller, K.M., Cahn, K., \& Orellana, E.R. (2012). Dynamics that contribute to racial disproportionality and disparity: Perspectives from child welfare professionals, community partners and families. Children and Youth Services Review, 34(11), 2201-2207. 
Miller, M. (2010). Destroyed by slavery. The effect of slavery on African American family formation following emancipation. Retrieved from: http://www.econ.ucla.edu/workshops/papers/History/Miller,\%20Slavery\%20and \%20Black\%20Families.pdf.

Milner, H. R. (2005). Stability and change in US prospective teachers' beliefs and decisions about diversity and learning to teach. Teaching and Teacher Education, $21,767-786$.

Miranda, J., McGuire, T. G., Williams, D. R. \& Wang, P. (2008). Mental health in the context of health disparities. American Journal of Psychiatry, 165(9), 1102-1108.

Moffitt, R. A. (2008). A primer on U. S. welfare reform. Focus, 26(1), 15-25.

Morgan, D. L. (1997). Focus groups as qualitative research (2nd edition). Thousand Oaks, California: Sage Publications Inc.

Morgen, S., Acker, J., \& Weigt, J. (2010). Stretched thin. Poor families, welfare work and welfare reform. Ithaca, New York: Cornell University Press.

Murray, K. O., \& Gesiriech, S. (2004). A brief legislative history of the child welfare system. Retrieved from: https://www.masslegalservices.org/system/files/library/Brief\%20Legislative\%20 History\%20of\%20Child\%20Welfare\%20System.pdf

Myers, J. E. B. (2008). A short history of child protection in America. Family Law Quarterly, 42(3). Retrieved from: https://www.americanbar.org/content/dam/aba/publishing/insights_law_society/C hildProtectionHistory.authcheckdam.pdf. 
Neubeck, K., \& Cazenave, N.A. (2001). Welfare racism. Playing the race card against America's poor. New York, New York: Routeledge.

National Child Abuse and Neglect Training and Publications Project (2014). The child abuse prevention and treatment act: 40 years of safeguarding America's children. Washington, DC: U.S. Department of Health and Human Services, Children's Bureau. Retrieved from: http://childlaw.sc.edu/doc/CAPTA.pdf.

National Indian Child Welfare Association. (2019). Disproportionality table. Retrieved from: https://www.nicwa.org/wp-content/uploads/2019/08/DisproportionalityTable-2019.pdf.

Office of Business Intelligence Department of Human Services. (2015). 2014 child welfare data book. Oregon Department of Human Services. Retrieved from: https://www.oregon.gov/DHS/CHILDREN/CHILD-ABUSE/Documents/2015cw-data-book.pdf.

Office of Policy Planning and Research. United States Department of Labor (1965). The negro family: The case for national action. Retrieved from: https://web.stanford.edu/ mrosenfe/Moynihan\%27s\%20The\%20Negro\%20Famil y.pdf.

Office of Reporting, Research, Analytics, and Implementation, (2018). Child welfare data book. Retrieved from: https://www.oregon.gov/DHS/CHILDREN/CHILDABUSE/Documents/2018-Child-Welfare-Data-Book.pdf.

Omi, M., \& Winant, H. (1994). Racial formation in the United States. From the 1960s to the 1990s (2nd Edition). New York, New York: Routledge.

Orshansky, M. (1963). Children of the poor. Social Security Bulletin, 3 - 13. 
Orshansky, M. (1965). Counting the poor: Another look at the poverty profile. Social Security Bulletin, 3 - 29.

Palmer, S., Maiter, S., \& Manji, S. (2006). Effective intervention in child protection services: Learning from parents. Children and Youth Services Review, 28, 812824.

Padilla, J., \& Summers, A. (2011). Disproportionality rates for children of color in foster care. Technical Assistance Bulletin. National Council of Juvenile and Family Court Judges. Office of Juvenile Justice and Delinquency Prevention. Retrieved from:

http://www.ncjfcj.org/sites/default/files/Disproportionality\%20TAB1_0.pdf.

Paxson, C., \& Waldfogel, J. (2002). Work, welfare, and child maltreatment. Journal of Labor Economics, 20(3), 435-474.

Peterson, R. (2012). The impact of historical boarding schools on Native American families and parenting roles. McNair Scholar's Journal of the University of Wisconsin-Superior, 13, 1-11. Retrieved from: https://minds.wisconsin.edu/handle/1793/66821

Pelton, L. (1978). Child abuse and neglect: The myth of classlessness. American Journal of Orthopsychiatry, 48(4), 607-617.

Pelton, L. H. (1981). The social context of child abuse and neglect. New York, New York: Human Sciences Press.

Pelton, L. H. (1989) For reasons of poverty. A critical analysis of the public child welfare system in the United States. New York, New York: Greenwood Publishing Group, Inc. 
Pelton, L. H. (1999). Doing justice. Liberalism group constructs and individual realities. Albany, New York: State University of New York Press.

Pelton, L. H. (2005). Frames of justice. Implications for social policy. New Brunswick, New Jersey: Transaction Publishers.

Pelton, L. H. (2011). Concluding commentary: Varied perspectives on child welfare. Children and Youth Services Review, 33(3), 481-485.

Pelton, L. H. (2015) The continuing role of material factors in child maltreatment and placement. Child Abuse \& Neglect, 41, 30-39.

Pheiffer, R. S. (2018). Poverty in the United States. Why it's a blight on American psyche. How we can wipe it out. Book Baby Self Publishing.

Piven \& R. A. Cloward (Eds.). (1993). Regulating the poor. The functions of public welfare. New York, New York: Vintage Books.

Polkinghorne, D. E. (2005). Language and meaning: Data collection in qualitative research. Journal of Counseling Psychology, 52(2), 137-145.

Popkin, S. J. (1990). Welfare: Views from the bottom. Social Problems, 37(1), 64-79.

Proceedings of the Conference on the Care of Dependent Children. (1909). Senate Documents, $60^{\text {th }}$ Congress: $2^{\text {nd }}$ Session, December 7, 1908 - March 4, 1909. Vol. 23. Washington Government Printing Office.

Putnam-Hornstein, E., Needell, B. King, B., \& Johnson-Montoyama, M. (2013). Racial and ethnic disparities: A population-based examination of risk factors involvement with child protective services. Child Abuse \& Neglect, 37, 33-46. 
Puzzanchera, C., \& Taylor, M. (2019). Disproportionality rates for children of color in foster care dashboard. National Council of Juvenile and Family Court Judges. Retrieved from: http://ncjj.org/AFCARS/Disproportionality_Dashboard.aspx.

Ranjith, S., \& Rupasingha, A. (2012). Social and cultural determinants of child poverty in the United States. Journal of Economic Issues, 46(1), 119-142.

Rattansi, A. (2007). Racism: A very short history. Oxford, New York: Oxford University Press.

Richards, E. A. (1951). Proceedings of the mid-century White House conference on children and youth. Raleigh, North Carolina: Health Publications Institute, Inc.

Richards, L., \& Morse, J. M. (2007). Users guide to qualitative research. Thousand Oaks, California: Sage Publications Inc.

Richardson, T. (2011). Child of the state, contingency and progress. White House conferences on children and youth. American Educational History Journal, 38(2), 377-397.

Ritchie, J., \& Lewis, J. (2003). Qualitative research practice. A guide for social science students and researchers. London, England: Sage Publications Inc.

Rivaux, S. L., James, J., Wittenstrom, K., Baumann, D. J., Sheets, J., Henry, J., \& Jeffries, V. (2011). Race, poverty, and risk. Understanding the decision to provide services and remove children. In D. Green, K. Belanger, R. McRoy \& L. Bullard (Eds.), Challenging racial disproportionality in child welfare. Research, policy and practice (pp. 91-100). Washington, D.C.: Child Welfare League of America. Roberts, D. W. (1951). Highlights of the midcentury White House conference on children and youth. American Journal of Public Health, 41, 96-99. 
Roberts, D. (2005). Black club women and child welfare: Lessons for modern reform. Florida State University Law Review, 32, 957-972. Retrieved from: https://www.law.upenn.edu/cf/faculty/roberts1/workingpapers/32FlaStULRev957 $\% 282005 \% 29 . p d f$.

Roberts, D. (2002). Shattered bonds. The color of child welfare. New York, New York: Basic Books.

Rose, S.J., \& Meezan, W. (1993). Defining child neglect: Evolution, influences, and Issues. Social Service Review, 67(2), 279-293.

Rosenbaum, S. (2018). Now, new welfare reform, of course. The Millbank Quarterly, $96(1), 13-16$.

Ruggles, P. (2008). Poverty measurement and politics: Why is it so hard to change the way we measure poverty? Review of Agricultural Economics, 30(3), 591-599.

Russell, M., Harris, B., \& Gockel, A. (2008). Parenting in poverty: Perspectives of highrisk parents. Journal of Children and Poverty, 1469 - 9389. Retrieved from: https://www.tandfonline.com/loi/cjcp20.

Schoefield, G., Moldestad, B., Hojer, I., Ward, E., Skilbred, D., Young, J., \& Havik, T. (2011). Managing loss and threatened identity: Experiences of parents of children growing up in foster care, the perspectives of their social workers and implications for practice. British Journal of Social Work, 41(1), 74-92.

Seccombe, K. (1999). "So you think I drive a Cadillac?” Welfare recipients' perspectives on the system and its reform. Needam Heights, Massachusetts: Allyn and Bacon. 
Seccombe, K., James, D., \& Walters, K. B. (1998). “They think you ain't much of nothing: The construction of the welfare mother."Journal of Marriage and Family, (60)4, 849-865.

Seccombe, K., Walters, K. B., \& James, D. (1999). Welfare mothers: Welfare reform urge compassion. Family Relations, 48(2), 197-206.

Sedlak, A., \& Broadhurst, D. (1996). Third national incidence study of child abuse and neglect: Final report. Washington, DC: U.S. Department of Health and Human Services.

Sedlak, A.J., Mettenburg, J., Basena, M., Petta, I., McPherson, K., Greene, A., \& Li, S. (2010). Fourth national incidence study of child abuse and neglect (NIS-4): Report to Congress, executive summary. Washington, DC: U.S. Department of Health and Human Services, Administration for Children and Families. Retrieved from:

http://www.acf.hhs.gov/sites/default/files/opre/nis4_report_exec_summ_pdf_jan2 010.pdf.

Semega, J., Kollar, M., Creamer, J., Mohanty, A., \& U. S. Census Bureau. (2019). Income and poverty in the United States: 2018. Washington, D.C.: U. S. Government Printing Office.

Semwaza, F. (2013). Surveying epistemology: Discursive impacts on the African understanding of childhood stories. Childhood in African: An Interdisciplinary Journal, 3(1), $1-11$. 
Senate Documents. (1909). Proceedings of the conference on the care of dependent children. $60^{\text {th }}$ Congress, $2^{\text {nd }}$ Session. Washington Government Printing Office 23(13).

Short, K. (2011). The research supplemental poverty measure: 2010. Consumer income. U. S. Census Bureau. Retrieved from: https://www.census.gov/prod/2011pubs/p60-241.pdf.

Short, K. (2012). The research supplemental poverty measure: 2011. Current populations report. U. S. Census Bureau. Retrieved from: https://www.census.gov/hhes/povmeas/methodology/supplemental/research/Short ResearchSPM2011.pdf.

Smeeding, T. M. (2005). Public policy, economic inequality, and poverty: The United States in comparative perspective. Social Science Quarterly, 86, 955-983.

Smeeding, T., \& Thevenot, C. (2016). Addressing child poverty: How does the United States compare with other nations. Academic Pediatrics, 16(3), 67-75. Retrieved from: https://www.academicpedsjnl.net/article/S1876-2859(16)00027-9/fulltext.

Smith A. (2009). Indigenous peoples and boarding schools: A comparative study. United Nations Permanent Forum in Indigenous Populations. Retrieved from: http://www.un.org/esa/socdev/unpfii/documents/IPS_Boarding_Schools.pdf.

Smith, J. A., Flowers, P., \& Larkin, M. (2009) Interpretive phenomelogical analysis. London, England: Sage Publications Inc.

Smock, K. (2014). 2014 Poverty in Multnomah County. Multnomah County Department of County Human Services, Community Services Division.

Snipp, M. C. (2005). American Indian and Alaska Native children: Results from the 2000 
Census. Stanford University. Retrieved from:

http://www.prb.org/pdf05/americanindianalaskachildren.pdf.

Soss, J., \& Schram, S. F. (2008). Coloring the terms of membership. In A.C. Lin \& D. R. Harris (Eds.), The colors of poverty. Why racial and ethnic disparities persist. A volume in the national poverty center series on poverty and public justice (pp. 293-322). New York, New York: Russell Sage Foundation.

Stark, B. (2009). Theories of poverty/poverty of theory. Brigham Young University Law Review, 2, 381-430.

Summers, A. (2015). Disproportionality rates for children of color in foster care (fiscal year 2013). Technical Assistance Bulletin. National Council of Juvenile and Family Court Judges. Office of Juvenile Justice and Delinquency Prevention. Retrieved from: http://www.ncjfcj.org/sites/default/files/NCJFCJ\%202013\%20Dispro\%20TAB\%2 OFinal.pdf.

Summers, A. Wood, S., \& Donovan, J. (2013). Disproportionality rates for children of color in foster care .Technical Assistance Bulletin. National Council of Juvenile and Family Court Judges. Office of Juvenile Justice and Delinquency Prevention.

Retrieved from:http://www.ncjfcj.org/sites/default/files/Disproportionality\%20Rates\%20for \%20Children\%20of\%20Color\%20in\%20Foster\%20Care\%202013.pdf.

Thurston, H. W. (1930). The dependent child. A story of changing aims and methods in the care of dependent children. New York School of Social Work. New York, New York: Columbia University Press. 
Thomas, M. L. (2012). One hundred years of children's bureau support to the child welfare workforce. Journal of Public Child Welfare, 6(4), 357-375.

Tolman, T. (2011). The effects of slavery and emancipation on African American families and family history research. Crossroads, Mar, 6-15. Retrieved from: http://www.leaveafamilylegacy.com/African_American_Families.pdf

Trattner, W. I. (1994). From poor law to welfare state. A history of social welfare in America. New York, New York: The Free Press.

U. S. Department of Health and Human Services. The children's bureau legacy: Ensuring the right to childhood. EBook. Retrieved from: http://cb100.acf.hhs.gov/CB_ebook.

U. S. Department of Health and Human Services, Administration for Children and families, Administration on Children, Youth and Families. (2013). Child maltreatment 2012. Retrieved from: http://www.acf.hhs.gov/programs/cb/research-data-technology/statisticsresearch/child-maltreatment.

U. S. Department of Health and Human Services, Administration for Children and families, Administration on Children, Youth and Families Children's Bureau. (2012). The story of the children's bureau. Retrieved from: http://www.acf.hhs.gov/programs/cb.

U. S. Department of Health and Human Services, Administration for Children and families, Administration on Children, Youth and Families Children's Bureau. Child Welfare Information Gateway Issue Brief. (2011). Addressing racial 
disproportionality in child welfare. Retrieved from:

https://www.childwelfare.gov/pubPDFs/racial_disproportionality.pdf.

Ventrell, M. (1998). Evolution of the dependency component of the Juvenile Court. Juvenile and Family Court Journal, 49(4), 17-77.

Ventrell, M. (2005). The legal framework of child welfare. The history of child welfare. In M. Ventrell \& D. N. Duquette (Eds.), Child welfare law and practice. Representing children, parents and state agencies in abuse, neglect, and dependency cases (pp. 113-142). Denver, Colorado: Bradford Publishing Company.

Watkins, S. A. (1990). The Mary Ellen myth: Correcting child welfare history. Social Work, 35(6), 500-503.

Wells, K., \& Guo, S. (1999). Reunification and reunification of foster children. Children and Youth Services Review, 22(4), 273-294.

Wells, S. J., Merritt, L. M., \& Briggs, H. E. (2009). Bias, racism, and evidence-based practice: The case for more focused development of the child welfare evidence base. Children and Youth Services Review, 31, 1160 - 1171.

Wight, V., Kaushal, N. Waldfogel, \& Garfinkel, I. (2014). Understanding the link between poverty and food insecurity among children: Does the definition of poverty matter? Journal of Children and Poverty, 20(1), 1-20.

Williams, C. (1987). The destruction of black civilization. Great issues of a race from 4500 B.C, to 2000 A.D. Chicago, Illinois: The World Press.

Wilson, D. \& Horner, W. (2005). Chronic child neglect: Needed developments in theory and practice. Families in Society, 86(4), 471-481. 
Wilson, J. W. (2010). Why both social structure and culture matter in a holistic analysis of inner-city poverty. The Annals of American Academy of Political and Social Science, 629, 200- 219.

Wilson, J. W. (2010). More than just race. Being black and poor in the inner city. United States: Norton Press.

Wolock, I., \& Horowitz, B. (1979). Child maltreatment and maternal deprivation among AFDC-recipient families. Social Service Review, 53, 175-194.

Wolock, I., \& Horowitz, B. (1984). Child maltreatment as a social problem: The neglect of neglect. American Journal of Orthopsychiatry, 54(4), 530-543.

Wright, G. C. (1977). Racism and welfare policy in America. Social Science Quarterly, Ed, $718-730$.

Wulczyn, F. \& Lery, B. (2007). Racial disparity in foster care admissions. Retrieved from: http://www.chapinhall.org/sites/default/files/old_reports/399.pdf.

Yatchmenoff, D. K. (2005). Measuring client engagement from the client's perspectives in nonvoluntary child protective services. Research on Social Work Practice, 15(2), 84-96.

Ziibiwing Center of Anishinabe Culture \& Lifeways (2011). American Indian boarding schools. An exploration of global ethnic \& cultural cleansing. A supplementary curriculum guide. Retrieved from: http://www.sagchip.org/ziibiwing/planyourvisit/pdf/aibscurrguide.pdf.

Zinn, H. (2001). People's history of the United States 1492 to present. New York, New York: Harper Collins Publishers. 
APPENDICES 


\section{APPENDIX A: Intersectionality of Poverty, Race, Child Welfare and Racial}

\section{Disproportionality Study Informed Consent}

You are invited to participate in a research project which aims to hear the independent views of families regarding the intersections of poverty race, child welfare and racial disproportionality. This research is being conducted by Angela Cause, MSW a doctoral student of Portland State University (PSU) School of Social Work. Your current involvement with the Family Stability and Employment Unit (FSEU) gives you the unique opportunity to speak to ability to improve overall family stability and functioning, including but not limited to enhanced coping skills to address daily stressors, increased capacity to establish economic security, strengthened ability to maintain child wellbeing/safety, pursuit of educational/vocational achievement, and attending to health/mental health issues. Additionally, we hope to learn how the Family Stability Units serve to prevent families from becoming involved with the child welfare system or aid families in situations where child welfare has already occurred. We are especially interested in hearing the perspectives of families of color whose experiences may help to better understand the overrepresentation of children from certain populations of color within the foster care system. You have been selected as a potential participant in this research study because of your involvement with a local Family Stability Unit.

We will conduct a series of focus groups with parents who are recipients of benefits under the Self Sufficiency Program and who are currently or have within the past two years received case management through a local Family Stability Unit. We will also conduct interviews with those families who are of color. Each focus group and interview will be conducted by a PSU researcher at a previously arranged time and will last approximately two hours. Each subsequent interview will also be interview conducted by a PSU researcher at a previously arranged time and will last approximately 90 minutes. Each focus group and interview will be audio taped to ensure accuracy of information. 
If you choose to participate in the focus group, your comments may be shared or used in the future to support policy and/or practice changes within (DHS) or further research about the intersections of economically disadvantaged families, racial disproportionality, child maltreatment and/or child abuse prevention. Your identity will be protected. Your name will not be revealed or shared in any way. The focus group may be audio recorded and notes may be taken to ensure the accuracy of the information. Should you decide to participate and later change your mind, you may terminate your participation in the focus group and/or interview at any time.

Each household represented as participating in the focus group will receive a $\$ 50$. gift certificate after having agreed to be in the focus group as indicated by your signature below, and before the focus group discussion begins.

If you decide to participate, your Self Sufficiency benefits and your relationship with DHS will not be impacted or change for the better or for the worse. However, the study will offer significant information to improve supports and services to Oregon families. There are no consequences to you for choosing to participate or not in the focus group.

You may contact the Human Subjects Research Review Committee, Office of research and Sponsored Projects, Portland State University, Market Center Building, $1600 \mathrm{SW} 4^{\text {th }}$ Avenue, Suite 620, (503) 725-4288 / 1-877-480-400 should you have any concerns or problems about your participation in this study or your rights as a research subject.

Please note that the researcher is required by law to notify authorities should you disclose abuse to any child, or the intention of any person to hurt her/himself or another during the focus group and/or interview.

You are encouraged to ask any question you may have about the focus group process. By signing below, you agree to participate in the focus group and/or interview, and to be contacted in the future to confirm the content of information from this focus group or if research opportunities come up. 
Your signature indicates that you have read and understand the above information and agree to take part in this study. Again, please understand that you may withdraw your consent at anytime without penalty, and that, by signing you are not waiving any legal claims, rights, or remedies. The researcher will provide you with a copy of this form for your records.

Signature

Printed Name 
APPENDIX B: Letter of Invitation

Hello,

This letter is an invitation for you to join in a research study that explores the intersections of poverty, race, child neglect and racial disproportionality in the child welfare system. Many families who become involved with child welfare system are also experiencing economic challenges. Information gained from this research may help advance policy and practice improvements within DHS Self Sufficiency and Child Welfare programs and potentially help to enhance the well being of children and families, particularly those of who are of color. In Oregon, as you may know, African American and American Indian/Alaska Native children are overrepresented in the State's foster care system when compared to their representation in the general population.

Your input as a family currently involved with the Family Stability and Employment Unit (FESU) is valuable. You are poised to bring a very unique perspective to this subject matter. The study will involve your participation in a 2.5 hour focus group. You will also be asked to participate in a follow-up meeting with the researcher that will occur at a later time. This follow-up meeting gives you the opportunity to verify the accuracy of information obtained from the focus groups.

In appreciation for your time and participation you will receive a $\$ 50.00$ gift card to a local store. Additionally you may also receive engagement credits and child care assistance during the time of the focus group from FESU. Should you have questions or want to have more information about the study please contact me at (971) 386-3690 or email agcause@pdx.edu. Your consideration as a participant in this research is appreciated. I hope you will agree to participate.

Sincerely, 


\section{APPENDIX C: Focus Group Guide}

Family Stability Research Study

Focus Group Guide

Research supports that most of the families becoming involved with the child welfare system are poor and are either receiving public welfare benefits or eligible to be receiving benefits. Many of these families are also disproportionately families of color; meaning that poor families of color are represented within the child welfare system more so than they are represented in the general population.

However, research also shows that most poor families, regardless of race, are not abusing and or neglectful toward the care of their children. We like to hear from you about your thoughts on this and your personal experiences with parenting.

1. Would you say that money affects your parenting capacity? Please explain.

Probe: Sometimes parents have to make a choice when they do not have the financial resources. Can you give some examples of when you've had to make a choice that impacted your parenting?

2. How do you see race influencing families becoming involved with the child welfare system?

Probe: Racial disproportionality has been found to exist in Oregon's child welfare system for African America and Native

American/Alaska Native children; meaning that these children have greater representation in the child welfare system than they do in the general population. What are your thoughts?

3. Do you see poverty and race influencing families becoming involved with the child welfare system? Please explain.

Probe: Some argue that poverty is sometimes confused with neglect and that results in families becoming involved with child welfare. What are your thoughts?

4. What supports do you find valuable in alleviating challenges to parenting and helpful in preventing becoming involved with the child welfare system?

5. How did it feel to participate in this study?

6. Is there anything else you would like to share? 


\title{
APPENDIX D: Demographic Questionnaire
}

\author{
Intersection of Poverty, Race, Child Neglect and \\ Racial Disproportionality in the Child Welfare System Study
}

Thank you for participating in this research study. The following questions will be helpful in developing a general profile of study participants. Please do not place your name or any other identifying information on this form.

Date

Focus Group Color

1. Gender:

Male

Female

2. Age:

$18-25$

$26-35$

$36-45$

$46-55$

$56+$

3. Racial/Ethnic group you most closely identify with:

$\begin{array}{lll}\text { White } & \text { Hispanic } & \text { White non-Hispanic } \_ \text {African } \\ \text { American } & \text { Asian } \_ \text {Native American (please specify tribe) } \\ & \text { Mixed heritage (please specify heritage) }\end{array}$

4. Education: Please select highest level completed.

$-\mathrm{K}-5^{\text {th }}$ Grade $\quad 6^{\text {th }}-8^{\text {th }}$ Grade $\quad 9^{\text {th }}-12^{\text {th }}$ Grade

_ Some college, no degree ___ College graduate __ Trade school/ certification

5. Marital/Partner Status: __ Never married __ Married _ Domestic partnership ___Divorced __ Separated __ Widowed

6. Household Composition: Please indicate all with whom you live. ___ Spouse _Partner _Child(ren) __Friend/roommate/housemate __Extended

family such as parent, brother/sister, grand parent, aunt/uncle, cousin etc.

7. Children in Home: Please indicate the numbers of children in home for each age category.

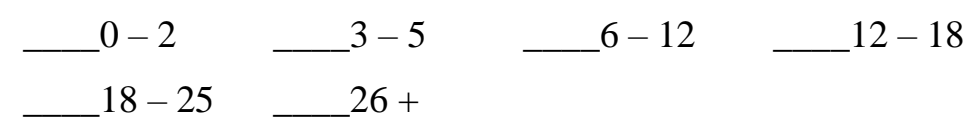


8. Income:___ Under $\$ 15,000 \_\$ 15,000-\$ 24,999 \_\$ 25,000-\$ 34,999$

9. Child Welfare History: ___ Previous contact with child welfare but never an open case Previous open case with child welfare and case now closed

Currently have an open case with child welfare

History with child welfare during my childhood

10. SSP History: __ History with public benefits during my childhood

Former history other than current case 